\title{
Neuromodulation, Short-Term and Long-Term Plasticity in Corticothalamic and Hippocampal Neuronal Networks
}

Sofie Sundberg

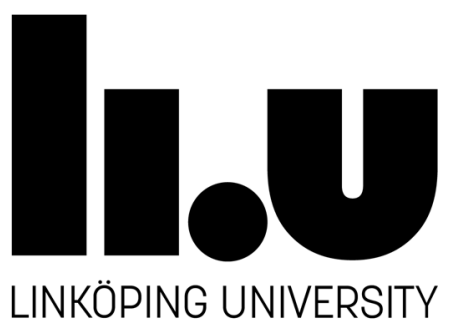

Division of Cell Biology

Department of Clinical and Experimental Medicine

Faculty of Medicine and Health Sciences

Linköping University, SE-581 83 Linköping, Sweden

Linköping, 2018 
(C) Sofie Sundberg, 2018

ISBN 978-91-7685-227-9

ISSN 0345-0082

During the course of the research underlying this thesis, the author was enrolled in Forum Scientium, a multidisciplinary doctoral program at Linköping University, Sweden.

Printed by LiU-Tryck, Linköping, Sweden October 2018 
Supervisor

\section{Björn Granseth, PhD}

Department of Clinical and Experimental Medicine Linköping University

Co-supervisor

Fredrik Elinder, Professor

Department of Clinical and Experimental Medicine Linköping University

Faculty Opponent

Eric Hanse, Professor

Department of Physiology, Institute of Neuroscience and Physiology University of Gothenburg 
Till er som betyder något för mig. 


\section{Abstract}

Research in neuroscience relies to a large extent on the use of genetically modified animals. Extensive validation of new and existing models is a requirement for the acquisition of trustworthy data and to enable generalization to human physiology and disease. This thesis includes, as one part (project I and II), validation of a transgenic mouse model with the expression of the enzyme Cre-recombinase restricted to neurons in a band in the deepest layer of the cerebral cortex. Secondly, in project III we use this mouse model to study the process of short-term plasticity in neuronal cultures. Lastly, we investigate synaptic plasticity by studying the effect that the developmental signaling factor Hedgehog (Hh) has on mature hippocampal cultures (project IV).

In project I and II, we identified the transgenic mouse Neurotensin receptor 1-Cre GN220 (Ntsr1-Cre) to have Cre expression targeted to the corticothalamic (CT) pyramidal neuron population in neocortical layer 6 . Further, we identified a small group of Ntsr1-Cre positive neurons present in the white matter that is distinct from the CT population. We also identified that the transcription factor Forkhead box protein 2 (FoxP2) was specifically expressed by CT neurons in neocortex. In project I, we further explored the sensitivity of CT neurons to cholinergic modulation and found that they are sensitive to even low concentrations of acetylcholine. Both nicotinic and muscarinic acetylcholine receptors depolarize the neurons. Presenting CT neurons as a potential target for cholinergic modulation in wakefulness and arousal. 
In project III we studied Ntsr1-Cre neurons in cortical cultures and found that cultured neurons have similar properties to CT neurons in the intact nervous system. Ntsr1-Cre neurons in culture often formed synapses with itself, i. e. autapses, with short-term synaptic plasticity that was different to ordinary synapses. By expressing the light-controlled ion channel channelrhodopsin-2 (ChR2) in Ntsr1-Cre neurons we could compare paired pulse ratios with either electrical or light stimulation. Electrical stimulation typically produced paired-pulse facilitation while light stimulation produced paired pulse depression, presumably due to unphysiological $\mathrm{Ca}^{2+}$ influx in presynaptic terminals. Thus, cultured Ntsr1Cre neurons can be used to study facilitation, and ChR2 could be used as a practical tool to further study the dependence of $\mathrm{Ca}^{2+}$ for short-term plasticity.

In project IV we investigated the role of Hedgehog ( $\mathrm{Hh}$ ) for hippocampal neuron plasticity. Non-canonical Hh-signaling negatively regulated NMDAreceptor function through an unknown mechanism resulting in changes in NMDA-receptor mediated currents and subsequent changes in AMPAreceptors in an LTP/LTD manner in mature neurons. Proposing Hh as a slow-acting factor with ability to scale down excitation for instances of excessive activity, e.g. during an epileptic seizure, as a mechanism to make the activity in the neuronal networks stable. 


\section{Populärvetenskaplig sammanfattning}

Inom neurobiologi står hjärnan och nervcellerna i fokus. Hjärnan är naturens mest komplexa organ, och den har en styrande roll för kroppen och den skapar medvetandet. Hur celler kommunicerar och hur den kommunikationen regleras med hjälp av minnesfunktioner på molekylär nivå är stora och viktiga frågor. Forskning inom neurobiologi syftar bland annat till att förstå hjärnans normala funktion, t ex sömn, minne och hur sinnesintryck behandlas, men även till att försöka bota sjukdomar i hjärnan som Alzheimers sjukdom, depression, eller epilepsi. För att kunna bedriva denna typ av forskning är behovet av pålitliga djurmodeller fortfarande stort. Under de senaste åren präglas djurförsök av principen "3R" - strävan att minimera, ersätta och förfina djurförsöken, något som kan leda till bättre fokus och kvalitet. Djurmodellerna har dessutom blivit mycket mer användbara med dagens genteknik. Särskilt tillgången på genetiskt modifierade möss har öppnat upp nya arenor för neurobiologisk forskning. För att kunna nyttja dessa djurmodeller krävs att man undersöker dem noggrant med olika metoder. På så vis kan man få en uppfattning om hur modellen beter sig, och vilka frågeställningar som är lämpliga att undersöka med modellen.

Denna avhandling beskriver arbetet som genomförts för att karaktärisera en viss musmodell, "Ntsr1-cre GN220", med avseende på hur den genetiska signalen (Ntsr1-Cre) förekommer i vissa celler i hjärnbarken. Med hjälp av denna modell har vi hittat en användbar proteinmarkör, Foxp2, som kan identifiera en celltyp i cerebrala cortex av intresse för bl.

a. hur vi behandlar sinnesintryck eller hur hjärnan styr vår 
uppmärksamhet. Vidare har vi kunnat karakterisera denna celltyp, och några undertyper, $\mathrm{i}$ denna modell, och visar att den liknar andra modellsystem. Celltypen vi intresserar oss för är de så kallade corticotalama (CT) nervcellerna som framförallt finns i det sjätte lagret i cerebrala cortex. CT neuronen kopplar till den del av hjärnan som kallas talamus som tar emot och förmedlar sinnesintryck. Cerebrala cortex är uppdelat i sex lager i de flesta däggdjur, och kopplingarna mellan cellerna i de olika lagren följer vissa mönster, dels i hur lagren är kopplade, men även hur andra delar av hjärnan kopplas samman med cortex.

En viktig aspekt som vi undersökt är huruvida vissa neuronala interaktioner influeras av historisk kommunikation. Signaler som upprepas kan orsaka förstärkning av nästkommande signal, så kallad "potentiering" av signalen, eller så orsakas försvagande av nästkommande signaler, så kallad "depression" av signalen. Denna modulering sker över olika tidsperioder och hjälper till att kontinuerligt forma nervcellernas nätverk. Dynamiken som detta medför för hjärnans konfiguration kallas ofta neuronal plasticitet och ligger till grund för vår inlärning och minnet. Det finns bl. a. belägg för att en familj av proteiner som kallas Hedgehog, som är oerhört viktiga under alla djurs utveckling, i den vuxna hjärnan spelar en viktig roll även för plasticiteten. 


\section{Table of Contents}

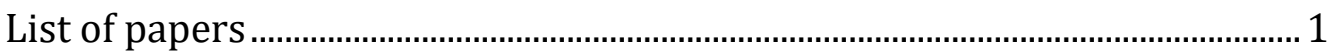

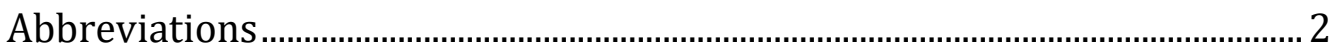

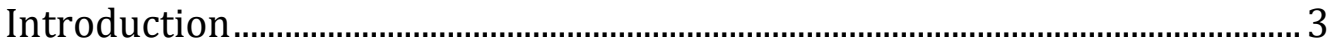

Brief introduction ......................................................................................... 3

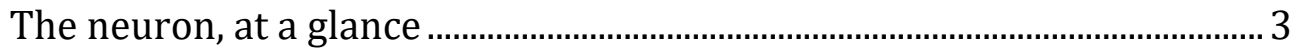

Neocortical development and organization.................................................. 9

Characteristics of pyramidal neurons in cortical layer 6 ............................. 14

The role of the corticothalamic system....................................................... 18

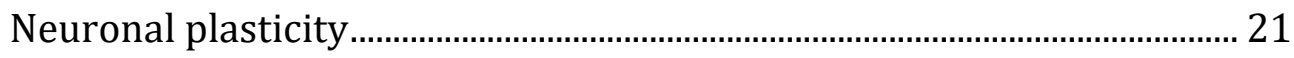

Morphogens in the developed nervous system, focus on Hedgehog ...... 28

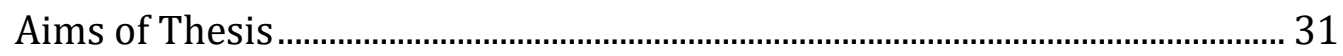

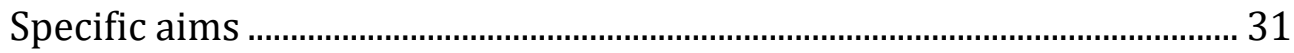

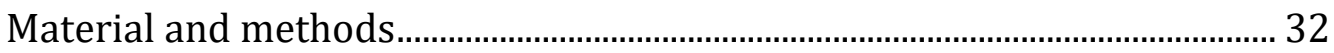

The Ntsr1-Cre GN220 transgenic mouse …................................................... 33

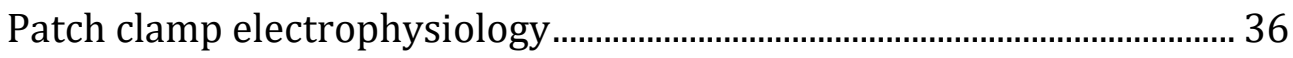

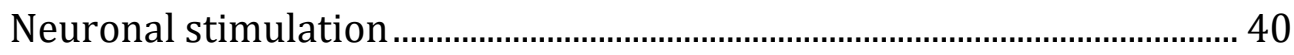

Antibody based methods................................................................................. 42

Results.................................................................................................................. 44

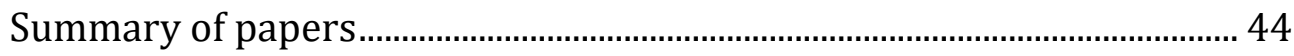

Results and Discussion........................................................................................ 51

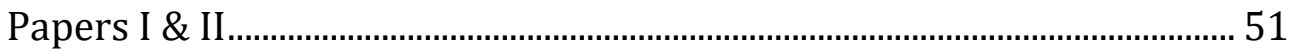

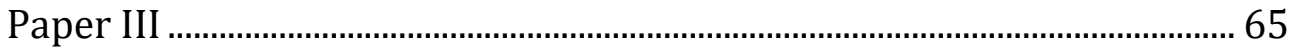

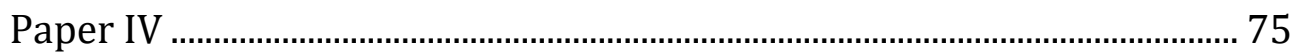

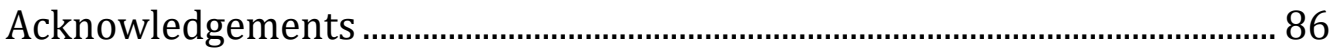

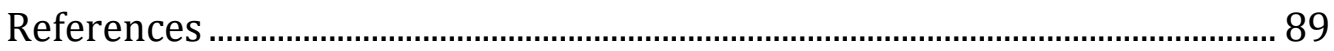





\section{List of papers}

I. Sundberg SC., Lindström SH., Sanchez GM., Granseth B. (2018) Cre-expressing neurons in visual cortex of Ntsr1-Cre GN220 mice are corticothalamic and are depolarized by acetylcholine. $J$ Comp Neurol; vol 526 (1): 120-132.

II. Sundberg SC., Granseth B. (2018) Cre-expressing neurons in the cortical white matter of Ntsr1-Cre GN220 mice. Neurosci Lett; 675: 36-40.

III. Sundberg SC., Johansson E., Granseth B. (2018) Corticothalamic neurons from the Ntsr1-Cre GN220 mouse display different modes of short-term synaptic plasticity in neocortical culture. Manuscript

IV. Sanchez GM. ${ }^{1}$, Sundberg SC. ${ }^{1}$, Andersson F., Alenius M. ${ }^{2}$, Granseth $B^{2}$. (2018) Hedgehog signaling regulates hippocampal NMDA receptor dependent synaptic plasticity. Manuscript

1 These authors contributed equally to this work, shared first author

2 These authors contributed equally to this work, shared last author 


\section{Abbreviations}

ACh, Acetylcholine

$\mathrm{Cav}, \mathrm{Kv}$ and $\mathrm{Nav}$, voltage gated $\mathrm{Ca}^{2+}, \mathrm{K}^{+}$and $\mathrm{Na}^{+}$channels

CC, Corticocortical

CCh, Carbachol

CCL, Corticoclaustral

ChR2, Channelrhodopsin-2

CL, Claustrum

CNS, Central Nervous System

CT, Corticothalamic

dLGN, Dorsal Lateral Geniculate Nucleus

EPSC, Excitatory Postsynaptic Current

FoxP2, Forkhead Box Protein 2

Hh, Hedgehog

mAChR, Muscarinic Acetylcholine Receptors

mEPSC, Miniature Excitatory Postsynaptic Current

nAChRs, Nicotinic Acetylcholine Receptors

Ntsr1, Neurotensin Receptor 1

PKA, Protein Kinase A

RGC, Radial Glial Cells

$\mathrm{R}_{\mathrm{i}}$, Input resistance

RIM, Rab3-Interacting Molecules

SNARE complex, Soluble NSF Attachment protein Receptor complex tdTom, tdTomato

TC, Thalamocortical

$\mathrm{V}_{\mathrm{m}}$, Membrane potential

WM, White Matter 


\section{Introduction}

\section{Brief introduction}

Our central nervous system (CNS) is composed of a vast number of different cell types closely packed within the bone of our skull and spinal column (for a recent discussion about neuron classification, see (Zeng and Sanes 2017)). Pioneering work performed by neuroanatomists such as Ramon Y Cajal and Camillo Golgi revealed and classified neurons based on their morphology and localization (Swanson et al. 2007). Today many methodologies exist to study the brain of humans and animals. This thesis focuses on neurons in, and from, cerebral cortex and hippocampus of rodent animal models. Rats and genetically modified mice were firstly, used to study neuronal morphology and the distribution of synaptic and nuclear proteins in brain sections ex vivo and in neuronal cultures; and secondly to study neuronal and synaptic physiology.

\section{The neuron, at a glance}

Neurons are the specialized cells that, together with supporting glia cells, make up the gross part of the CNS. Neurons are optimized for communicating with other neurons as well as with in the body. Neurons can have extremely variable morphology, but most have extensions (generally: "neurites") called dendrites and axons, and a cell body called soma. Dendrites are the structures that receive input from surrounding neurons, and they express various forms of receptors that transfer signals from the outside to intracellular signals processed by the neuron. Some of 
that processing takes place in the dendrites but also in the soma and a specialized part of the axon called the axon initial segment. The axon is traditionally considered the output part of the neuron, ending with presynaptic terminals.

Neurons are excitable cells, they communicate by the use of electrical signals carried by ions flowing across the cell membrane. Ions can pass the electrically impermeable membrane only through ion channel proteins or transporters. Along the axon there are $\mathrm{Na}^{+}$and $\mathrm{K}^{+}$ion channels regulated by membrane voltage (voltage gated ion channels). In the axon initial segment a particularly high concentration of voltage gated $\mathrm{Na}^{+}$ion channels (Nav) are present. Coordinated opening of Nav channels in the axon initial segment promotes a depolarization of the membrane voltage marking the start of the nerve impulse, also called the action potential. Simply explained, the action potential is the coordinated opening of $\mathrm{Nav}$ followed by voltage gated $\mathrm{K}^{+}(\mathrm{Kv})$ channels along the axon. Once reaching the presynaptic terminal the action potential depolarization opens voltage gated $\mathrm{Ca}^{2+}$ (Cav) channels and $\mathrm{Ca}^{2+}$ flows into the presynaptic terminal. The $\mathrm{Ca}^{2+}$ ions stimulate release of synaptic vesicles filled with neurotransmitter molecules. Various proteins interact with the synaptic vesicles and the presynaptic membrane coordinating the elaborate process of vesicle retrieval, release and recycling. Neurotransmitters diffuse in the synaptic cleft and encounter receptors at the postsynaptic density and signals to the postsynaptic neuron. (Hille 1978, Catterall et al. 2012, Parekh and Ascoli 2015, Rizo 2018) 


\section{The chemical synapse}

The specialized cellular structure for communication between neurons, the synapse, is composed of the presynaptic terminal the space between the two neurons called the synaptic cleft and the post-synaptic terminal that is often located on dendrites but can be located anywhere on the neuron. To maintain this organization there are extracellular matrix proteins and cytoskeletal protein that cross-link the presynaptic and postsynaptic terminals and support the extracellular fluid space of the synaptic cleft. Cadherins and catenins form adherens junctions located perisynaptically linking the pre- and postsynaptic neurons (Uchida et al. 1996).

The controlled exocytosis of presynaptic vesicles requires a number of molecular components. Simplified, the role of the active zone where vesicles are found in the terminal is to organize $\mathrm{Ca}^{2+}$ triggered neurotransmitter release to a small area of the presynaptic plasma membrane closely opposed to a membrane area rich in postsynaptic receptors (Sudhof 2012, Rizo 2018). Neurotransmitters are signaling molecules that carry the signal across the synaptic cleft. These neurotransmitters are packed into intracellular membrane vesicles in the presynaptic terminal. The most common neurotransmitter of the brain is glutamate, and an estimated $70-80 \%$ of all neurons in the brain are glutamatergic (Konishi et al. 2002). Glutamate is the deprotonated form of the amino acid glutamic acid and it is an excitatory neurotransmitter. Glutamate or glutamic acid can be synthesized in all cells from alpha- 
ketoglutarate (from the Krebs cycle) and alanine via transamination to pyruvate and glutamic acid (Niciu et al. 2012). Glutamate require the action of vesicular glutamate transporters (vGluTs) to be packed into synaptic vesicles. vGluTs are localized in the synaptic vesicular membrane and fill glutamate into the vesicular lumen in the millimolar concentration range (Edwards 2007, Eriksen et al. 2016).

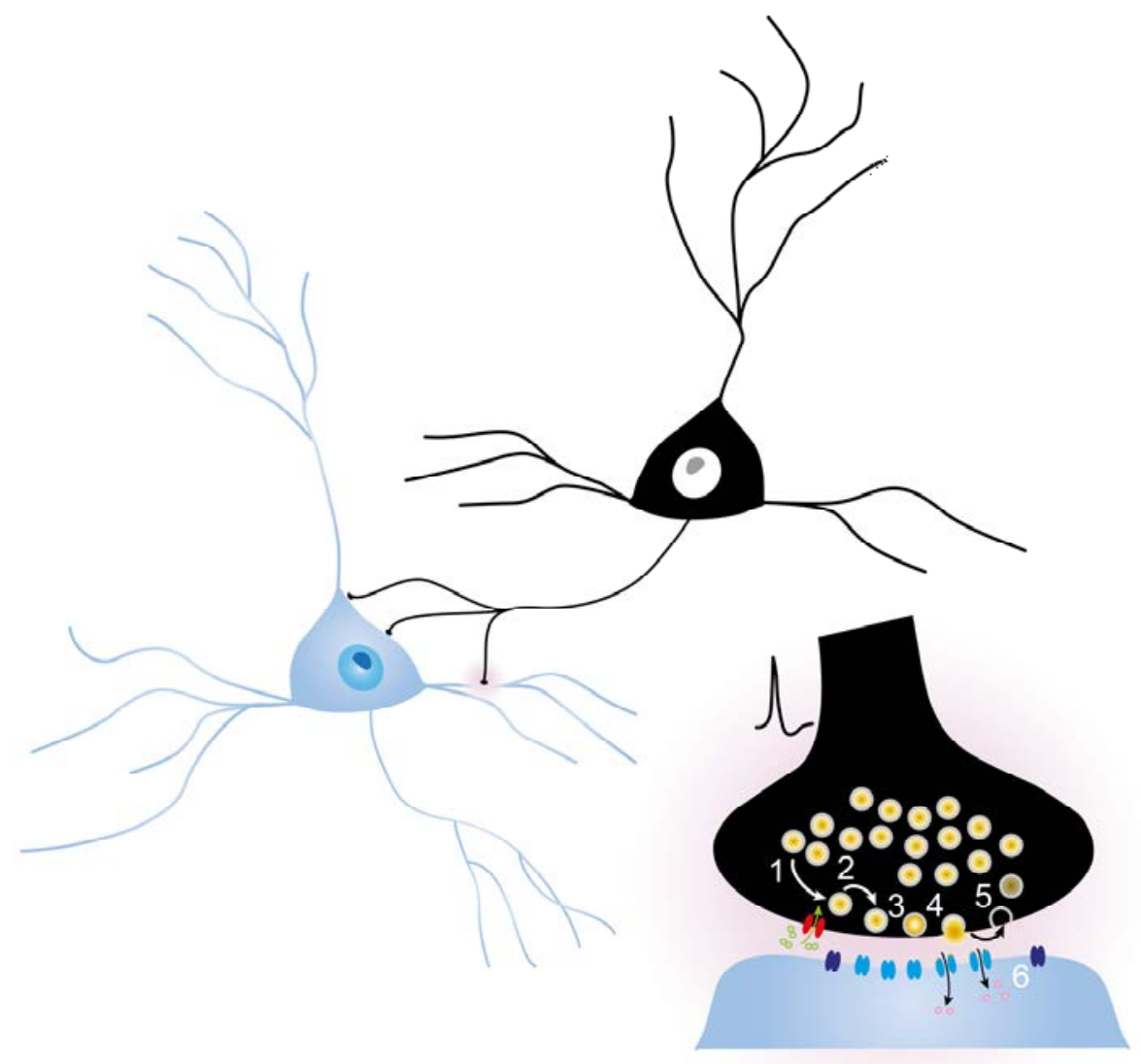

Figure 1 Schematic drawing of two neurons with synaptic contacts. The black cell forms the presynaptic neuron and the blue cell forms the postsynaptic neuron (zoomed inset). 1) Recruitment of synaptic vesicles from the reserve pool; 2) docking; 3) priming; 4) fusion with plasma membrane and release of neurotransmitters; 5) endocytosis, and recycling of released vesicle; 6) postsynaptic response to neurotransmitter. 
Synaptic vesicles need to be recruited from the large pool of reserve or recycling vesicles present in the presynaptic terminal and brought to the plasma membrane close to the release site, the active zone (Granseth and Lagnado 2008) (Figure 1). Vesicles are then attached to the presynaptic membrane via protein-protein interactions, this is referred to as the process of docking (Rizo and Rosenmund 2008, Imig et al. 2014). Once docked synaptic vesicles go through a process called priming before they can become release competent, i.e. they will be rapidly exocytosed when reached by the $\mathrm{Ca}^{2+}$ signal. Priming is required for the fast coupling between incoming action potentials and subsequent fusion of synaptic vesicles with the plasma membrane. During priming the molecular machinery for vesicle release assembles on docked synaptic vesicles and the vesicles get prepared for rapid $\mathrm{Ca}^{2+}$ influx and subsequent fusion (Rizo and Rosenmund 2008, Kaeser 2011). The number of primed vesicles is often considered to correspond to the readily releasable pool (RRP) of vesicles although what defines the RRP seems to be highly variable between different types of synapses (Rosenmund and Stevens 1996, Kaeser and Regehr 2017). Presynaptic scaffolding proteins, such as RIM (Rab3-interacting molecules) and RIM binding proteins (RBP) are essential for recruiting and stabilizing proteins that participate in docking, priming and release (Kaeser 2011). The priming step is executed by Munc13s via their MUN domain, and RIM proteins recruit, activate and stabilize Munc13s (Kaeser and Regehr 2017, Lai et al. 2017). The proposed function of the MUN domain is to promote a transformation of syntaxin-1 from a "closed" to an "open" state enabling syntaxin-1 to form 
SNARE-complexes (Soluble NSF Attachment protein Receptor complexes) (Sudhof 2012, Kaeser and Regehr 2017, Lai et al. 2017). The scaffolding proteins RIM and RBP also recruits $\mathrm{Ca}_{\mathrm{v}}$ channels to the active zone. It is essential that $\mathrm{Cav}_{\mathrm{v}}$ channels are localized correctly at the release site for vesicle fusion to take place (Han et al. 2011). Cav channels acts to translate the electrical signal in the form of an action potential to a chemical signal; the release of neurotransmitter. Fast conventional synapses predominantly express the $\mathrm{Ca}_{2} 2$ subfamily of $\mathrm{Cav}_{\mathrm{v}}$ channels conducting P/Q-, N- and R-type calcium currents (Nanou and Catterall 2018). Postsynaptic structures also need to be aligned with the presynaptic terminal to fully achieve transsynaptic signaling of the synapse.

The SNARE protein complex is substantially involved in the process of vesicle fusion (Rizo and Rosenmund 2008, Sudhof and Rothman 2009). The SNARE complex is composed of; syntaxin-1, synaptobrevin, and SNAP25. Syntaxin-1 is a protein that spans the plasma membrane of the presynaptic terminal. Synaptobrevin, on the other hand, is anchored to the plasma membrane of the presynaptic terminal, and SNAP-25 is a cytosolic protein that is associated with the terminal membrane. These three proteins associate into a bundle linking the synaptic vesicle to the plasma membrane of the presynaptic terminal (Baker and Hughson 2016, Rizo 2018). Subsequent folding of the SNARE complex releases energy used to overcome the repulsive forces of the two opposing membranes, preparing the membranes for fusion (Sudhof and Rothman 2009). However, fusion does not occur until $\mathrm{Ca}^{2+}$ binds to synaptotagmin, the proposed $\mathrm{Ca}^{2+}$ 
sensor that triggers exocytosis of transmitter. Synaptotagmins are a family of $\mathrm{Ca}^{2+}$ binding proteins essential for synaptic vesicle release usually coordinating synchronous release of vesicles where incoming action potentials generate a well-timed presynaptic $\mathrm{Ca}^{2+}$ influx that results in a fast postsynaptic response (Catterall et al. 2013, Sudhof 2013). There are many synaptotagmin isoforms and the function of several of them remains unknown.

\section{Neocortical development and organization}

The cerebral cortex develops from the dorsal telencephalon, from the anterior forebrain specified in the anterior neural plate shortly after gastrulation (Andoniadou and Martinez-Barbera 2013). The telencephalic vesicles are formed around the primary anterior vesicle, which will then transform into the lateral ventricles as the cortical hemispheres take shape (DeSesso et al. 1999). Initially, the neuroectodermal tissue consists of neuroepithelial cells. They transition through asymmetric division and differentiation to radial glia cells (RGC) (Paridaen and Huttner 2014), which are considered the main neurogenic precursor cell for both neurons and glial cells, the main "neuronal stem cell" in all parts of the CNS (Anthony et al. 2004). This transition occurs in the first distinct cellular layer of what will become the cerebral cortex: the ventricular zone (VZ), which will remain the major proliferative zone during corticogenesis. The onset of neurogenesis is around E9-10 in the mouse (10-11 in rats and 2428 in humans (Bystron et al. 2006, Clancy et al. 2007, Semple et al. 2013)). 
The RGC begin with symmetric division, giving rise to two RGCs. The mode of division then shifts to asymmetric. They can divide asymmetrically in two different modes, either producing another RGC and a post-mitotic neuron, or an RGC and an intermediate precursor cell (IPC). In turn, the IPC divides symmetrically to produce two mature neurons. Initially, the RGC produces neurons and IPC, but after a few divisions they switch to production of glial cells (Rowitch and Kriegstein 2010). RGC typically remain in the VZ, but daughter cells migrate radially outwards forming the preplate (PP) that will contain post-migratory cells and neuropil. Another proliferative zone develops as IPC migrate into what becomes the subventricular zone (SVZ) localized immediately dorsal to the VZ. Together, VZ and SVZ make out the areas from which most cortical neurons originate. The RGC cell bodies span the thickness of the tissue to provide a scaffold for migrating developing neurons to adhere to and follow. Migrating immature neurons and glia from VZ and SVZ pass through the PP and start forming the cortical plate (CP) developing the cortex in an inside-out sequence with layer 6 first and layer 2/3 last. They stop migrating when they encounter the secreted molecule reelin expressed by Cajal-Retzius neurons in the most superficial part of the developing cortex, the marginal zone (MZ) that eventually forms layer 1 (Bystron et al. 2008).

The CP is preceded in development by the subplate (SP), a heterogeneous compartment forming below the PP composed of neurons, RGC-processes, migrating neurons, developing glial cells and ingrowing afferents from thalamus, basal forebrain and ipsilateral cortex. In rodents the SP can be 
seen as a band in the developing cortex by ca E16. The SP together with the intermediate zone (IZ), an area located below the SP and above the SVZ will eventually form subcortical structures that remain into adulthood. The intermediate zone becomes the white matter (WM) with afferent and efferent axonal projections passing through. Most neurons in the SP mature early and have a short lifespan, but a few remain into adulthood located in the WM. By E18 in the mouse, layers 1-6 have formed and continue to mature during the post-natal period.

\section{Development of corticothalamic neurons}

In mice, around E11 the first neurons start to migrate from the VZ gradually invading the CP. By approximately E12.5 they have reached their final position (Galazo et al. 2016, Diao et al. 2017). These newborn neurons migrate radially (in direction towards the pial surface) expressing genes essential for development of projection neurons such as T-box brain 1 (Tbr1), FEZ family zinc finger 2 (Fezf2) and COUP TF1interacting protein 2 (Ctip2). Neurons will migrate and populate the CP, building up neocortex in an inside-out fashion (Figure 2) (Molyneaux et al. 2007, Greig et al. 2013). They migrate until they encounter the migratory stop signal Reelin, forming the first laminae of neocortex that is also to be the deepest layer of cortex, layer 6 (Diao et al. 2017). The cells of interest for this thesis, the corticothalamic (CT) neurons that have their principal axon projecting to the thalamus will develop earliest of the cortical neurons during cortical development (Thomson 2010). The CT neuron axons, emerging from the IZ, will project to the primary thalamic nuclei, meet the thalamocortical (TC) axon projections and, together, form the 
internal capsule (Torii and Levitt 2005). Recently the transcriptional coregulator "Friend of GATA-2" (Fog2) has been shown to coordinate CT neuron development in later embryonic stages, by determining CT subtype differentiation e.g. CT axon extension (Galazo et al. 2016).
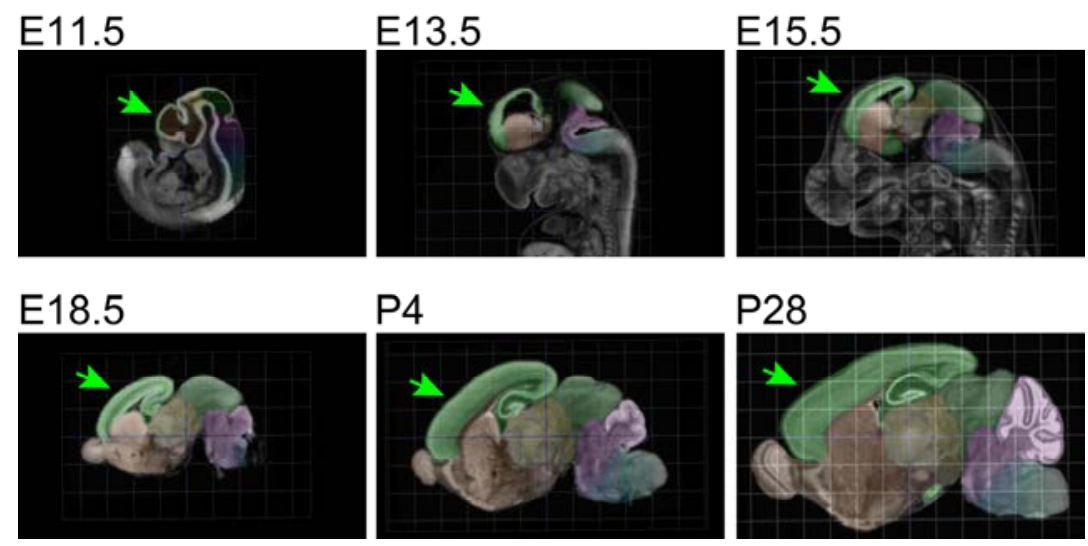

Figure 2. Cortical development with cerebral cortex indicated by the green arrow. Image exported from Allen Brain Atlas, Brain Explorer 2, mouse.brainmap.org/static/brainexplorer.

In case of the visual system, the thalamic nuclei that CT neurons primarily projects to is the dorsolateral geniculate nucleus (dLGN). Preceding the CT axons are axons from neurons of the SP that acts as guidance neurons for the growing CT neurons (McConnell et al. 1989). Guidance cues and expression of a number of genes, e.g. Tbr1, determine the CT axonal grown and direction of it (Hevner et al. 2001, Hevner et al. 2002). Semaphorins are essential for CT axonal outgrowth from the CP and into the IZ and to stimulate them to grow in a lateral and ventral direction. CT axons continue via guidance of a number of factors to grow in a medial direction 
just reaching the edge of the subpallium where they pause for 1 day until they invade the subpallium. In the subpallium CT axons encounter TC axons (Diao et al. 2017). This encounter has been developed into a theory called the "handshake model" where it is proposed that CT and TC axons interact and use the axons as guides to their terminal location (Molnar and Blakemore 1995). This model has been challenged (Miller et al. 1993) but seems to explain the initial pathfinding of the first CT and TC axons to reach their final location (Molnar et al. 2012). CT axons continue after the "handshake" to enter the internal capsule and then the prethalamus. By approximately E16 they interact with thalamic reticular neurons (TRN) and it takes additional days before the axons enter dLGN. By the end of the first postnatal week (approximately P7) dLGN is well innervated by corticothalamic axons (Grant et al. 2012).

\section{A note on nomenclature of the subplate}

The subplate, SP, can be seen as a structure in adult humans, primates, rodents and other species, but once the organism has reached adulthood it is no longer called "subplate". Depending on species, the neurons remaining from the SP in the adult organism have been referred to with different terminology. Researchers working with humans or primates tend to refer to these neurons as interstitial cells of the white matter (WM). In rodents the neurons of the SP can be referred to as either forming a layer $6 \mathrm{~b}$ or layer 7 or referred to as persistent SP neurons or simply WM neurons. As different authors define this neuron-populated area of the WM differently it is sometimes difficult to compare results from studies. In paper II we studied a population of neurons located in the WM in cortical 
sections from Ntsr1-Cre GN220 mice and we chose to refer to these cells as WM neurons and will use that terminology throughout this thesis.

\section{Characteristics of pyramidal neurons in cortical layer 6}

Layer 6 of neocortex, named lamina multiforme based on the histology, is a highly heterogeneous layer in terms of the cell types it contains. Primarily, there are three types of pyramidal neurons that can be further subdivided into additional groups based on morphology and projection pattern. The three pyramidal neurons in layer 6 are; corticocortical neurons (CC); corticoclaustral neurons (CCL) and corticothalamic neurons (CT) (Thomson 2010). The name indicates their main axonal projection; hence CC neurons have axonal targets within cortex, CCL neurons project subcortically with targets in claustrum and CT neurons target thalamic neurons (Figure 3). Out of the three pyramidal neurons in layer 6, CT neurons are the most numerous making out approximately 50-60\% of the total population (Zhang and Deschenes 1997, Olsen et al. 2012, Kim et al. 2014, Crandall et al. 2017). CC and CT neurons show no overlap between their structural targets (Petrof et al. 2012). CC, CCL and CT neurons differ in their morphology and electrophysiology.

CC neurons are a diverse group of pyramidal neurons with large dendritic variability. Dendrites of CC neurons remain in the infragranular layers and can be: uniform and "star-like", long without tuft, inverted pyramids, short upright pyramids or spiny bipolar (Brumberg et al. 2003, Mercer et al. 2005, Kumar and Ohana 2008). 


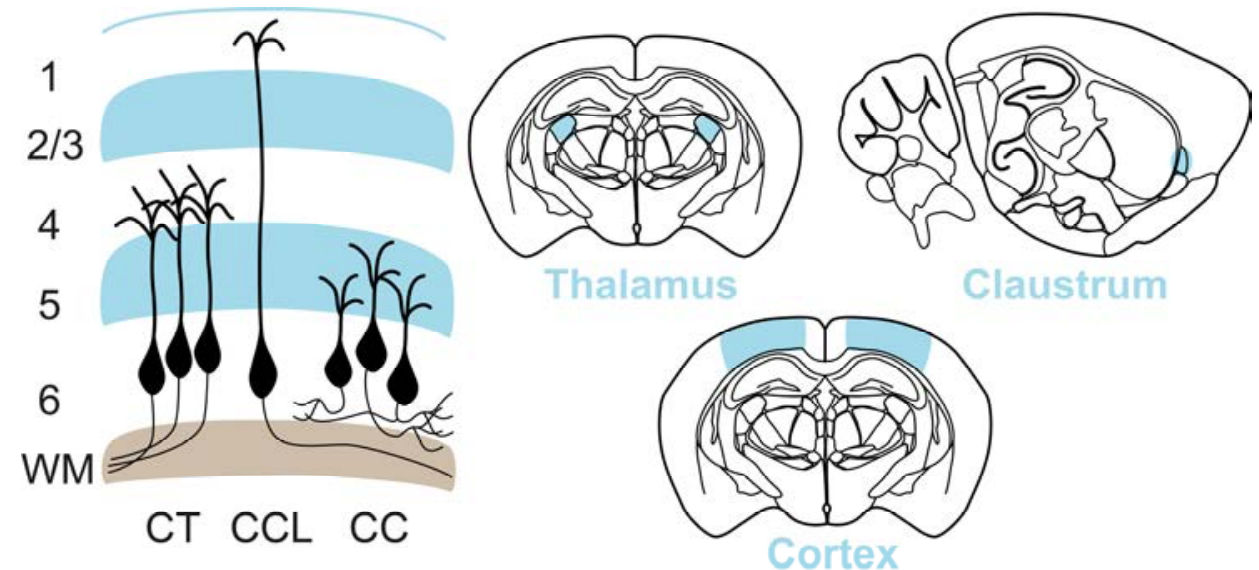

Figure 3. Pyramidal neurons in cortical layer 6 (left), with their main projection targets marked in schematic brain sections (right). CC, Corticocortical; CCL, Corticoclaustral; CT, Corticothalamic.

Their axonal projections can be long and they extend horizontally within the infragranular layers and preferentially make synaptic contacts with pyramidal neurons in layers 5 and 6 rather than interneurons (Mercer et al. 2005). CC neurons can also project contralaterally over corpus callosum to innervate excitatory neurons in the neighboring hemisphere (Segraves and Innocenti 1985). CC neurons fire action potentials phasically or regularly when stimulated with depolarizing current injections. With increased current intensities they initially fire 2-3 action potentials in very rapid succession followed by continuous action potential firing at a more moderate frequency (Mercer et al. 2005, Kumar and Ohana 2008, Velez-Fort et al. 2014, Crandall et al. 2017). CC neurons 
show short-term depression when stimulated repeatedly with short stimulus intervals (Mercer et al. 2005).

Both CCL and CT neurons are subcortical projection neurons, with primary axonal targets in claustrum and thalamus, respectively. These cell types have clear pyramidal shape with basal dendrites remaining mostly in layer 6 and apical dendrites extending radially in the direction of pia mater. CCL neurons are often described to have a tall morphology, meaning that their apical dendrites reach layer 1 and terminate with a small tuft. Along the way to layer $1 \mathrm{a}$ few branches from the apical dendrite terminates in layers 4 and 2/3 (Katz 1987, Mercer et al. 2005, Cotel et al. 2018). The CCL neurons are rarer than both CT and CC neurons. CCL neurons located in sensory cortices sparsely project subcortically to the ipsilateral claustrum (Atlan et al. 2017, Wang et al. 2017), compared to CT neurons that form a dense axonal projection extending subcortically reaching primary and secondary thalamic nuclei and the thalamic reticular nucleus (TRN) (Zhang and Deschenes 1997).

Injecting anterograde fluorescent dyes or genetically expressing a fluorescent reporter protein (as in the Ntsr1-Cre GN220 mouse) will clearly visualize the CT projection and the thalamic nuclei where it terminates (Figure 4). Apart from the subcortical axonal projection CT neurons have axon collaterals ascending to layer 4 (Zhang and Deschenes 1997, Tarczy-Hornoch et al. 1999, Kumar and Ohana 2008, Crandall et al. 2017) and to layer 5 and layer 6 (Zhang and Deschenes 1997, Kim et al. 
2014, Crandall et al. 2017). Compared to CCL neurons CT neurons can be depicted to be short pyramidal neurons, i.e. they have dendritic arbors terminating in layer 4 with an extensive tuft (Katz 1987, Brumberg et al. 2003, Mercer et al. 2005, Kumar and Ohana 2008, Cotel et al. 2018).

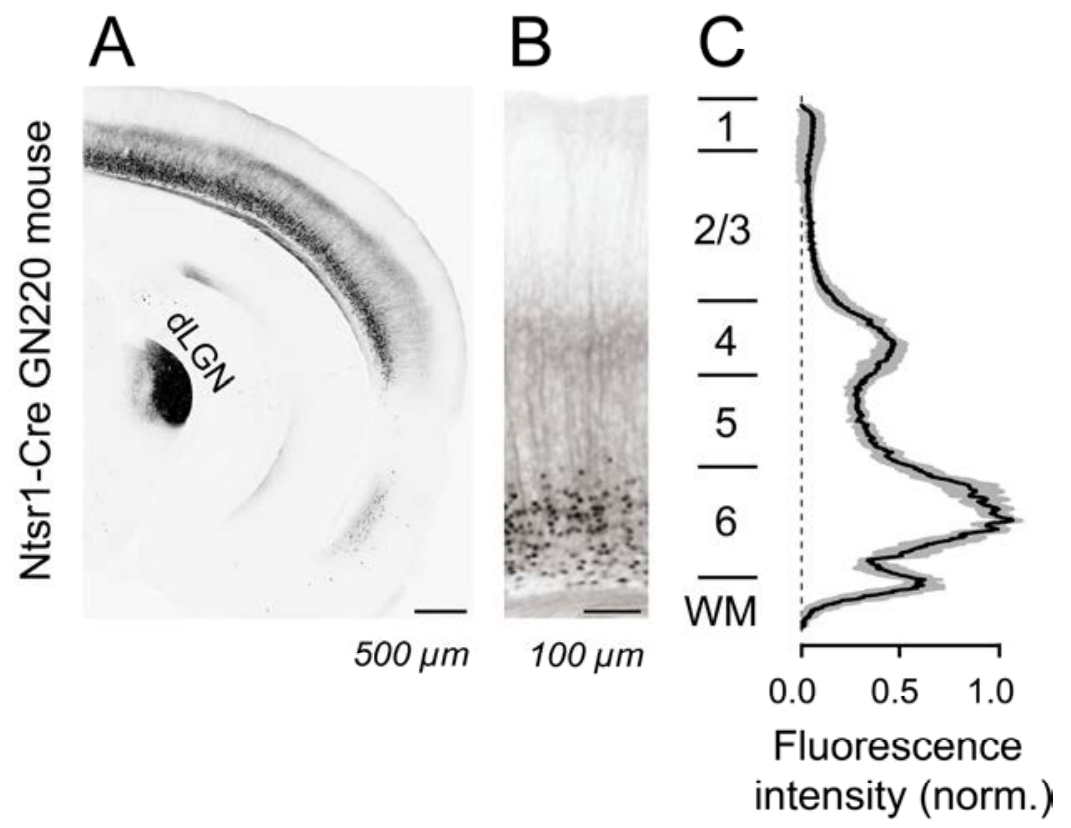

Figure 4 A, Confocal image showing a section of one hemisphere from Ntsr1-Cre GN220 mouse, note extensive signal (black) in dLGN and in cortex layer 6; $B$, section from primary visual cortex. Ntsr1 cell bodies are concentrated in layer 6; $C$, fluorescence intensity profile of $B$, showing layer number ( $y$-axis) and normalized intensity (0-1 on $x$-axis).

CCL and CT neurons fire action potentials in a similar pattern when stimulated with a square depolarizing current pulse, and they cannot be differentiated based on their intrinsic pattern of electrical activity (Mercer et al. 2005, Cotel et al. 2018). Both CCL and CT neurons fire action potentials regularly throughout a current step and classify as regular firing neurons (Mercer et al. 2005, Crandall et al. 2017, Cotel et al. 2018). 
Their functional properties instead make it possible to differentiate between them. In paired recordings with a CCL or a CT as the presynaptic neuron reveals that CCL neurons show short-term depression and that CT neurons show short-term facilitation with paired-pulse stimulation (Cotel et al. 2018). CT neurons have a high initial failure rate at the synapses formed in the thalamus (Granseth and Lindstrom 2003) and in cortex. In contrast, CCL neurons have a low initial failure rate (Cotel et al. 2018). The initial failure rate upon stimulation of a synapse is an indication of the release probability of that synapse and this correlates with the mode of plasticity. Where high initial failure rate seems to correlate with facilitation and low initial failure rate with depression (Granseth and Lindstrom 2003). CT neurons in vivo show low rates of sensory evoked spontaneous activity, lower than CC neurons. This could in part be due to their intrinsic membrane properties making them less excitable but in awake animals the spike firing triggered by visual stimuli is as rapid in CT neurons as in cells in other layers of the cortex (Livingstone and Hubel 1984, Crandall et al. 2017).

\section{The role of the corticothalamic system}

CT neurons have been shown and hypothesized to be involved in many different processes. For example, in the regulation of attention (Crick 1984, Ahlsen et al. 1985), seizure control and seizure development (Hedström and Lindström 1987, McCormick and Contreras 2001, Bomben et al. 2016), acting as activity-related gatekeeper of sensory information to the cortex (Ahlsen et al. 1985, Crandall et al. 2015, Guo et al. 2017), 
providing cortical gain control (Olsen et al. 2012) etc. CT neurons have similar anatomy and physiology across species examined and seems to perform similar function, albeit with exceptions, in the three sensory modalities primarily investigated, namely visual, auditory and somatosensory systems. The suggested consensus role of CT neuron feedback are: firstly to act on thalamic neurons shifting their tuning and/or sharpening receptive fields, secondly to enhance the transmission of sensory input from the periphery to cortex (Briggs and Usrey 2008).

Diffuse projection neurons from the basal forebrain (BF) targets visual cortex and the release of acetylcholine (ACh) improves reliability of processing of visual sensory input (Goard and Dan 2009). BF cholinergic projection neurons have extensive axonal projections that span the entire neocortex (Villano et al. 2017). At least in the prefrontal cortex BF cholinergic axons extensively innervate layer 6 (Bloem et al. 2014) exciting postsynaptic nicotinic ACh receptors (nAChRs) containing $\beta_{2}$ and $\alpha_{5}$ subunits (Poorthuis et al. 2013) augmenting long-term strengthening of layer 6 pyramidal neurons (Verhoog et al. 2016). ACh acts as a neuromodulator in the central nervous system regulating arousal, attention and sleep-wakefulness (Metherate et al. 1992, Jones 2005, Klinkenberg et al. 2011). The anatomical localization and physiological response of CT neurons with their pronounced short-term facilitation present them as interesting targets for ACh-mediated neuromodulation. 
One study implicated CT neurons in the direct development of cortical epileptic seizures. Electrical stimulation of visual cortex layer 6 could promote the generation of focal tonic-clonic epileptic seizures in cats only when layer 6 was recruited (Hedström and Lindström 1987). Because of the CT neuron feedback projection, they have been suggested to function as neuronal amplifiers (Ahlsen et al. 1985, Granseth 2004). Depending on attentional demand this amplification is variably required, amplifying relevant sensory stimuli and disregarding non-relevant stimuli.

Crandall et al. showed that CT feedback in somatosensory cortex might dynamically shift activity from inhibition to excitation. Low action potential frequency promoted inhibition while high frequency promoted excitation. They showed that enhancement of thalamic processing is dependent on short-term plasticity of monosynaptic CT neurons and disynaptic TRN neurons. Stimulating CT neurons at a physiologically relevant frequency $(10 \mathrm{~Hz})$, was enough to engage mechanisms of shortterm plasticity promoting the switch from suppression to enhancement (Crandall et al. 2015). Stimulating CT with optogenetics in vivo in primary visual cortex (V1) produced intracortical suppression via activation of cortical fast-spiking interneurons and inhibitory TRN neurons suppressing the dLGN (Olsen et al. 2012, Bortone et al. 2014). Contrary to V1, activating L6 CT neurons in primary auditory cortex (A1) produces a net excitatory effect in all layers. Additionally, the action of L6 CT neurons in A1 has behavioral implications for sound discrimination and sound detection. Depending on the timing between A1 spikes and CT neuron 
activation sensory activity could be either enhanced or suppressed (Guo et al. 2017).

\section{Neuronal plasticity}

\section{Short-term plasticity}

Neurons have the fascinating ability to modify their output based on its previous signaling. This activity-dependent plasticity can favor enhancement or depression of activity. One can discuss it in terms of synaptic strength where some synapses strengthen with activity (synaptic enhancement) and some weaken with activity (synaptic depression) (Zucker and Regehr 2002, Dutta Roy et al. 2014). If these changes occur in the time scale from milliseconds to minutes they are classified as shortterm plasticity (STP). One can further sub-categorize STP into enhancing processes that lasts for tens of milliseconds to seconds (facilitation) and those with longer duration that last tens of seconds to minutes (augmentation and post-tetanic potentiation). Both augmentation and PTP are beyond the scope of this thesis and will not be described further (Zucker and Regehr 2002, Regehr 2012).

A common method to probe STP is to deliver pairs of stimuli to one or several neurons to then observe the response in a connected neuron (Figure 5). This is called a paired pulse protocol. By varying the interval between the pulses (the interpulse interval, IPI) from short (tens of milliseconds) to long (several seconds) one can observe the time course of STP. Calculating the ratio between the second response, EPSC2, over the 
first, EPSC1, (EPSC $\left.2 / E_{1} C_{1}\right)$ you get the paired pulse ratio (PPR) for that IPI. A PPR below 1 when stimulating at IPIs from 50-200 ms, is characteristic of synaptic depression (Regehr 2012), instead if the PPR is above 1 for pulses delivered 50 or $100 \mathrm{~ms}$ apart the synapse is facilitating (Zucker and Regehr 2002) see Figure 5.

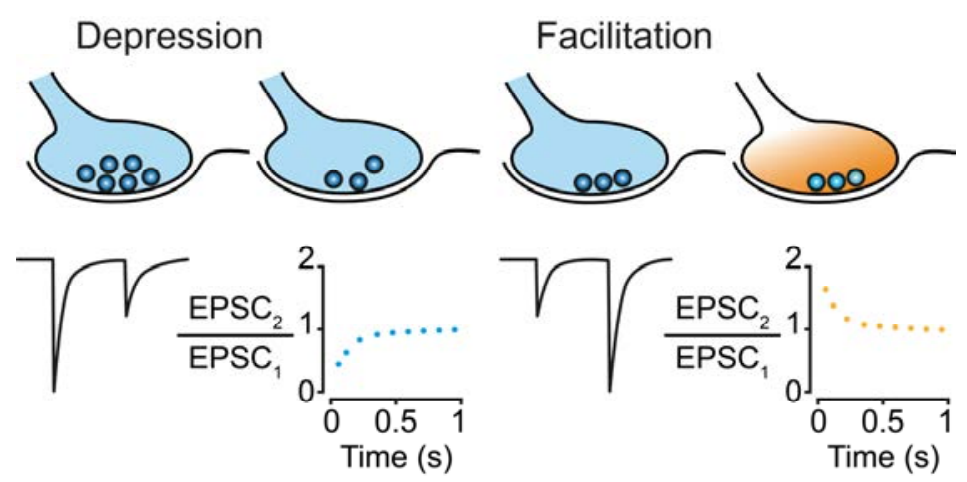

Figure 5 Schematic image showing short-term plasticity in two different neurons: depression caused by vesicle depletion; facilitation caused by increased release probability. Also showing a fictive graph illustrating the paired-pulse ratio for different interpulse intervals for a depressing synapse (blue) and a facilitating synapse (orange).

\section{Facilitation}

There are a number of different, although somewhat overlapping, theories for explaining the mechanisms for facilitation. All of them converge on the $\mathrm{Ca}^{2+}$ entry that triggers exocytosis in the presynaptic terminal (Jackman and Regehr 2017). Here follows a summary of some theories explaining facilitation: 


\section{Residual $\mathrm{Ca}^{2+}$}

The oldest theory on facilitation is the residual $\mathrm{Ca}^{2+}$ hypothesis suggested by Katz and Miledi in 1968 (Katz and Miledi 1968). When an incoming action potential reach the presynaptic terminal the depolarization leads to opening of $\mathrm{Cav}$ channels and inflow of $\mathrm{Ca}^{2+}$ into the terminal (via its electrochemical gradient across the membrane). This local $\mathrm{Ca}^{2+}$ signal ([ $\left.\left.\mathrm{Ca}^{2+}\right]_{\text {local }}\right)$ can reach the concentration range of tens to hundreds of micromolar (that is approximately 100-1000-times that of the normal neuronal $\mathrm{Ca}^{2+}$ concentration intracellularly) but this large increase in $\mathrm{Ca}^{2+}$ is transient. The residual $\mathrm{Ca}^{2+}$ hypothesis states that moderately elevated concentration of $\mathrm{Ca}^{2+}$ nevertheless will remain in the presynaptic terminal for 10-100 ms, affecting future release events. Residual $\mathrm{Ca}^{2+}$ has been estimated to approximately $1 \%$ of $\left[\mathrm{Ca}^{2+}\right]_{\text {local }}$ and at most synapses that would be too low of a concentration to directly affect release at most synapses (Zucker 2001, Neher and Sakaba 2008). Although, residual $\mathrm{Ca}^{2+}$ exists on its own it is not enough to explain the amplification of responses present at facilitating synapses, such as the CT synapse, where transmitter release can be enhanced 3-5 times (Granseth 2004).

\section{A presynaptic $\mathrm{Ca}^{2+}$ sensor}

If residual $\mathrm{Ca}^{2+}$ were to cooperate with a $\mathrm{Ca}^{2+}$ binding protein that binds $\mathrm{Ca}^{2+}$ slowly but with high-affinity, that could affect release probability. One suggested protein for this function has been synaptotagmin 7 (Syt7) that is a synaptotagmin isoform not responsible for triggering fast synaptic vesicle release. Syt7 binds $\mathrm{Ca}^{2+}$ and interacts with Syt1 (the vesicle release 
trigger) affecting release probability (Jackman et al. 2016, Jackman and Regehr 2017).

\section{High-affinity $\mathrm{Ca}^{2+}$ buffers}

The idea is that these proteins would "highjack" the local $\mathrm{Ca}^{2+}$ signal by binding $\mathrm{Ca}^{2+}$ before it reaches the release site, this mechanism would reduce the initial release probability. If the neuron is stimulated in a sufficiently short time after the first stimulation the $\mathrm{Ca}^{2+}$ buffering proteins will be occupied or saturated and more $\mathrm{Ca}^{2+}$ can reach the release site for the second stimulation compared to the first. Local buffer saturation could by this mechanism contribute to facilitation (Rozov et al. 2001, Zucker 2001, Burnashev and Rozov 2005, Regehr 2012).

\section{Slow $\mathrm{Ca}^{2+}$ binding proteins}

Like fast binding high-affinity $\mathrm{Ca}^{2+}$ buffering proteins facilitation can also be affected by slow kinetic $\mathrm{Ca}^{2+}$ binding proteins i.e. proteins that act similarly to EGTA. Slow $\mathrm{Ca}^{2+}$ binding proteins binds $\mathrm{Ca}^{2+}$ too slowly to affect local $\mathrm{Ca}^{2+}$ influx, in contrast to the fast binding ones and does not affect initial release probability. They instead target the residual $\mathrm{Ca}^{2+}$ component and decrease it and thus regulating the time course of facilitation (Rozov et al. 2001, Regehr 2012).

\section{Effects on $\mathrm{Ca}_{v}$ channe/s}

A number of $\mathrm{Ca}^{2+}$ binding proteins also interact and modify the $\mathrm{Cav}_{\mathrm{v}}$ channels. For example, P-type $\mathrm{Ca}^{2+}$ channels that are commonly expressed at presynaptic terminals are regulated by calmodulin. Depending on which 
site calmodulin interacts with on the intracellular side of the channel protein either a facilitated $\mathrm{Ca}^{2+}$ current or an inactivated $\mathrm{Ca}^{2+}$ current can be achieved (Catterall et al. 2013, Nanou et al. 2016). However, for CT synapses facilitation is unchanged in knock out mice for P-type $\mathrm{Ca}^{2+}$ channels (Bomben et al. 2016).

\section{Synaptic depression}

\section{Synaptic vesicle depletion}

The most straightforward theory regarding synaptic depression is that it comes from the depletion of synaptic vesicles as they are released (Figure $5)$. Depletion of synaptic vesicles is directly related to the size of the RRP at the active zone. If the release probability of the synapse is high, one stimulus to the presynaptic terminal would release a large amount of the vesicles from the RRP. If the replenishment rate of the RRP is slow shortterm depression will dominate due to vesicle depletion (Betz 1970, Zucker and Regehr 2002).

\section{Effects on endocytosis or occupying release sites}

Endocytosis can affect synaptic depression. When endocytosis is blocked a more pronounced depression is generated. The idea is that the released synaptic vesicle protein and membrane occupies the release sites inhibiting any release before endocytosis has had time to occur (Regehr 2012, Hua et al. 2013). 


\section{Inactivation of $\mathrm{Ca}_{\mathrm{v}}$ channe/s}

As mentioned above, use dependent effects of Cav channels can also affect synaptic depression. Especially intense high frequency stimulation decreases $\mathrm{Ca}^{2+}$ entry with time, probably due to a negative feedback regulation of the Cav channels by calmodulin binding $\mathrm{Ca}^{2+}$ and interacting with at least two regulatory sites of the Cav protein (Catterall et al. 2013).

\section{Recovery from depression}

Calmodulin and the concentration of $\mathrm{Ca}^{2+}$ in the presynaptic terminal is affecting the speed of which depression recovers. Where increased $\left[\mathrm{Ca}^{2+}\right]_{\text {ic }}$ promotes faster recovery and inhibiting calmodulin prevents it. There is also $\mathrm{Ca}^{2+}$-independent recovery from depression involving cyclic AMP (cAMP) where increased cAMP favor recovery from depression. The presynaptic protein Bassoon normally acts to prevent synaptic depression by rapidly replenishing synaptic vesicles at the release sites. If this function is blocked the recovery from depression will be prolonged (Fioravante and Regehr 2011, Regehr 2012).

\section{Long-term potentiation and depression}

Changes in synaptic strength maintained for hours to months and even longer are classified as long-term synaptic plasticity. Long-term synaptic plasticity involves molecular processes generating learning and memory formation that exists throughout the brain but is most widely studied in the hippocampus (Bliss and Collingridge 1993, Luscher and Malenka 2012). In the middle of the $20^{\text {th }}$ century Donald Hebb, a Canadian 
psychologist, proposed in his book The Organization of Behavior (1949) a theory stating "cells that fire together wire together" meaning that cells that undergo simultaneous activation will be strengthened. Donald Hebb never experimentally tested this, but his theory has been greatly influential (Luscher and Malenka 2012). Pioneering work by Bliss and Lømo showed that excitatory responses in the hippocampus were potentiated upon stimulating with a high frequency train (tetanic stimulation) (Bliss and Lomo 1973). This process of potentiation that remained 10 hours after the initial stimulation was later to be called longterm potentiation (LTP). There are many different forms of LTP but classically it involves activation of NMDA-receptors (NMDARs) causing $\mathrm{Ca}^{2+}$ influx and later an increase in AMPA-receptors (AMPARs) expressed in the postsynaptic plasma membrane (Luscher and Malenka 2012). LTP is specific to synapses that have encountered the stimulation. Influx of $\mathrm{Ca}^{2+}$ ions through NMDARs is an essential step for the intracellular signaling associated with LTP, where activation of $\mathrm{Ca}^{2+}$-Calmodulin-dependent kinase II (CaMKII) is a central effector (Barria et al. 1997, Malenka and Nicoll 1999). As synapses can undergo process of LTP to become potentiated they can also encounter situations where the opposite happens, that synapses are weakened, i.e. depressed. The process of longterm depression (LTD) can be initiated experimentally when neurons are repeatedly stimulated at low stimulation interval. LTD is also NMDARdependent, and low level of $\mathrm{Ca}^{2+}$ influx has been believed to be central to the induction of LTD (Dudek and Bear 1992, Mulkey and Malenka 1992). However, work by Navabi et al (Nabavi et al. 2013) showed that LTD could 
be achieved without $\mathrm{Ca}^{2+}$ influx through NMDARs, suggesting a previously unknown metabotropic signaling effect by NMDARs (Dore et al. 2017).

\section{Morphogens in the developed nervous system, focus on Hedgehog}

The small secreted protein Hedgehog $(\mathrm{Hh})$ is important for patterning and differentiation during embryogenesis and early development (Dessaud et al. 2008), especially in the neural tube. Hh was first discovered in Drosophila melanogaster in the 1980s (Nusslein-Volhard and Wieschaus 1980, Lee et al. 1992), and Sonic Hedgehog (Shh) is the most potent vertebrate homolog of the Hedgehog family, which includes Indian hedgehog (Ihh) and Desert hedgehog (Dhh). There are various orthologous hedgehog proteins throughout the animal kingdom, and more Hh variants than Shh, Ihh and Dhh (Zardoya et al. 1996). Hh can bind the 12-transmembrane protein Patched (Ptc, Ptc1 and -2 in vertebrates) (Stone et al. 1996), which in turn is normally bound to, and thereby repressing, the 7-transmembrane protein Smoothened (Smo) (Murone et al. 1999) (Figure 6). The binding of Hh to Ptc releases Smo to activate downstream signaling (Hynes et al. 2000). The targets downstream of Smo are the Gli transcriptional effector proteins (zinc-finger proteins) Gli1, -2 and -3. Gli3 acts as a transcriptional repressor, while Gli2 and Gli1 are transcriptional activators. Gli1 and Ptc are transcribed upon Hhsignaling to act as positive, and negative, transcriptional feed-back to Hhsignaling activity (Cohen et al. 2015), Gli3 transcription is repressed upon Hh-signaling (Marigo et al. 1996). Generally, the hedgehog signal shifts the balance from the predominant Gli3 repressive activity toward Gli1 and -2 transcriptional activation (Hui and Angers 2011). The direct involvement 
of Gli proteins in the Hh cascade signifies the canonical pathway (Ingham and McMahon 2001), but there is also a non-canonical signaling chain that utilizes Gli-independent effectors, with or without Smo involvement (Jenkins 2009). The non-canonical signaling may include Gi-coupled signals, downstream of Smo, which activate RhoA and further downstream transcriptional responses, or a Smo-independent non-canonical cascade that involves Ptc-signaling onto caspases and cell cycle mediators (Chinchilla et al. 2010).

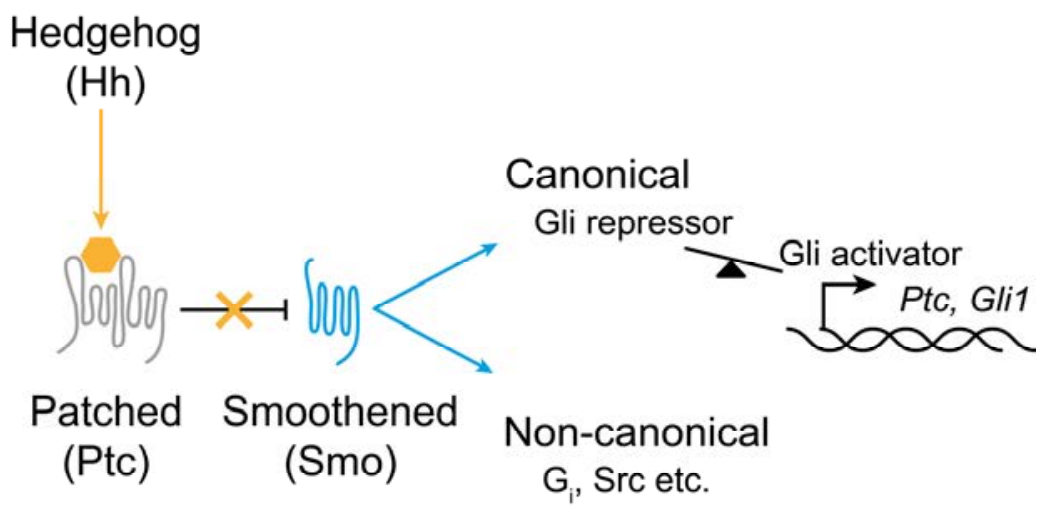

Figure 6 Simplified Hedgehog signaling pathway.

During development morphogens often act in antagonistic pairs, with positive gradients towards opposites poles of a developing organism. Two such pairs are $\mathrm{Hh}$ and Wingless-related integration site (Wnt). Their developmental roles have been heavily investigated involving body segment patterning and polarizing the neural tube (Dessaud et al. 2008). In recent years their roles in adult organisms have attracted more interest. Hh-signaling have been implicated in adult neurogenesis (Yao et al. 2016) 
and the regulation of astrocytes in the adult forebrain (Garcia et al. 2010). Increased concentrations of Hh can be detected in cortical gray matter and in the cerebrospinal fluid (CSF) after brain injury (Sirko et al. 2013) and Hh-signaling can protect dopaminergic neurons from neurotoxicity (Petrova and Joyner 2014). Wnt has been implicated in the induction of LTP (Chen et al. 2006), via synaptic up-regulation of NMDAR-mediated currents (Cerpa et al. 2011). Non-canonical Wnt maintains basal NMDAR mediated synaptic transmission via the tyrosine kinase-like orphan receptor 2 (RoR2) (Cerpa et al. 2015). Hh-signaling in the olfactory system can regulate the expression of olfactory receptors both in adult fruit fly, Drosophila Melanogaster, and in adult mice (Sanchez et al. 2016, Maurya et al. 2017). 


\section{Aims of Thesis}

\section{Specific aims}

- To determine the neuronal identity of layer 6 neurons in the cerebral cortex of Ntsr1-Cre GN220 transgenic mice (paper I)

- To investigate how these neurons respond to cholinergic drugs (paper I)

- To investigate if Ntsr1-Cre is expressed in a population of neurons located in the white matter (WM) below the visual neocortex of the transgenic GN220 Ntsr1-Cre mouse (paper II)

- To study short-term plasticity of Ntsr1-Cre neuron synapses in cortical cultures (paper III)

- To investigate the role of Hedgehog (Hh) signaling in the regulation of neuronal signaling and synaptic strength in mature hippocampal cultures (paper IV) 


\section{Material and methods}

We have used transgenic mice or embryonic rats in the four projects included in this thesis. The transgenic mice were used to collect tissue for slice patch-clamp electrophysiology, antibody-based methods (Papers I \& II) and cell culture (Paper III). The embryonic rat pups were used for hippocampal cell cultures (Paper IV). All animal work procedures have been evaluated and approved by the animal ethical committee and follow Swedish and EU laws and regulations concerning animal research.

Working with any animal model implies ethical considerations, as well as questions of biological generalizability. When, and to what extent, the peculiarities of a model paradigm are translatable into humans and other species is not often easily understood. Comparative medicine (Macy and Horvath 2017) is important for animal research in fields ranging from developmental programming (Rabadan-Diehl and Nathanielsz 2013) to neuropsychiatry (Hall et al. 2014). It is often difficult to assess which model is the most suitable for a specific question, and so it may be crucial to employ a battery of distinct models - especially in pharmacological investigations (Loscher 2002). Today researchers are instructed to apply the 3R principle when applying for ethical permission for animal research, meaning that researchers have to consider how to Reduce, Refine and Replace animals in research when possible. Great strides have been made in cell-based in vitro systems, such as organoids (Camp et al. 2015) and genetically controlled iPSC systems (Wen et al. 2014), but these models still need years of comparative experimentation and have limitations, 
especially for the study of behavior. Animals have been, and continue to be, crucial for research in neurobiology.

\section{The Ntsr1-Cre GN220 transgenic mouse}

Techniques for manipulating the genetic material has been around for over 40 years (Cohen 2013), with the discovery and use of restriction enzymes, endonucleases and ligation reactions marking the emergence of a new genetic era of animal models in research. The Cre-loxP system (Hoess et al. 1984, Sauer 1987, Sauer and Henderson 1988) opened-up the possibility of more selective genetic manipulation of research animals (Thomas and Capecchi 1987, Gu et al. 1994). The Cre-loxP system works in principle by the use of the restriction enzyme Cre-recombinase that recognizes a specific sequence of nucleotides called the loxP site. Whenever Cre-recombinase encounters a loxP site it makes a cut in the DNA sequence (Sauer and Henderson 1988, Ghosh and Van Duyne 2002). For example, flanking a gene (or a crucial part of it) with loxP sites (i.e. the gene is flanked by loxP - "floxed") will result in a deletion (or inversion) of that sequence when Cre-recombinase is introduced.

Two floxed mouse lines have been used in this thesis: floxed tdTomato and floxed Channelrhodopsin-2-YFP (Figure 7). They both use the same principle, that is: a stop cassette flanked by loxP sites was introduced into the mouse genome together with either tdTomato (tdTom) or Channelrhodopsin-2-YFP (ChR2). This manipulation occurs in all cells with a nucleus. The stop cassette hinders the expression of tdTom or ChR2 
unless Cre-recombinase is introduced, whereupon the stop cassette is excised and the genes are released.

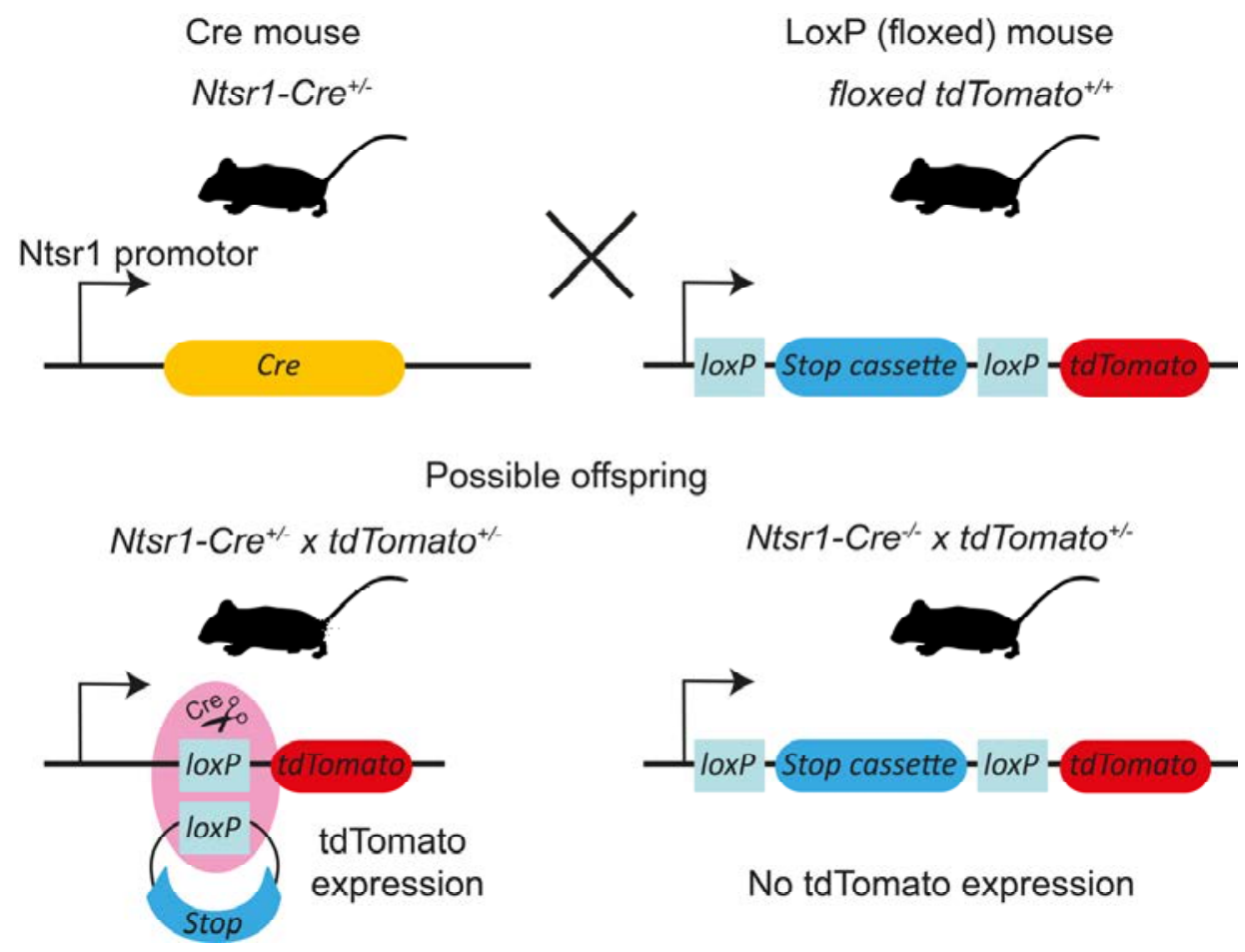

Figure 7. Basic description of Cre-loxP genetic manipulation of mice. In the Ntrs1Cre GN220 mouse Cre recombinase is expressed under control of the promotor for the Ntsr1 gene. Wherever Cre encounters a loxP site it will make a cut in the DNA sequence.

Targeted, or conditional, expression of the genes tdTom or ChR2 is achieved by clever positioning of the gene for Cre-recombinase in the genome. If the Cre-recombinase gene is placed under the control of a promotor sequence that targets gene expression to a subset of cells in an area or a specific cell type, the Cre-recombinase, and subsequently tdTom 
and ChR2 will only be expressed there. There are many advantages with manipulating only a select population of cells. This approach limits compensatory mechanisms, embryonic lethality and widespread effects that can occur with traditional knock-out or knock-in techniques (Bernstein and Breitman 1989, Cohen-Tannoudji and Babinet 1998). A number of problems have been acknowledged when working with transgenic mice expressing Cre-recombinase, including expression in offtarget tissues, variable expression rates among littermates and variable activity of Cre depending on parental origin of the Cre gene (Heffner et al. 2012). Expression of Cre in off-target tissues could mean that the Cre gene is no longer restricted to the specific promotor it was designed to be controlled under, this would lead to ectopic expression of Cre.

The Cre-line used in papers I-III of this thesis is the Neurotensin receptor 1 Cre GN220 (Ntsr1-Cre) transgenic line (RRID: MMRRC_017266-UCD) developed by Gong et al. (Gong et al. 2007). This line was developed as part of the Gene Expression Nervous System Atlas (GENSAT) Project (gensat.org, (Gong et al. 2003)). The Ntsr1-Cre line was developed using bacterial artificial chromosome (BAC) constructs to introduce the gene for Cre-recombinase into pronuclei of fertilized oocytes of FVB/N mice. Mice where then backcrossed to the C57BL/6J strain, and stable expression of Cre-recombinase was confirmed. We followed the MMRRC (Mutant Mouse Resource \& Research Centers supported by $\mathrm{NIH}^{1}$ ) guidelines for genotyping and breeding of mice. For stable colony holding we bred male

\footnotetext{
${ }^{1} \mathrm{mmrrc} .0 \mathrm{rg} /$ catalog/sds.php?mmrrc_id=17266
} 
heterozygous Ntsr1-Cre mice with wild type C57BL/6J female mice, only male offspring were kept for breeding of experimental mice. Experimental mice for slice patch-clamp electrophysiology, confocal microscopy of cortical brain sections and cortical cell cultures were generated from breeding of male heterozygous Ntsr1-Cre mice and female homozygous tdTomato reporter mice or homozygous ChR2 mice. Animal facility staff collected ear samples for genotyping 14 days post-birth. Animals with positive Ntsr1-Cre genotype were used for experiments regardless of sex.

To assess if off-target expression of Ntsr1-Cre had occurred during the projects of this thesis we thoroughly studied the expression pattern of Ntsr1-tdTom every time we performed slice patch-clamp experiments or confocal microscopy in a way to see that tdTom was restricted to layer 6 and that the intensity of tdTom was not aberrant. We did not, as a rule, investigate other brain areas for ectopic expression of tdTom, but when performing confocal microscopy that was inevitable, and sporadic tdTomexpressing neurons could be found in hippocampus.

\section{Patch clamp electrophysiology}

The patch-clamp technique for recording ionic currents at high resolution from small cells was developed by Hamill et al., in 1970-80s, (Hamill et al. 1981). The patch-clamp technique allowed Bert Sakmann and Erwin Neher to perform recordings from single ion channels in the plasma membrane, earning them the Nobel Prize in Medicine and Physiology in 
$1991^{2}$. In the patch-clamp technique fluid filled glass micropipettes with a small bore size is approached to a cell's plasma membrane forming a highresistance seal between the glass micropipette and the plasma membrane allowing even currents from single ion channels to be resolved and recorded (Sakmann and Neher 1984). Once a high-resistance seal is formed the patch-clamp technique can be modified to suit different research questions.

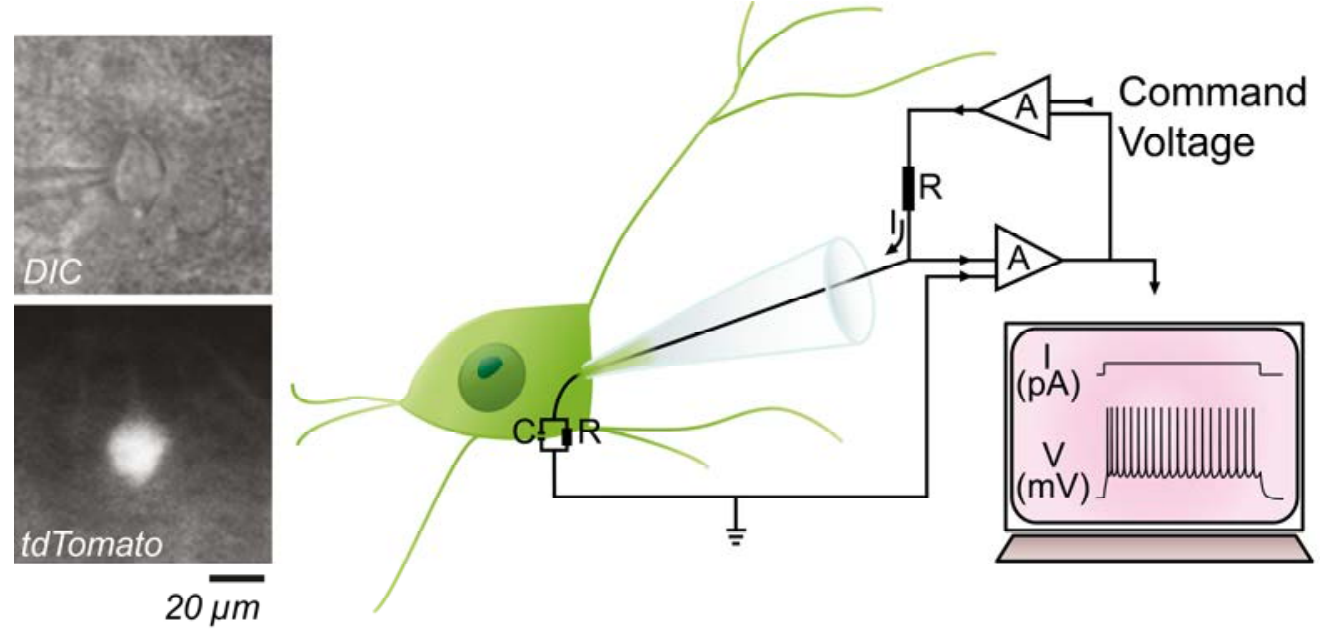

Figure 8. The principle of patch-clamp electrophysiology. A, An image showing a layer 6 Ntsr1-tdTom pyramidal neuron and a recording micropipette using differential interference contrast (DIC) microscopy (top) and the tdTom fluorescence emission from the same neuron (bottom). B, A schematic image of a neuron targeted for patch-clamp electrophysiology (here in whole-cell mode) recording action potential firing upon delivery of a depolarizing current pulse (current clamp). A, amplifier; $C$, capacitance; I, current; $R$, resistance.

In this thesis the patch clamp technique has been used in the whole-cell mode. In whole-cell mode once a high resistance seal has been formed

\footnotetext{
${ }^{2}$ www.nobelprize.org/prizes/medicine/1991/summary/
} 
between the micropipette and the cell plasma membrane the membrane within the pipette is ruptured, forming a fluid continuum between the fluid of the micropipette and the intracellular fluid. This allows for recordings of ionic currents and potentials across the plasma membrane, see Figure 8. The recordings of currents or potentials are based on Ohm's law $(\mathrm{U}=\mathrm{R} \times \mathrm{I})$.

In whole-cell mode one should be aware that the buffer in the micropipette will equilibrate with the cytosolic cell solution. Thus, it is important to carefully consider the composition of the pipette buffer. In project I, we recorded changes in membrane potential (current clamp mode) upon application of cholinergic drugs. In that setting we used a pipette buffer mimicking that of a neuron. We used a potassium gluconatebased buffer to achieve stable $\mathrm{pH}$ and supply non-permeable anions to balance the high $\mathrm{K}^{+}$concentration. Instead, in projects III and IV the aim was to record (sometimes) small postsynaptic currents (voltage clamp mode) and we used a cesium gluconate-based buffer in the pipette. Cesium ions are used to substitute cytosolic $\mathrm{K}^{+}$ions. $\mathrm{Cs}^{+}$will block $\mathrm{K}^{+}$ channels (Hagiwara et al. 1976), together with additional blockers of voltage dependent $\mathrm{K}^{+}$and $\mathrm{Na}^{+}$channels present in the plasma membrane, more reliable voltage clamping can be achieved. Blocking voltage dependent $\mathrm{K}^{+}$and $\mathrm{Na}^{+}$conductances in the recorded neuron permits postsynaptic currents at distant dendrites to be resolved (improving space clamp). The mixture of solutions in whole-cell mode occurs quickly and can lead to a wash-out of small soluble molecules present in the cell, 
something that should be considered for certain research questions (i.e. gprotein signaling and second messengers). Sometimes a series resistance can build-up blocking the path for current and potential recordings in the pipette-cell junction. If the series resistance is high the voltage command will be offset and current recordings will be off (Axon Guide, Molecular devices). We monitored series resistance by delivering a test pulse of -10 or $-20 \mathrm{mV}$ before and after recording protocols were run.

Visual cortex tissue for patch-clamp slice electrophysiology was prepared from female or male Ntsr1-Cre positive animals aged 3 to 8 weeks. At this age-span, mice have opened their eyes ensuring processing of relevant sensory input to visual cortex and maturation of CT neurons (Warren and Jones 1997, Grant et al. 2012). Additionally, preparing slices from mice older than 8 weeks can result in poor cell survival ex vivo resulting in recording from unhealthy or dying cells.

One of the advantages of slice patch-clamp electrophysiology is that, if carefully prepared and incubated in buffers with balanced composition at controlled temperature, cells maintain their activity and behavior ex vivo for a number of hours in the lab. Allowing stable recordings that makes it possible to compare baseline before a drug is added to the drug-induced response in recordings from individual cells and/or the surrounding network. In order to get reproducible results all procedures, from sacrificing the mice to generating brain slices and recordings, were strictly prepared and performed according to protocols optimized in the lab. 
In projects III and IV we performed whole-cell recordings of neurons in cortical and hippocampal cell cultures, respectively. Cortical cultures were prepared from newborn Ntsr1-tdTom or -ChR2 mice pups (postnatal day 0 to day 2, p0-2) and hippocampal cultures were prepared from wild type Sprague-Dawley rat embryos (E17.5-18.5). Cultures were grown in a humidified incubator set to $37^{\circ} \mathrm{C}$ with $5 \% \mathrm{CO}_{2}$, changing half of the medium twice per week. Cortical cultures were grown for minimum of 14 days in vitro (14DIV) until recordings were started, by that time neurons have formed extensive networks. Hippocampal cultures were grown for either 10-12 DIV or 20-21 DIV to record postsynaptic currents in developing and mature neurons after incubations with drugs affecting the Hh signaling pathway. Hh signaling drugs were incubated for a minimum of $48 \mathrm{~h}$ before recordings could be initiated, unless acute effects of drugs were investigated. Tetrodotoxin (TTX) was applied to hippocampal cultures to silence action potential firing and enable recordings of miniature postsynaptic currents (mEPSCs). Hippocampal neurons were voltage clamped at $-70 \mathrm{mV}$ and a minimum of 100 mEPSCs was collected for analysis.

\section{Neuronal stimulation}

In project III we stimulated neurons by current injection and light stimulation of ChR2. ChR2 is a tool/technique to achieve neuronal activation by stimulation with light (Nagel et al. 2003). ChR2 was developed from light responsive proteins expressed by algae. These proteins work as light-activated ion channels and have proven very useful 
in the field of neuroscience - allowing researchers to manipulate neuronal excitability without physically interfering with the cells. Compared to rhodopsins, expressed in the retina, channelrhodopsins do not require a second messenger-based signal transduction. The light responsiveness and the ion channel property of channelrhodopsins are parts of the same protein (Deisseroth and Hegemann 2017). ChR2 is mostly sensitive to light in the blue spectrum and when illuminated ChR2 opens and permit flow of a cation current across the membrane (Nagel et al. 2003).
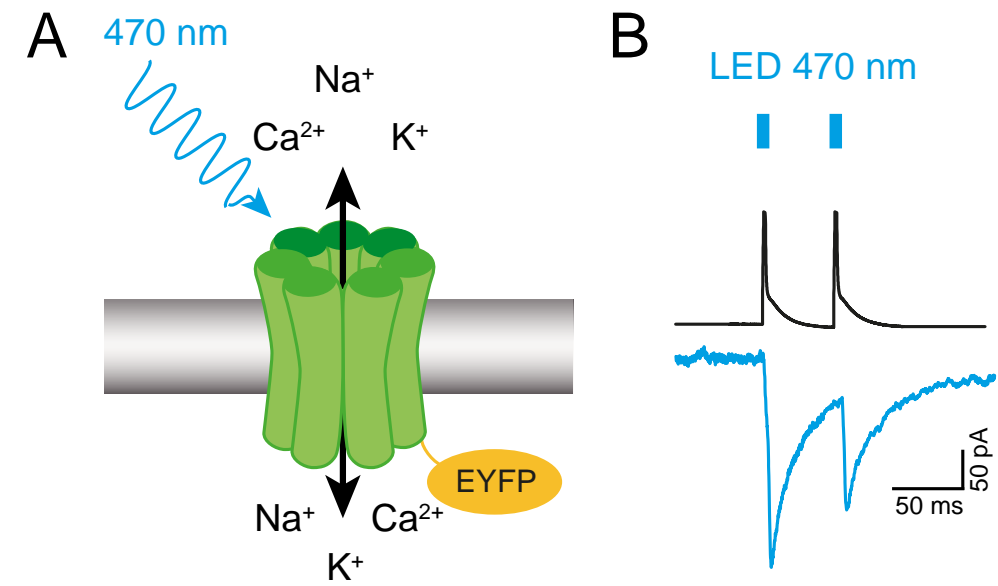

Figure 9. Basic principle of light-controlled excitation by Channelrhodopsin-2. A, Schematic image of ChR2 coupled to enhanced yellow fluorescent protein (EYFP). ChR2 sits in the plasma membrane with its 7 transmembrane helices forming a light controlled cation channel. ChR2 is controlled by blue light ( $470 \mathrm{~nm})$, and when illuminated the channel opens allowing flow of $\mathrm{Na}^{+}, \mathrm{K}^{+}$and $\mathrm{Ca}^{2+}$ ions. B, Short 470 $\mathrm{nm}$ light pulses (top) can stimulate action potential firing in a ChR2 positive neuron (middle) evoking excitatory postsynaptic responses in a neighboring neuron (bottom).

We triggered action potential firing by activation of ChR2 using a $470 \mathrm{~nm}$ LED, illuminating the whole field of view in the microscope. Light pulses were externally triggered and the intensity of the LED was manually 
adjusted for each recorded cell to reach action potential threshold. Light pulses were delivered at a duration of 1-2 ms. To clearly determine if we got action potential firing from ChR2 activation the Ntsr1-ChR2 positive cell was whole-cell patch clamped to record changes in membrane potential while delivering light pulses (Figure 9).

Action potential firing was also stimulated with injection of depolarizing currents through the patch pipette, the threshold for achieving action potential firing was assessed for every cell and the range differed between injections of $400-1000 \mathrm{pA}$ for 1-2 ms duration. Naturally any Ntsr1tdTom or Ntsr1-ChR2 cells that failed to evoke action potentials were considered unhealthy and were not used in experiments. Generally, light exposure of cultured neurons was minimized during cell isolation, culture maintenance and experimental procedures to avoid phototoxicity from fluorescent protein excitation and unspecific activation of $\mathrm{ChR} 2$ and with that a potentially uncontrolled neuronal network activation.

\section{Antibody based methods}

We have used antibody-based methods in all projects of this thesis. Antibodies were used to detect proteins in cortical and hippocampal cell cultures and in cortical brain sections. In project I we searched for a protein specifically expressed in the layer 6 CT population. We screened several candidates and found that forkhead box protein 2 (FoxP2) had showed to be specifically expressed in cortical layer 6 of adult mice (Hisaoka et al. 2010). In order to detect FoxP2 in our cortical sections we had to optimize an antigen retrieval protocol to generate a clear 
fluorescence signal with high signal-to-noise ratio. We treated our sections in Tris-EDTA with high $\mathrm{pH}(\mathrm{pH} 9)$ at $80{ }^{\circ} \mathrm{C}$ for 2 minutes to retrieve the FoxP2 antigen. We regularly prepared cortical sections omitting FoxP2 primary antibody incubation, and used them as negative controls of antibody staining. In project IV we used antibodies to detect ionotropic glutamate receptors in hippocampal cultures after incubation of Hh signaling affecting drugs (namely: GluA1, GluA2, GluA3, GluN1A, GluN2A and GluN2B). In this project we performed quantitative immunohistochemistry, and needed to optimize antibody concentrations and protocols to be able to detect an increase or a decrease in surface protein expression of receptors. Negative and positive controls using no primary antibody or pre-incubation with the specific antigen peptide, respectively was performed to ensure specific staining of receptors. 


\section{Results}

\section{Summary of papers}

\section{Paper I}

Aims: To determine the neuronal identity of layer 6 neurons in the cerebral cortex of Ntsr1-Cre GN220 transgenic mice and additionally, to investigate how these neurons respond to cholinergic drugs

\section{Results in brief}

- Ntsr1-Cre expressing neurons in neocortical layer 6 of the Ntsr1Cre GN220 transgenic mouse project to thalamus (corticothalamic, CT, neurons) and do not include neurons projecting to claustrum (CCL neurons) or within neocortex (corticocortical, CC neurons)

- The nuclear protein Forkhead box protein 2 (FoxP2) co-localizes with Ntsr1-Cre driven tdTomato

- About $25 \%$ of Ntsr1-Cre positive adult neurons have an apical dendrite that extends to layer 1

- Low concentration of acetylcholine, similar to that of volume transmission, increases action potential firing frequency

- The cholinergic agonist Carbachol (CCh) produces a large depolarization and increase in input resistance of CT neurons. Fastspiking interneurons are minimally affected

- CT neurons are depolarized by both muscarinic and nicotinic acetylcholine receptors 
- The depolarization and change in input resistance from $\mathrm{CCh}$ are a result of $\mathrm{K}^{+}$channel closure

Conclusion: Cre positive neurons in layer 6 of the Ntsr1-Cre GN220 mouse are corticothalamic (CT) and FoxP2 can be used as an immunohistochemical marker to detect these neurons. CT neurons in visual cortex show high sensitivity to cholinergic signaling and both muscarinic and nicotinic acetylcholine receptors are responsible for the effect. CT neurons could be a target for cholinergic signaling from other brain regions, such as the basal forebrain, to potentially modulate attention and cortical gain. 


\section{Paper II}

Aim: To investigate if Ntsr1-Cre is expressed in a population of neurons located in the white matter (WM) below the visual neocortex of the transgenic GN220 Ntsr1-Cre mouse

\section{Results in brief}

- Cre-expressing neurons of the Ntsr1-Cre GN220 mouse are primarily present in layer 6 , but a small subset (about $7 \%$ ) of neurons can be found in the WM of the visual cortex

- CT neurons, identified by retrobead injections to the dLGN, are prevalent throughout layer 6 and is similar in upper and lower parts

- CT neurons are present in the WM

- Significantly fewer neurons co-express FoxP2 in WM compared to the upper and lower parts of layer 6

Conclusion: About half of the Cre-expressing neurons located in the WM of Ntsr1-Cre mice have a phenotype differing from CT layer 6 neurons that always express FoxP2. We estimate that 15-40 \% of WM neurons are Crepositive. Cre-expressing neurons located in the WM of the Ntsr1-Cre GN220 mouse should be considered when using Cre-driven optogenetics, chemogenetics etc. to target and investigate corticothalamic function. 
Paper III

Aim: To study short-term plasticity of Ntsr1-Cre neuron synapses in cortical cultures

\section{Results in brief}

- Ntsr1-Cre positive neurons from cerebral cortex in culture maintain electrophysiological and morphological characteristics of corticothalamic (CT) neurons

- Regardless of recording temperature (room temperature or physiological temperature), pairs of synaptically connected neurons (Ntsr1-Cre positive: presynaptic; Ntsr1-Cre negative: postsynaptic) were similar with regard to paired pulse facilitation and EPSC peak amplitudes

- Half of the connected pairs stimulated with current pulses displayed marked paired-pulse facilitation whereas the other was non-facilitating

- The facilitating pairs had significantly lower $\mathrm{EPSC}_{1}$ peak amplitude compared with non-facilitating pairs

- Many Ntsr1-Cre positive neurons had functional autapses that always displayed paired pulse depression. Ntsr1-Cre autaptic EPSC $_{1}$ peak amplitude was higher, and time-to peak was significantly shorter compared to facilitating Ntsr1-Cre positive to negative pairs. Autapses and non-facilitating Ntsr1-Cre positive to negative pairs were very similar. 
- Neurons expressing Ntsr1-Cre driven Channelrhodopsin-2 (ChR2) behaves as Ntsr1-Cre neurons expressing tdTomato and have the characteristic firing response pattern of CT neurons.

- Ntsr1-Cre x ChR2 neurons stimulated with light pulses for paired pulse recordings displayed short-term depression with significantly lower PPR at $100 \mathrm{~ms}$ IPI and significantly higher $\mathrm{EPSC}_{1}$ peak amplitude compared to Ntsr1-Cre positive neurons stimulated with electrical pulses.

Conclusion: Ntsr1-Cre neurons in cultures behave as corticothalamic (CT) neurons in ex vivo cortical slices and can be used to study short-term plasticity in vitro. Recording temperature does not affect short-term plasticity, at the CT synapse under our recording conditions. Overall, facilitation was the default direction of short-term plasticity of Ntsr1-Cre neuron. Half of the recorded pairs did not facilitate but seemed to have fast facilitation overlaid on a slowly recovering depression. Autaptic Ntsr1-Cre positive responses always showed depression in stark contrast to facilitating Ntsr1-Cre positive neurons. Suggesting that, in this case, the postsynaptic neuron could influence the mode of short-term plasticity of the presynaptic neuron. Using $\mathrm{ChR} 2$ to stimulate synapses turns facilitating Ntsr1-Cre neurons into strictly depressing neurons with high neurotransmitter release probably. Most likely, this effect is due to $\mathrm{Ca}^{2+}$ inflow through ChR2 affecting the release machinery and hence release probability. ChR2 should be used with caution for research on CT shortterm plasticity, but could also be used as an advantageous tool for the study of the $\mathrm{Ca}^{2+}$-dependence of short-term plasticity. 


\section{Paper IV}

Aim: To investigate the role of Hedgehog $(\mathrm{Hh})$ in the regulation of neuronal signaling and synaptic strength in mature hippocampal cultures

\section{Results in brief}

- Blockade of Hh-signaling for $48 \mathrm{~h}$ using the selective Smoantagonist Vismodegib increases the peak amplitude but not frequency of miniature excitatory postsynaptic currents (mEPSC) in mature (21 days in vitro, DIV) rat hippocampal neurons in vitro

- Blockade of the canonical Hh-signaling pathway using GANT-61 does not affect peak mEPSC amplitude but increase their frequency in mature neurons

- Immature hippocampal neurons (12-14 DIV) are unaffected by Vismodegib but GANT-61 incubation results in an increased mEPSC frequency, as in mature neurons

- The increased mEPSC amplitude after Vismodegib incubation was accompanied by a significant increase in surface expression of GluA2 AMPA-receptor subunits

- The Vismodegib-mediated increase in mEPSC amplitude was dependent on ionotropic and metabotropic NMDA-receptor signaling

- Spontaneous NMDA-receptor mediated currents were affected by Vismodegib incubation with increased half-width, decay time constant and charge transfer compared to controls 
- We did not see any change in the surface expression of NMDAreceptor subunits GluN1A, GluN2A or GluN2B after Vismodegib incubation

Conclusion: Canonical and non-canonical Hh-signaling affects hippocampal neurons differently. Non-canonical Hh-signaling affects mature neurons, whereas the canonical signaling is present in both immature and mature networks. The canonical pathway likely acts presynaptically, regulating synapse growth. Non-canonical Hh-signaling in mature neurons suppress NMDA-receptor function through an unknown mechanism resulting in changes in NMDA-receptor mediated currents and subsequently effects AMPA-receptors surface expression in an LTP/LTD manner. This points towards a role for Hh-signaling in synaptic scaling and plasticity e.g. to counteract the recurrence of epileptic seizures. 


\section{Results and Discussion}

\section{Papers I \& II}

The Ntsr1-Cre GN220 mouse was developed within the large-scale project GENSAT to generate transgenic mouse lines with Cre-expression targeted to different cell types and areas of mouse cerebral cortex. Many lines were probably assessed before it was discovered that placing the Crerecombinase gene under the control of the Neurotensin receptor 1 promotor generated a mouse line with Cre-expression targeted to a pyramidal cell population of cortical layer 6 (Gong et al. 2003, Gong et al. 2007). This was the case for the GN220 mouse but not in other Ntsr1-Cre mouse lines (e.g. GN209).

Cortical layer 6 is populated by three types of pyramidal neurons; corticocortical (CC), corticoclaustral (CCL) and corticothalamic (CT) with differing dendritic and axonal projection patterns (Thomson 2010). It was unclear whether Cre was expressed in one or several of these layer 6 pyramidal cell types in the Ntsr1-Cre GN220 mouse. We wanted to investigate the specificity of the Ntsr1-Cre line using anatomical tracing, electrophysiology and antibody-based techniques. Additionally, we wanted to assess how cholinergic signaling potentially could affect these Cre-expressing layer 6 neurons. 
Cre-expression in the Ntsr1-Cre GN220 transgenic mouse is targeted to the corticothalamic population of layer 6 neurons

Firstly, we observed that in cortical brain sections from Ntsr1-Cre mice, the Cre driven fluorescent reporter tdTomato was localized to neuronal somata in layer 6 together with intense fluorescent signals in white matter (WM) below neocortex and in primary thalamic nuclei such as the dorsal lateral geniculate nucleus (dLGN) and with less intense fluorescence signals in layers 5, 4 and 2/3 (see Figure 4 in Introduction). Injecting fluorescently-conjugated latex beads (retrobeads) into the dLGN and into the Claustrum generated retrobead-labeled somata in sensory cortex (Figure 10). We saw a large degree of co-labeling between retrobeads and Cre-driven tdTomato expression in layer 6 of visual cortex when we injected Ntsr1-Cre mice with retrobeads into dLGN. Over $85 \%$ of tdTomato expressing neurons were labeled with retrobeads. Injecting retrobeads into claustrum generated sporadic labeling of neuron somata in layer 6 of visual and somatosensory cortices, none of these neurons were tdTomato expressing ( 0 neurons out of 34 retrobead labeled neurons in V1 and SS1). These anatomical tracing experiments support the notion that Cre-expressing neurons in Ntsr1-Cre GN220 mice belongs to the CT population of layer 6 pyramidal neurons. 


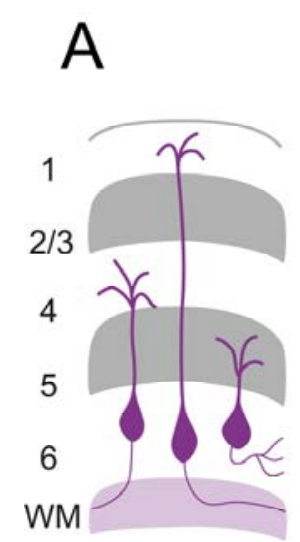

$\mathrm{CT} \mathrm{CCl} \mathrm{CC}$
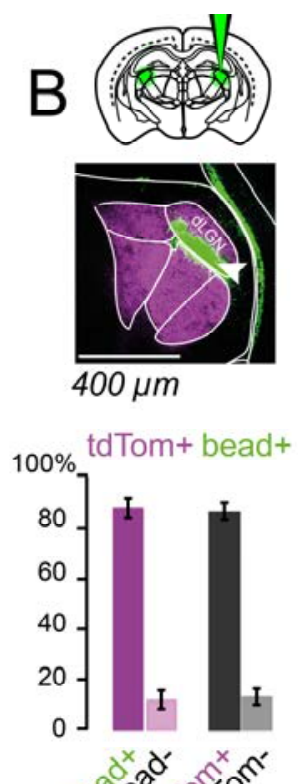

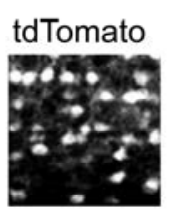

Retrobeads

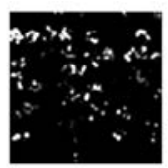

Merge

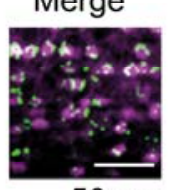

$50 \mu m$

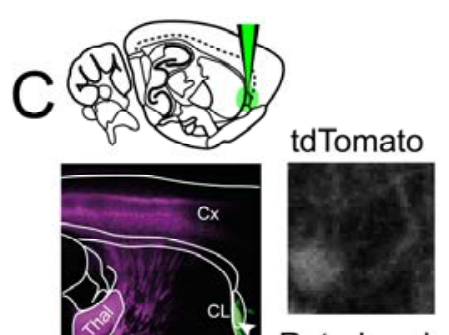

Retrobeads

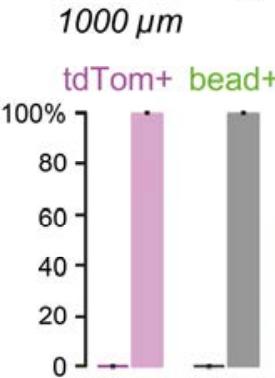

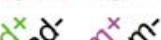

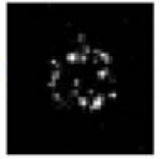

Merge

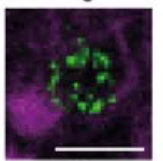

$20 \mu m$

Figure 10. Bead injected into $d L G N$ and CL. A, schematic overview of layer 6 pyramidal neurons; $B$, retrobeads injection into $d L G N$, and confocal images of layer 6 at higher magnification, with quantification; $C$, as in $B$, but injection localized to claustrum.

The electrophysiological properties of CC, CCL and CT neurons are different and together with differences in apical dendrite morphology that is visible with neurobiotin labeling of the recorded neuron, it is possible to differentiate between these layer 6 pyramidal cell types (Brumberg et al. 2003, Mercer et al. 2005, Thomson 2010, Velez-Fort et al. 2014). We performed patch-clamp electrophysiology in ex vivo slices of visual cortex from Ntsr1-Cre GN220 mice, recording from Cre-driven tdTomato expressing and non-expressing neurons to map their electrophysiological and morphological features. Neurobiotin was included in the recording patch pipette to enable tracing of neuronal morphology. The tdTomato 
expressing neurons had an apical dendrite extending radially towards the pial surface, in most cases ending with a dendritic tuft in mid cortex (layer 4) this is the typical morphology of CT neurons (Gilbert and Wiesel 1979, Mercer et al. 2005). In approximately 30\% of tdTomato expressing neurons their apical dendrites extended all the way to layer 1 ending with a smaller tuft. Superficially projecting apical dendrites have not been traditionally seen as a characteristic of CT neurons, but rather CCL neurons (Katz 1987, Mercer et al. 2005).

Other studies on CT neurons using the Ntsr1-Cre GN220 mouse line suggest that layer 1 projecting apical dendrites is a possible morphological trait of CT neurons (Kim et al. 2014, Velez-Fort et al. 2014, Guo et al. 2017). Additionally, since we did not observe any neurons with retrobead uptake together with tdTomato expression in cortex after CL injections we speculated that CT neurons, at least in Ntsr1-Cre mice, might have long apical dendrites naturally. We quantified apical dendrites in layer 2/3 during three time points: one-day-old (d1), 5-week old (w5) and 24-week old (w24) mice. Having apical dendrites that reach layer $2 / 3$ is a morphological trait that was present during all time points investigated. About one fourth of dendrites in layer 5 continue and extend also into layer $2 / 3$ in both w5 and w24 mice. In tdTomato negative neurons morphologies were more diverse than in tdTomato expressing neurons. We observed both upright and inverted pyramidal neurons, which had dendrites extending locally in all directions. Morphologically tdTomato expressing and tdTomato negative neurons showed clear differences that 
correspond well with what has been reported for CT and CC neurons, respectively in earlier literature (Mercer et al. 2005, Kumar and Ohana 2008, Thomson 2010, Cotel et al. 2018).

The electrophysiological profiles recorded in current clamp mode in Ntsr1-Cre positive neurons with either short or long apical dendrite were similar. Injecting depolarizing current pulses above rheobase into CT neurons generated regular action potential firing where the first pair of action potentials were more closely spaced than the subsequent ones (Nowak et al. 2003, West et al. 2006, Cotel et al. 2018), see Figure 11. CC neurons have been reported to display both phasic firing and regular firing (Brumberg et al. 2003, Mercer et al. 2005, Kumar and Ohana 2008, Velez-Fort et al. 2014). As with CT neurons, Velez-Fort et al. showed that mice CC neurons indeed could be classified as regular firing neurons. A clear differentiator between CC and CT neurons was that CC neurons responded with an initial pair of action potentials in more rapid succession compared to steady state firing (Velez-Fort et al. 2014). In Ntsr1-tdTomato expressing neurons the mean ratio between the frequencies of the initial pair of action potentials compared with the steady state was indeed lower compared with Ntsr1-tdTomato negative neurons ( $2.04 \pm 0.06$ positive vs $3.7 \pm 0.53$ negative, mean \pm SEM) . 


\section{A $\quad$ B}

Ntsr1-tdTom+ Ntsr1-tdTom-

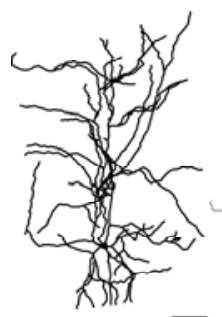

$100 \mu m$
Ntsr1-tdTom+

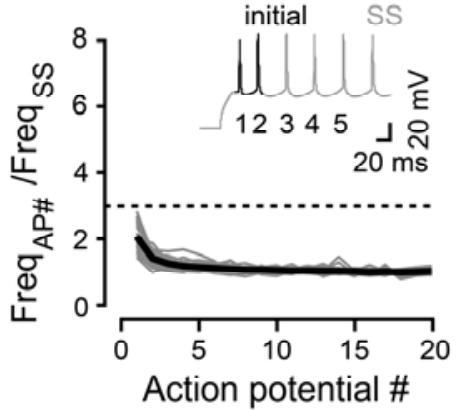

Ntsr1-tdTom-

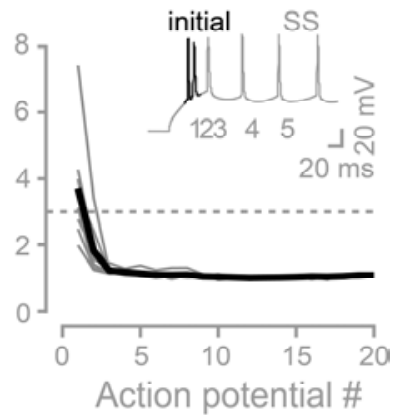

Figure 11. A, Morphology of Ntsr1-tdTom+ and tdTom-neurons; B, action potential response to square-pulse depolarizing currents at rheobase. Inset: example traces of action potentials showing initially higher frequency in Ntsr1-tdTom- neurons. Freq $_{A P \#,}$ instantaneous action potential firing frequency initial pair; SS, steady state.

In recordings from tdTomato negative neurons we did not expect that all neurons would behave as CC neurons, but at least some would. In our sample of Ntsr1-tdTomato negative neurons $(n=11)$ we observed that approximately half of the cells had both morphological and electrophysiological properties agreeing with CC neurons. This was much different to the Ntsr1-Cre positive CT neurons.

A subset of Cre-positive neurons belongs to a population of white matter neurons in visual cortex

We observed that a proportion of Cre-driven tdTomato neurons in Ntsr1Cre GN220 mice were located in the WM underneath the neocortex (Figure 12). We wanted to determine if these neurons belonged to the CT population or to a separate group of WM neurons. Injections of retrobeads into dLGN and immunohistochemistry for a CT neuron marker (FoxP2) 
and a general neuronal marker (neuronal nuclei, NeuN) was used to investigate the identity of WM-located tdTomato expressing neurons.

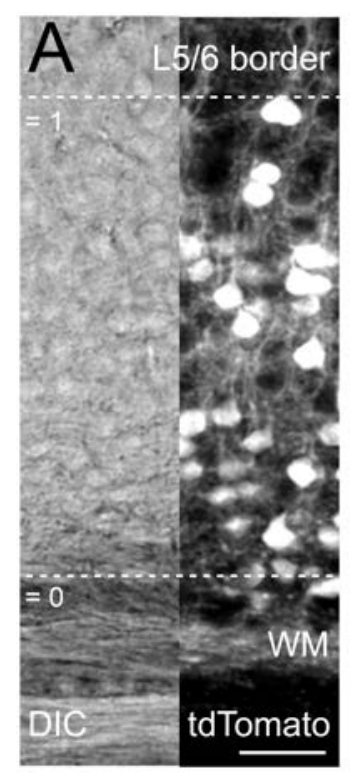

$100 \mu m$
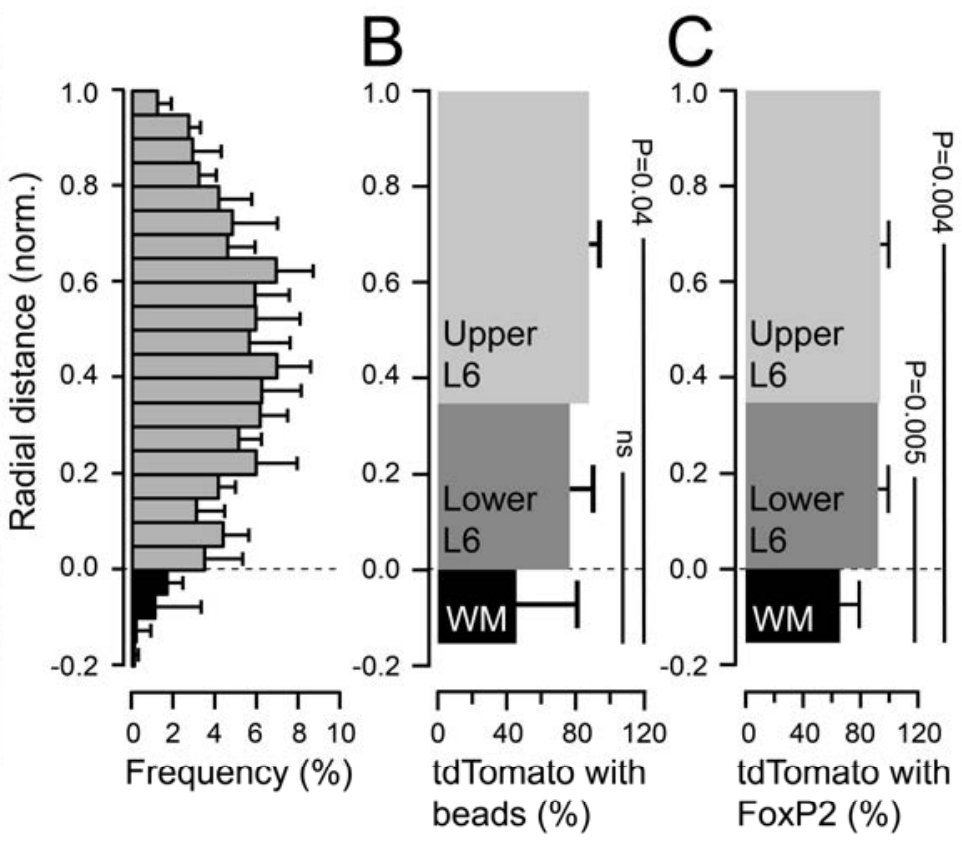

Figure 12. Ntsr1-Cre neurons in WM. A, DIC and fluorescence tdTomato image, and distribution of Ntsr1-Cre cells across layer 6 and WM; B, distribution of Ntsr1-Cre positive neurons with beads (same Y-axis as in A); C, distribution of Ntsr1-Cre positive cells with Foxp2 (same Y-axis as in A).

When we quantified the locations of Ntsr1-Cre positive neurons about 7\% were located in the WM. These neurons appeared to have a flatter soma compared to tdTomato expressing neurons located in layer 6. We confirmed that they were neurons by co-labeling with the nuclear marker NeuN. Quite a large proportion of neurons in WM had both markers; a little more than one third. Looking at retrobead uptake from injections to the dLGN, less than half of the tdTomato expressing neurons in WM 
contained beads. This is markedly different to layer 6 . When we stained for FoxP2 in layer 6 and WM we saw that the proportion of neurons that where FoxP2 and Ntsr1-Cre positive in WM where significantly fewer compared to layer 6 (both upper and lower parts of layer 6). Taken together, we have identified a small population of Ntsr1-Cre positive neurons localized to the WM, that do not show a CT phenotype meaning that they probably adhere to one or several WM neuron types. Neurons located to the WM with axonal projections to the dLGN and that stained positive for FoxP2 could belong to a group of CT neurons that did not separated fully from the subplate during development, although such developmental mis-separation has not been described before. The proportions of neurons located to layer 6 or WM is of course dependent on where the border between the structures is drawn. In the mouse brain that border is probably less distinct than the line drawn to divide the two areas that we make when classifying neurons to one layer or the other. Generally, the border between the neocortex and the WM in human and primates is more clear-cut (Suarez-Sola et al. 2009). What remains of the subplate after development in mice is more diffuse and embedded within the WM. WM-located neurons have heterogeneous morphology (Clancy et al. 2001). We did not look into differences in morphology of the Creexpressing neurons in WM further than the observation that they tend to have flatter soma. But differentiating projection patterns and electrophysiological behavior would have been informative. Performing antibody staining against other targets might pinpoint if the Creexpressing population is homogeneous or diverse. In the rat, neurons 
positive for Neurotensin receptor 1 and 2 in the WM have been shown to affect excitation of pyramidal neurons and interneurons in layer 6 (Case et al. 2017). Neurotensin is a neuropeptide that promotes wakefulness (Castel et al. 1989), if CT neurons are greatly influenced by these neurotensin receptor expressing WM neurons this would provide with an additional link that CT neurons are important for transferring between states of arousal.

A cause of worry when working with Cre-expressing mice is the problem of ectopic or off-target expression of Cre to other sites than intended (Heffner et al. 2012). If this explains the presence of Cre-expressing neurons in the WM of Ntsr1-Cre mice is unclear, and something that our methodological approach cannot elucidate. In order to determine if ectopic expression of Cre has taken place one would have to specifically isolate the Cre-expressing cells located in the WM and perform DNA sequencing to investigate if the Cre gene is still positioned correctly. Within layer 6 ectopic expression of Cre does not seem to be an issue, due to the fact that we, and others (Bortone et al. 2014, Kim et al. 2014, Guo et al. 2017) have observed large overlaps between Cre-driven reporter protein expression and neurons labeled by retrobead injections to primary thalamic nuclei, together with few Ntsr1-Cre positive neurons that did not take up beads (Figure 10).

If we combine the results from NeuN, retrobead and FoxP2 labeling, we estimate that about $15-40 \%$ of WM neurons are Cre-expressing. Thus, our 
main conclusion from this paper is that one should be cautious and consider their potential impact when interpreting results from experiments using the Ntsr1-Cre GN220 transgene to drive expression or deletion of proteins to investigate the CT neuron pathway function. However, the vast majority of Ntsr1-Cre positive neurons in cortex are CT neurons.

CT neurons can be directly affected by cholinergic signaling Having established that Ntsr1-Cre expression is specific to the layer 6 CT neuron population in neocortical layer 6 , we used this knowledge to answer a physiological question. Acetylcholine (ACh) has an established role in arousal and attention (Steriade 2004, Guillem et al. 2011) two physiological processes hypothesized to involve CT neuron signaling (Crick 1984). It remains unknown if CT neurons are sensitive to cholinergic signaling. To answer this question, we applied cholinergic drugs to neocortical cortical slice preparations from the visual cortex of Ntsr1-Cre mice and studied the effects on resting membrane potential, input resistance and action potential firing frequency of Ntsr1-Cre positive neurons in layer 6. Applying a low concentration of ACh, similar to that experienced during volume transmission (Vinson and Justice 1997), we saw a significant increase in instantaneous action potential firing frequency that remained elevated after ionotropic glutamatergic receptor blockade (Figure 13). Suggesting that ACh binds to cholinergic receptors on CT neurons directly and not indirectly mediating effects through other excitatory neurons. 

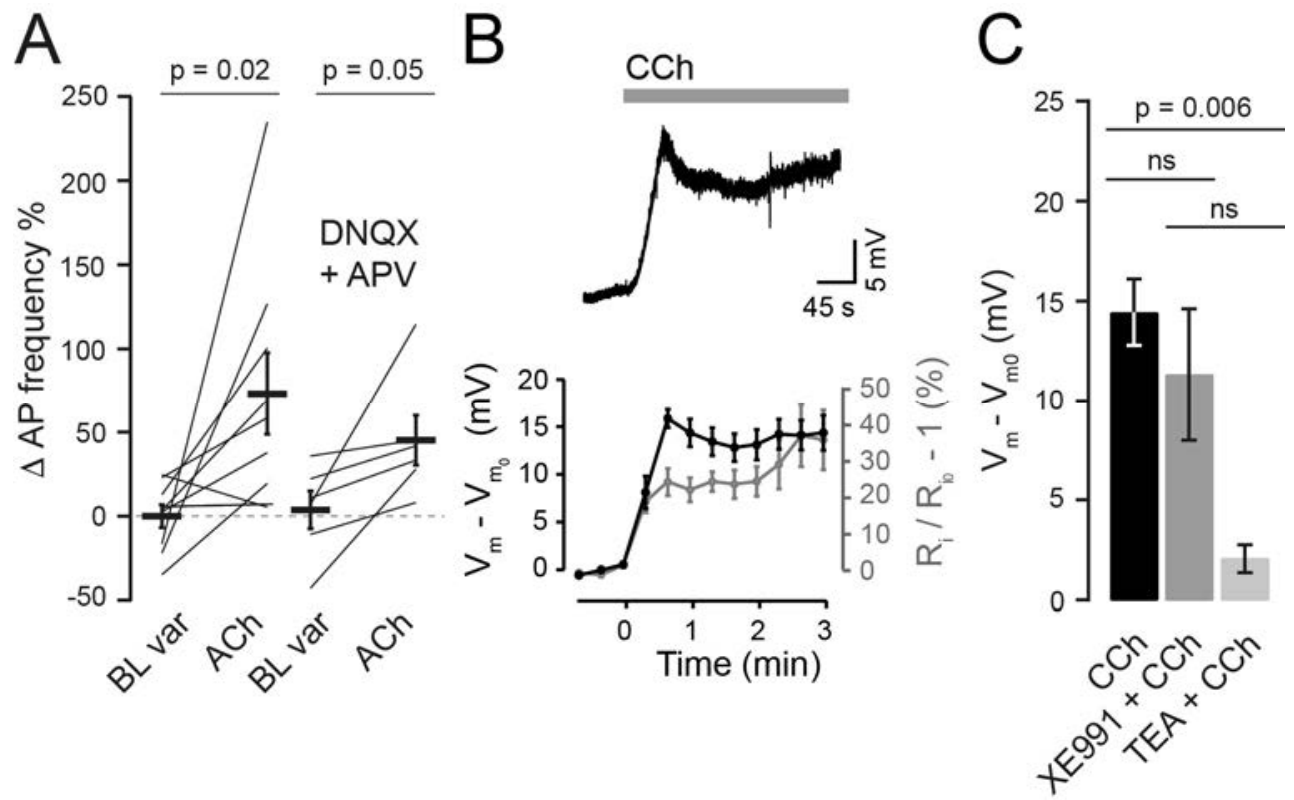

Figure 13. Acetylcholine and Carbachol induced effects. A, \%-increase in action potential frequency with $100 \mathrm{nM} \mathrm{ACh}$ (left), and in the presence of blockers (right) compared to baseline variability (BL var); B, example trace of a Ntsr1-Cre neurons membrane potential response during application of CCh (top). Depolarization (black) and increase in input resistance (grey) upon CCh application (bottom); C, CCh-dependent depolarization without blockers, with m-current blocker (XE991), and with general $K_{V}$ channel blocker (TEA).

ACh has a short half-life in a slice preparation due to the abundance and efficiency of the enzyme acetylcholine esterase. For the remainder of the experiments we used the acetylcholine esterase-resistant general cholinergic agonist Carbachol (CCh) at a concentration that should saturate receptor binding. Network activity was also blocked throughout by tetrodotoxin, TTX. CT neurons responded to $\mathrm{CCh}$ with a strong membrane depolarization and increase in input resistance, further supporting a direct effect of cholinergic signaling on CT neurons. Looking 
at the time-course of the depolarization, $\mathrm{CCh}$ produced a sharp and transient depolarization that was followed by a more moderate steady state depolarization that persisted for the remainder of the recording. The transient was not present when the slices were pre-incubated with either a nicotinergic antagonist or when the general muscarinergic agonist Muscarine was used instead of $\mathrm{CCh}$. We believe that the transient $\mathrm{CCh}$ depolarization is from nicotinergic ACh receptors (nAChRs) on the CT neurons and the steady state depolarization an effect from muscarinergic ACh receptors (mAChRs). Indeed it has been shown that nicotinergic receptors are expressed on layer 6 neurons/CT neurons (Hedrick and Waters 2015, Hay et al. 2016) and that layer 6 pyramidal neurons respond to certain nicotinergic agonists (Verhoog et al. 2016).

When we added $\mathrm{CCh}$ there was, in parallel to the membrane depolarization, an increase in membrane input resistance. Input resistance could be described as a measure of ion permeability of the membrane, reflecting the opening or closure of ion channels. An increased input resistance indicates decreased ion leak/permeation over the membrane suggesting closure of ion channels. Given that the cells depolarized it seems reasonable to suspect that the closure of $\mathrm{K}^{+}$channels is mediating the effect from CCh. Pre-incubation with the general $\mathrm{K}^{+}$ channel blocker TEA did not result in increased input resistance, or depolarization of the membrane potential, with CCh. We further hypothesized that closure of KCNQ channels could be a result of CCh signaling. The KCNQ2, KCNQ3 and KCNQ5 subunits form heterotetrameric 
$\mathrm{K}^{+}$channels, Kv7.2/3/5, that generate a hyperpolarizing $\mathrm{K}^{+}$current at resting membrane potential and during depolarization (Wang et al. 1998), and are affected by mAChR signaling, hence the name M-current (after muscarinic) (Thiele 2013). Activation of $M_{1}, M_{3}$ and $M_{5}$ types of mAChRs all initiate $\mathrm{G}_{\mathrm{q}}$ coupled signaling that activates phospholipase C (PLC) and hydrolysis of phosphatidylinositol 4,5-bisphosphate ( $\mathrm{PIP}_{2}$ ) into inositol triphosphate $\left(\mathrm{IP}_{3}\right)$ and diacylglycerol (DAG) and depleting $\mathrm{PIP}_{2}$ in the membrane. PIP2 is required for Kv7.2/3/5 channel opening, thus $\mathrm{M}_{1-}-\mathrm{M}_{3}-$, M5-receptor signaling leads to closure of the channels resulting in a depolarization of the membrane potential (Thiele 2013). Additionally, KCNQ2, KCNQ3 and KCNQ5 mRNA has been shown to be expressed in Ntsr1-Cre positive neurons in visual cortex ((Tasic et al. 2016);3). In line with these positive mRNA results we observed a small but significant membrane potential depolarization when we incubated with XE991 alone indicating that Kv7.2/3/5 channels are open during basal conditions. When CCh was added to slices pre-incubated with XE991, a nonsignificant depolarization was seen. This indicates that Kv7.2/3/5 heterotetrameric $\mathrm{K}^{+}$channels are present but might not be the sole $\mathrm{K}^{+}$ channel that mediates the effect from cholinergic signaling.

We show that CT neurons do respond to cholinergic signaling with both mAChRs and nAChRs together with the finding that cholinergic projections might favor more specialized synaptic-like contacts (Hay et al., 2016) rather than traditional volume transmission shows that release of

\footnotetext{
${ }^{3}$ casestudies.brain-map.org/celltax
} 
ACh excites CT neurons. We were not able to determine the exact $\mathrm{K}^{+}$ channel responsible for the strong membrane potential depolarization. Generating increased excitation of CT neurons from timed release of ACh could push CT neurons closer to the action potential firing threshold also making the neurons fire action potentials at higher frequency. This could be a mechanism for CT neurons to boost the transfer of sensory information through the thalamus to the cerebral cortex when engaged by ACh release from the basal forebrain. 


\section{Paper III}

After identifying that the large majority of Ntsr1-Cre positive neurons in neocortex and underlying WM in Ntsr1-Cre GN220 mice are CT neurons, we have a powerful tool to selectively investigate the function of this type of neuron. In the next project we prepared cultures from Ntsr1-Cre GN220 mice to study the synaptic properties of CT neurons. At first, we had to establish if Ntsr1-Cre neurons behaved in cultures as CT neurons in slices ex vivo.

We cultured neurons from mice either expressing Ntsr1-tdTomato (Ntsr1tdTom) or -Channelrhodopsin-2-EYFP (Ntsr1-ChR2) to be able to record basic neuronal properties and stimulate synaptic responses with either current pulses (electrical stimulation) and/or light pulses (activation of ChR2). There have been indications that driving neuronal signaling using ChR2 affects short-term plasticity (Olsen et al., 2012; Jackman et al., 2017), most likely due to $\mathrm{ChR} 2$ being a cation channel conducting $\mathrm{Na}^{+}, \mathrm{K}^{+}$as well as $\mathrm{Ca}^{2+}$ ions (Nagel et al. 2003). The $\mathrm{Ca}^{2+}$ dependence for short-term plasticity is very important and manipulating intracellular $\mathrm{Ca}^{2+}$ concentrations especially affects facilitation (Granseth et al. 2002, Blatow et al. 2003, Fioravante and Regehr 2011, Nanou and Catterall 2018). Thus, we wanted to investigate if and how the sign of short-term plasticity was affected by the way of stimulation, i.e. electrical or light stimulation. Further, exploring the feasibility of Ntsr1-Cre neurons in culture as a tool to investigate mechanisms of facilitation. 
Ntsr1-Cre neurons in culture have similar properties as CT neurons in slice preparations

Firstly, we established that Ntsr1-Cre positive neurons in culture showed similar properties as Ntsr1-Cre neurons in ex vivo slices regarding resting membrane potential, morphology, FoxP2 expression and response to depolarizing current pulses above rheobase (Figure 14). One thing that differed slightly was the higher input resistance of neurons in culture. This is probably a reflection of their smaller size compared to the intact brain. A small proportion of neurons negative against FoxP2 antibody staining (less than $4 \%$ ) are present in the cultures and this cell population could correspond to the non-CT Ntsr1-Cre positive group of neurons we identified in the WM in project II. The scarcity of this kind of neurons in the cultures makes it very unlikely that they will be chosen for electrophysiological recordings. Furthermore, the WM neurons often had flatter soma morphology something that we did not see in the cultures, where Ntsr1-Cre positive neurons had pyramidal soma (Sundberg and Granseth 2018). Comparing parameters as membrane potential, morphology and response the depolarizing currents above rheobase, we saw very similar behavior of Ntsr1-tdTom or Ntsr1-ChR2 neurons in cultures compared to recordings from Ntsr1-tdTom neurons in ex vivo cortical slices (Figure 14). 


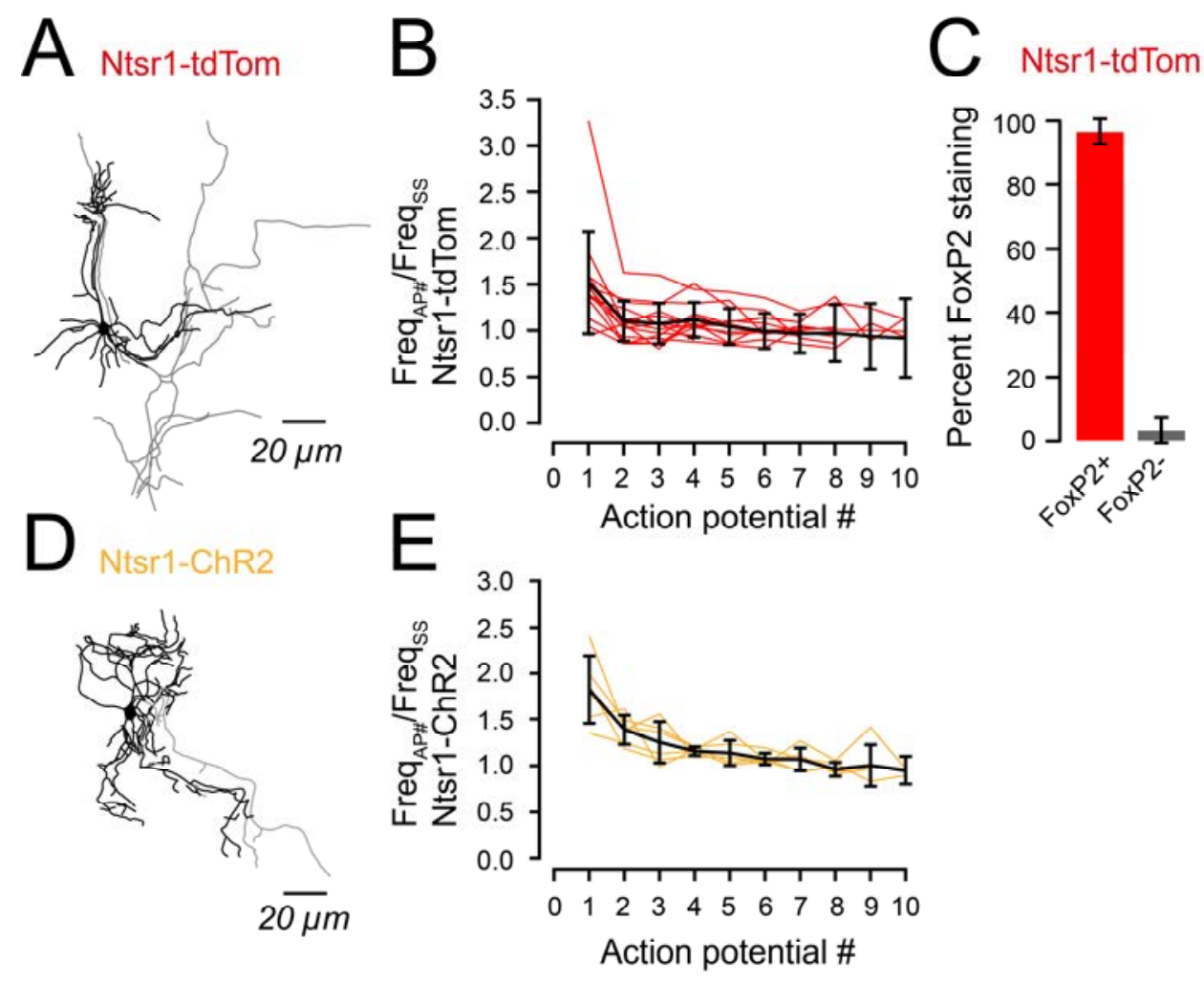

Figure 14. Basic properties of cultured Ntsr1-Cre neurons. A, Cell tracing; B, ratios of instantaneous action potential firing frequency over steady-state action potential firing frequency (Freq $q_{A P}$ /Freq SS) $_{\text {) }}$ of neurons injected with square depolarizing current above rheobase; $C$, quantification of Foxp2+ cells in cortical cultures; D, cell tracing; E, as in B but with ChR2.

Electrical and optogenetic stimulation of Ntsr1-Cre synapses produces short-term plasticity with different direction

When comparing the evoked synaptic responses stimulating with either depolarizing current injections (electrical stimulation) or optogenetic stimulation (light stimulation) there were clear differences in synaptic responses. Paired pulse protocols delivered in a pseudo-randomized sequence of interpulse intervals (200, 2000, 100, 50, 5000, $500 \mathrm{~ms}$ ) generated opposite excitatory postsynaptic current (EPSC) response 
ratios (EPSC $2 /$ EPSC $_{1}$ ) depending on stimulation type. Light stimulation showed a paired pulse ratio at $100 \mathrm{~ms}$ stimulation interval that was lower and well below $1(0.7 \pm 0.1, \mathrm{n}=6)$ compared to responses generated by electrical stimulation $(2.7 \pm 3.7$ electrical, $\mathrm{n}=23$; $\mathrm{P}=0.001$; Mann-Whitney U-test). Stimulation with light clearly generated paired pulse depression and electrical stimulation paired pulse facilitation (Figure 15).

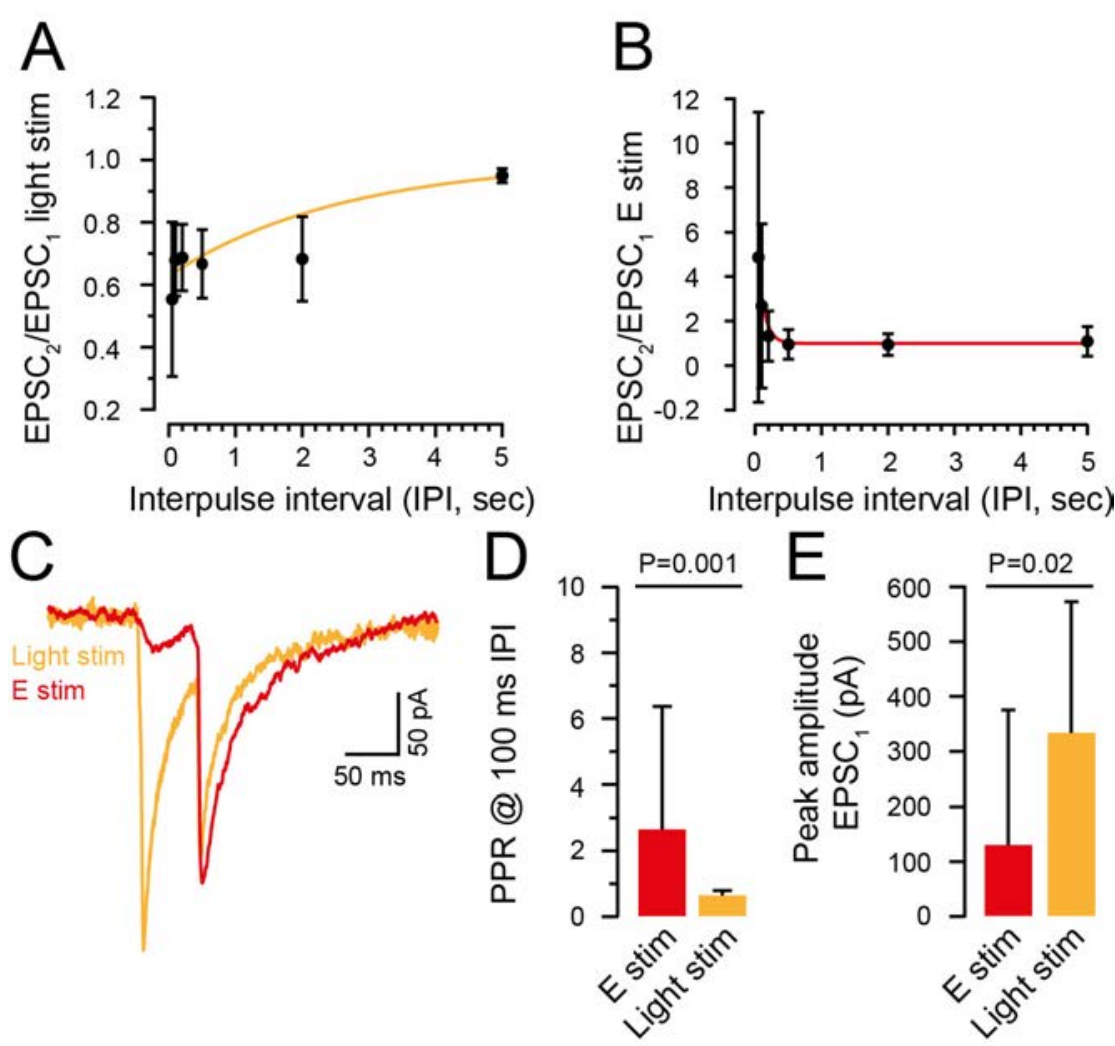

Figure 15. Responses from light and electrical stimulation of Ntsr1-Cre neurons. A, Paired-pulse ratio generated by light stimulation; $B$, paired-pulse ratio generated by electrical stimulation; $C$, example traces of paired-pulse stimulation with light or electrical stimulation at 50 ms interpulse interval (IPI)l; D, paired-pulse ratio at 100 ms IPI; E, peak amplitude of EPSC 1 . 
The difference between electrical and light stimulation was clear also when comparing the amplitude of $\mathrm{EPSC}_{1}$, where light stimulation resulted in significantly larger amplitude than electrical stimulation (334.9 \pm 238.2 pA light, $n=8 ; 131.6 \pm 243.9$ pA electrical, $n=26 ; \mathrm{P}=0.02$ ) (Figure 15). Paired pulse depression together with increased EPSC $_{1}$ amplitude suggests an increase in initial release probability with light stimulation. Release probability is dependent on synaptic $\mathrm{Ca}^{2+}$ influx (Thanawala and Regehr 2013). Elevating the $\mathrm{Ca}^{2+}$ influx can render more vesicles release competent and enhance vesicle fusion.

It has previously been shown that activating and opening ChR2 allows larger influx of $\mathrm{Ca}^{2+}$ than with electrical stimulation, suggesting light stimulation promotes an increase in release probability (Zhang and Oertner 2007). However, the authors showed that a major source of $\mathrm{Ca}^{2+}$ influx was from Cav channels, activating during the after depolarization phase that occur upon a light triggered action potentials not through ChR2 (Zhang and Oertner 2007). Stimulating CT axons with light and recording synaptic responses in dLGN ex vivo slices showed short-term depression (Olsen et al. 2012) whereas recordings from CA3 hippocampal neurons ex vivo displayed normal plasticity with transgenic ChR2 expression (Jackman et al. 2014). Showing that different synapses display variable sensitivity to ChR2-induced stimulation effects. CT neuron synapses might be markedly more affected by ChR2-dependent stimulation effects due to their initially extremely low release probability (Granseth and Lindstrom 2003). The un-physiologically high $\mathrm{Ca}^{2+}$ influx in CT synaptic terminals 
could likely affect neurotransmitter release and short-term plasticity. It would have been interesting to repeat the experiments in the presence of an intracellular $\mathrm{Ca}^{2+}$ chelator to see whether paired pulse depression is still present with light stimulation. Moreover, increased influx of $\mathrm{Ca}^{2+}$ via ChR2 activation could, with optimization, be used as a tool to further study how $\mathrm{Ca}^{2+}$ regulates facilitation in the CT synapse.

Connectivity and short-term plasticity of Ntsr1-Cre neurons in culture When probing possible synaptically connected pairs of neurons in Ntsr1Cre cultures we were a little surprised that only about half of the attempted pairs displayed synaptic connections (34 out of 71 pairs). All attempted pairs where present in the same field of view and had overlapping neurites. Considering that CT neurons in vivo anatomically have extensive synaptic connections with thalamic relay neurons and GABAergic reticular neurons, it is a little surprising that we did not observe higher connectivity. Although, in hippocampal cell cultures it has been reported that less than half of pairs attempted for dual recordings were synaptically connected (Mennerick et al. 1995).

The synaptic responses to electrical paired pulse stimulation was overall facilitating for short interpulse intervals (50 to $200 \mathrm{~ms}$ separation). The paired pulse ratio present for interpulse interval $100 \mathrm{~ms}$ was similar to that of rat CT synapses in an ex vivo dLGN slice preparation (Granseth and Lindstrom 2003). Indicating that facilitation of CT synapses in vitro is partly preserved. However, the unitary amplitudes of EPSC 1 were much higher in cortical cultures compared to the thalamic slice preparation 
(Granseth and Lindstrom 2003). Cultured CT neurons are lacking relevant sensory input and its major synaptic partners thalamic neurons, which might help explain this deviation.

Looking more closely at the 26 pairs of Ntsr1-Cre neurons stimulated electrically we could see that responses could be categorized into two groups: neurons with a paired pulse ratio above 1 and neurons with a paired pulse ratio below 1 . The averaged paired pulse ratio for $100 \mathrm{~ms}$ interpulse interval differed significantly between facilitating and nonfacilitating neurons (facilitating $4.2 \pm 4.7 \mathrm{n}=13$, vs non-facilitating $1.03 \pm$ $0.5 \mathrm{n}=12 ; \mathrm{P}=0.0007$ Mann-Whitney U-test). This dual behavior of CT synapses in culture differ compared to CT input onto thalamic relay neurons where facilitation is always present (Turner and Salt 1998, Granseth et al. 2002, Granseth 2004). This non-facilitating pattern does not seem to categorize into classical short-term depression either, since at shorter interpulse intervals the paired pulse ratio is close to zero, indicating no plasticity at all (Figure 16). Once the interval is increased, depression is apparent. Suggesting perhaps that opposing mechanisms of facilitation and depression act at these synapses though operating at different time durations. The appearance of a non-facilitating behavior of CT presynaptic terminals could indicate that de-differentiation of CT neurons in culture are taking place. From our extensive comparison between cultured Ntsr1-Cre and ex vivo Ntsr1-cre neurons we established that properties of intrinsic excitability and positive expression of FoxP2 
argues against widespread de-differentiation of cultured Ntsr1-Cre neurons.

Another possibility might be that cultured neurons mainly lack the correct synaptic partners, which are thalamic relay and thalamic inhibitory reticular neurons. It would be interesting to investigate the nature of the postsynaptic partners of Ntsr1-Cre neurons. Perhaps facilitating and nonfacilitating pairs represent different sets of postsynaptic partner neurons? Another interesting experiment would be to co-culture Ntsr1-Cre with thalamic neurons to see if CT synapses onto thalamic neurons display a more uniform short-term plasticity.

Autaptic synapses always display paired pulse depression Ntsr1-Cre neurons readily formed autapses, i.e. synapses with themselves. Autapses displayed large amplitude initial EPSCs and paired pulse depression when stimulated electrically (Figure 16). Autaptic synapses behaved significantly different from synapses with paired pulse facilitation in the cultures. The formation of functional autapses could be a divergence between Ntsr1-Cre neurons in cortical cultures and ex vivo cortical slices. We never observed autaptic responses in CT neurons in ex vivo slices, which does not necessarily mean that they do not exist. Generally, autapses seem to be more prevalent in cultured neurons although certain neurons have shown extensive autapse formation in brain tissue (Lubke et al. 1996, Tamas et al. 1997, Bekkers 1998, Connelly and Lees 2010). 

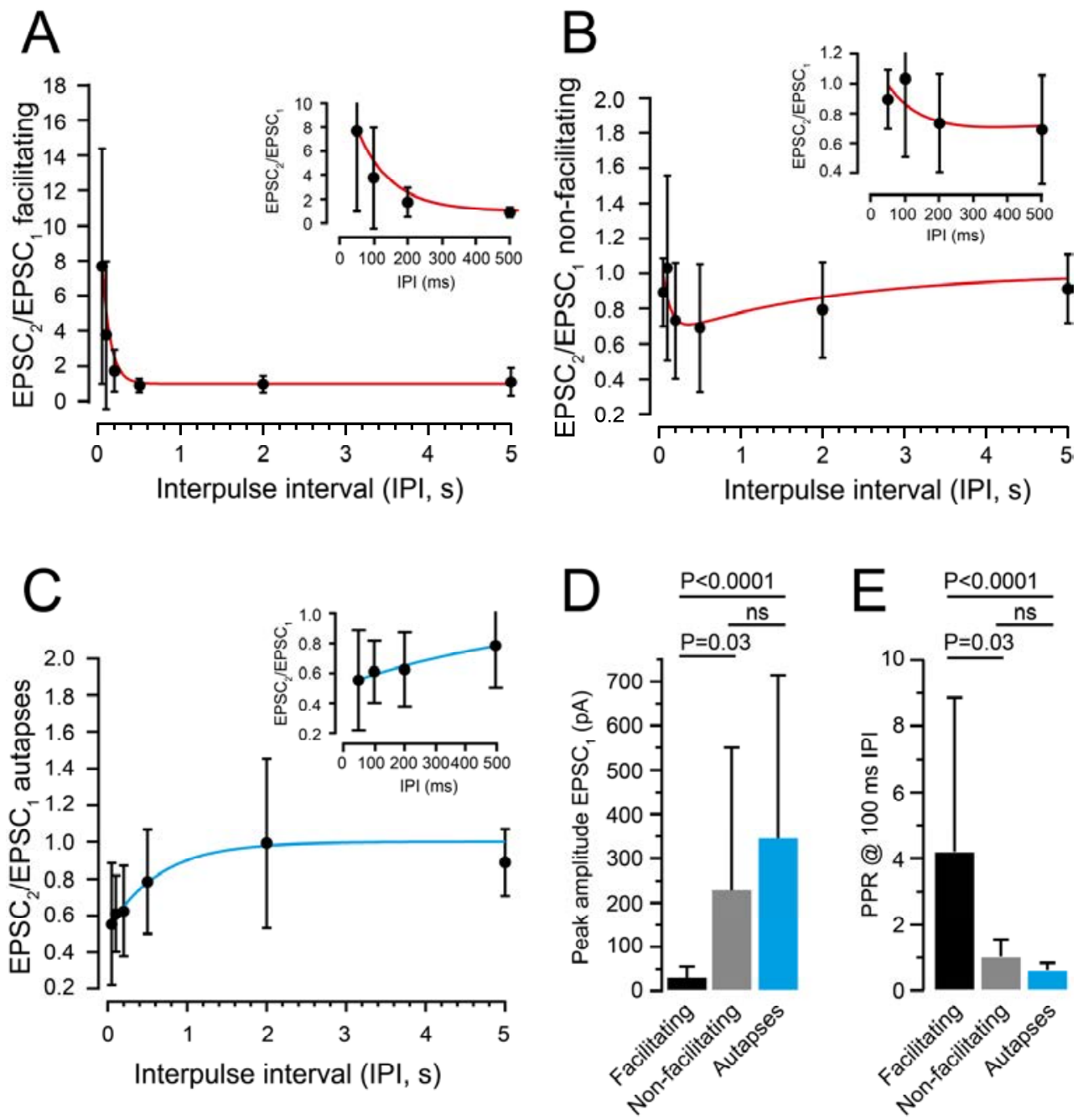

Figure 16 Electrical paired pulse stimulation of A: facilitating neurons; B: nonfacilitating neurons; $C$ : autapses; $D$, peak amplitude of $E P S C_{1} ; E$, paired-pulse ratio at 100 ms interpulse interval.

Are autapses per default depressive? Autapses can show either short-term depression or facilitation but they seem to more readily display depression (Mennerick and Zorumski 1995, Brody and Yue 2000). The extracellular buffer composition matters for the mode of plasticity of autapses, using more physiological concentrations of $\mathrm{Ca}^{2+}$ and $\mathrm{Mg}^{2+}$ 
favored depressive autapses (Mennerick and Zorumski 1995, Brody and Yue 2000). Liu et al. extensively investigated the difference between interneuronal synapses (between two different neurons) and autaptic connections and found that autapses seemed optimized for maximal transmission with larger EPSC amplitude and charge, RRP size and paired pulse depression, arguing that neurons can distinguish between synapses onto itself and with another neuron (Liu et al. 2013). Neurons also seem to distinguish between different types of postsynaptic partners. As an example, CT neuron synapses onto thalamic local inhibitory interneurons within primary thalamic nuclei are depressive, whereas CT synapses onto primary thalamic relay neurons are facilitating (Augustinaite et al. 2011). Retrograde signals may be involved in modulating presynaptic release probability at each synaptic site. To my knowledge no specific retrograde signal has been identified for CT synapses at different synaptic sites.

Recording temperature does not alter paired pulse plasticity of Ntsr1cre neurons

The surrounding temperature can affect release probability and shortterm plasticity of a neuron (Barrett et al. 1978, Klyachko and Stevens 2006, Granseth and Lagnado 2008). We performed paired pulse experiments with electrical stimulation at room temperature (RT; $23 \pm$ $2^{\circ} \mathrm{C}$ ) and physiological temperature $\left(36 \pm 1^{\circ} \mathrm{C}\right)$ and compared the timecourse, paired pulse ratio and $\mathrm{EPSC}_{1}$ peak amplitude. Surprisingly, we could not detect any significant differences of the above-mentioned parameters between the two temperatures. 


\section{Paper IV}

It has been shown that Hedgehog (Hh) is released during high frequency activity, such as during an epileptic seizure (Su et al. 2017). Additionally, the effect of Hh signaling on immature hippocampus has revealed that Hh promotes growth of presynaptic terminals and increasing the frequency of spontaneous vesicle release (Mitchell et al. 2012). In adult fruit flies, Drosophila Melanogaster, Hh-signaling regulates the surface expression of odorant receptors in the fly antenna (Sanchez et al. 2016) and controls the expression of odorant receptors and the odorant response in adult mice olfactory system (Maurya et al. 2017). These findings triggered our interests to investigate if $\mathrm{Hh}$-signaling could regulate receptor expression in mature central neurons as in the olfactory system.

Endogenous Hh suppress synaptic strength via activation of the noncanonical pathway in mature hippocampal neurons

We decided to explore this question using hippocampal neurons grown for 21 days in vitro (DIV) as a model system for mature neurons, applying drugs targeting the Hh-signaling pathway (Figure 6, Figure 17) and studied network behavior and receptor expression.

Primarily we used the drug Vismodegib, an antagonist for the Hh signal transducer receptor Smoothened (Smo, Figure 17) and let the neurons incubate with the drug or control medium for different lengths of time. Blocking Smo-signaling is expected to block both the canonical (Glimediated nuclear transcription factor pathway) and non-canonical (intracellular signaling mediated pathway) signaling pathways. 


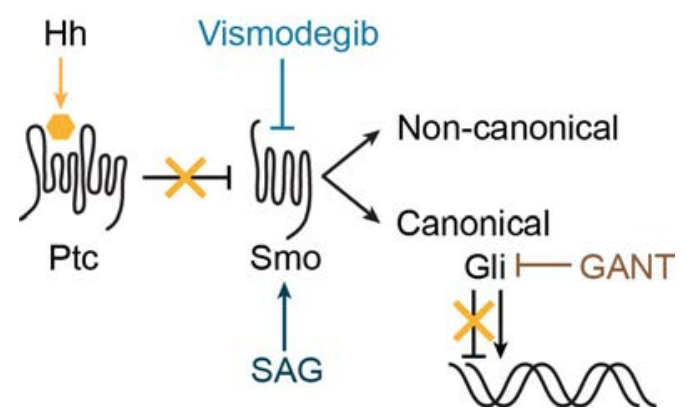

Figure 17. Simplified Hh signaling pathway with drug targets

We observed that incubating mature hippocampal cultures with Vismodegib for $48 \mathrm{~h}$ resulted in a large and significant increase in the average mEPSC amplitude (-30.3 +/- 9.49 pA vismodegib, $n=10 ;-20.6+/-$ $6.42 \mathrm{pA}$ controls, $\mathrm{n}=15 ; \mathrm{p}=0.0019$ one-way ANOVA with Dunnett's multiple comparisons test) see Figure 18. Providing evidence that hippocampal cultures produce endogenous Hh. Previous reports have shown presence of Hh in synaptic vesicles, large dense-core vesicles and in endosomes of adult rat hippocampal neurons (Petralia et al. 2011b, Su et al. 2017). Ptc and Smo have also been detected in mature hippocampal neurons, primarily localizing to dendrites, spines and postsynaptic sites (Traiffort et al. 1999, Petralia et al. 2011a).

Incubating the cultures with the Smo-agonist SAG (Figure 18) produced the opposite effect on mEPSC amplitude compared to Vismodegib (-14 +/$4.62 \mathrm{pA}, \mathrm{n}=11 ; \mathrm{p}=0.032$ one-way ANOVA with Dunnett's test). Inhibiting or activating the Hh-signaling effector Smo thus generates opposite effects on synaptic strength, suggesting a suppressive action upon Smo activation 
in hippocampal neurons. The increase in mEPSC amplitude but not frequency with Vismodegib primarily indicates a postsynaptic site of action (Wierenga et al. 2005).

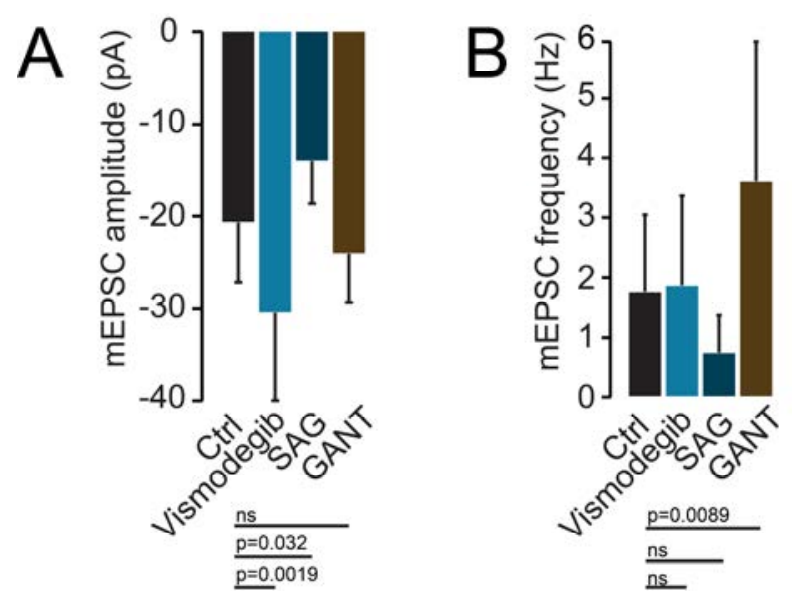

Figure 18 A, mEPSC peak amplitude recorded from hippocampal neurons after drug incubations; $B, m E P S C$ frequency after drugs.

The canonical pathway targets gene expression via action by the Gliproteins. There are three Gli isoforms, 1, 2 and 3, in the absence of $\mathrm{Hh}$ a transcriptional repression mediated by Gli3 and to some extent Gli2 dominates. Once Hh is present Smo signaling results in positive effects on transcription via Gli1 and Gli2 acting as an activators of gene expression (Patel et al. 2017). Since Vismodegib and SAG required 48h incubation time to affect synaptic strength, we speculated that the canonical pathway to be responsible for the Smo-mediated effect on synaptic strength. Thus, incubating the cultures with GANT-61, a drug that block Gli from binding to DNA, would silence the canonical pathway. Surprisingly, GANT-61 did not affect mEPSC amplitude but significantly increased the mEPSC 
frequency (f $\mathrm{f}_{\mathrm{GANT}} 3.50 \pm 2.26 \mathrm{~Hz}, \mathrm{n}=13$ vs fctrl $1.71 \pm 1.24 \mathrm{~Hz} \mathrm{n}=15 ; \mathrm{P}=$ 0.0089, Dunnett's multiple comparison following 1-way ANOVA; Figure 18), not replicating what we saw with Vismodegib. This suggests that the canonical pathway is targeting another site of action than general Smo signaling. A change in mEPSC frequency could be attributed to an increase in synapse number or increase in release probability of presynaptic terminals (Wierenga et al. 2005).

A change in synaptic strength, seen here as an increase in mEPSC amplitude, could be explained by induction of mechanisms of LTP/LTD (Choi and Lovinger 1997). Activation of NMDA-receptors (NMDARs) postsynaptically is essential for both LTP and LTD (Luscher and Malenka 2012). We wanted to test if NMDAR activity was important for the increase in mEPSC amplitude seen during Smo block. Co-incubating Vismodegib with either the general NMDAR antagonist APV or the NMDAR pore blocker MK-801 abolished the mEPSC amplitude increase seen with Vismodegib alone (IVismoAPV $-15.7 \pm 5.6 \mathrm{pA} ; \mathrm{n}=13$ vs IVismo $-25.6 \pm 10.5 \mathrm{pA}$ $\mathrm{n}=10$; vs IVismomk $-9.3 \pm 3.4 \mathrm{pA}, \mathrm{n}=10 ; \mathrm{P}=0.018$, Tukey's test) showing that activation of NMDARs is essential for the effect (Figure 19). Perhaps blocking Smo would even affect NMDAR currents? We decided to record NMDAR-mediated mEPSCs holding the neurons at $+40 \mathrm{mV}$ while blocking AMPA/kainite-receptors and GABA-receptors. Inhibition of Smo during 48h with Vismodegib affected the kinetics of NMDAR-mEPSCs, increasing their duration, half-width and decay time constant. No significant effect was seen on NMDAR-mEPSC amplitude or frequency. However, analyzing 
the NMDA-mEPSC current traces we could see that the charge transfer of the current was doubled. Together these effects on NMDA-mEPSCs indicates that Hh-signaling via Smo can reduce NMDAR responses, functionally reducing the ion flux through the receptor. Looking at the NMDAR subunit expression level of the hippocampal neurons after Vismodegib using quantitative immunohistochemistry we could not observe any differences in fluorescence intensity or receptor density of GluN1A, GluN2A or GluN2B compared to control neurons.
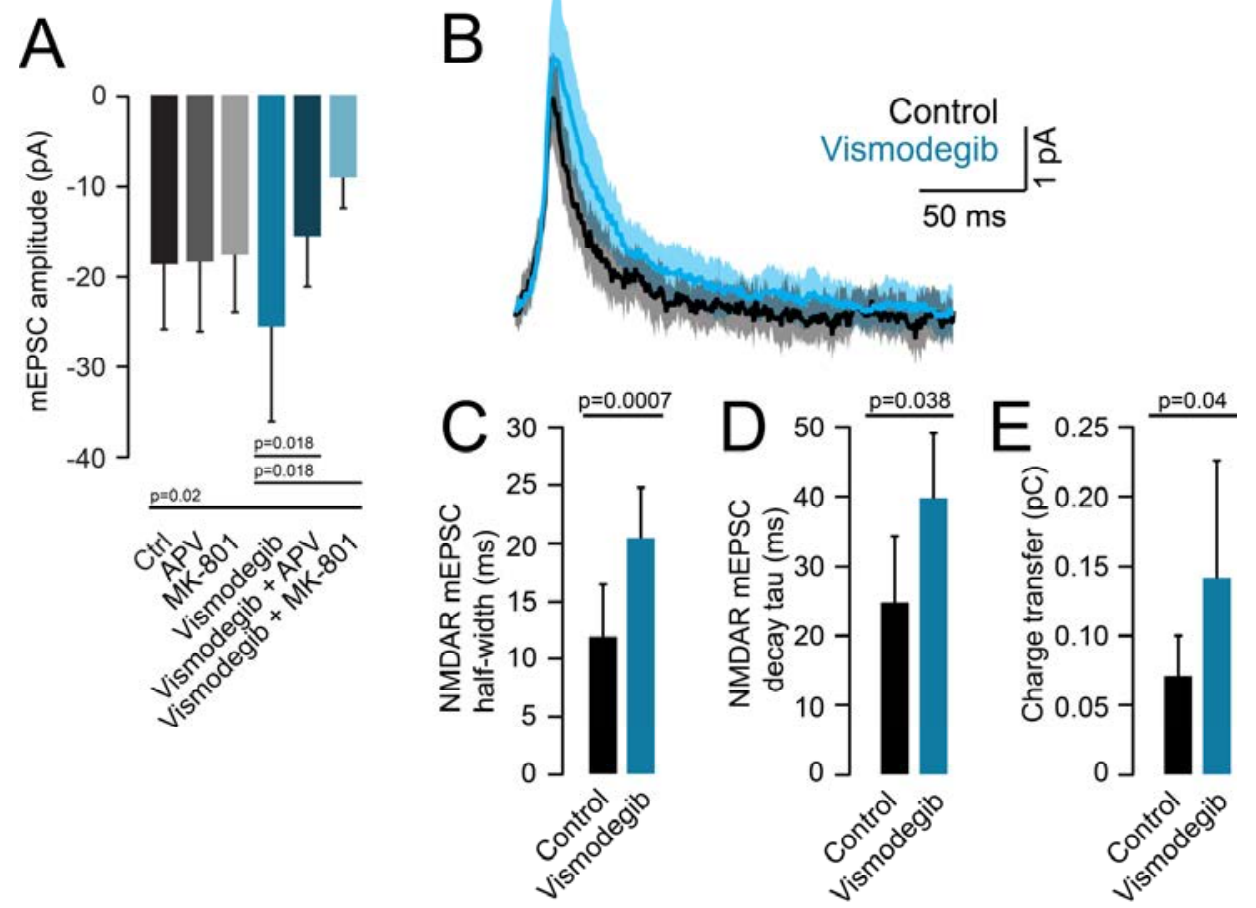

Figure 19 A, mEPSC peak amplitude with drugs; NMDA-mEPSCs (B) averaged current traces (shaded area represents SEM), (C) half-width, (D) decay tau, and (E) charge transfer.

The large increase in mEPSC amplitude we see with Vismodegib should primarily be from AMPA-receptor (AMPAR) mediated currents (clamping 
cells at $-70 \mathrm{mV}$ holding potential). Investigating AMPAR subunit expression using quantitative immunohistochemistry we did not see any different to control of GluA1 but GluA2 subunits had a significant increase in fluorescence intensity $(2.6 \pm 1.2$ times control intensity; $\mathrm{n}=8$ neurons from 3 different culture batches; $P=0.006$, Student's t-test) (Figure 20). A large increase in AMPARs containing GluA2 after Vismodegib incubation can explain the large amplitude of mEPSCs. We also assessed GluA3 expression but it seemed to localize mostly to glial cells similarly regardless of control vehicle or Vismodegib incubation and was not further studied.

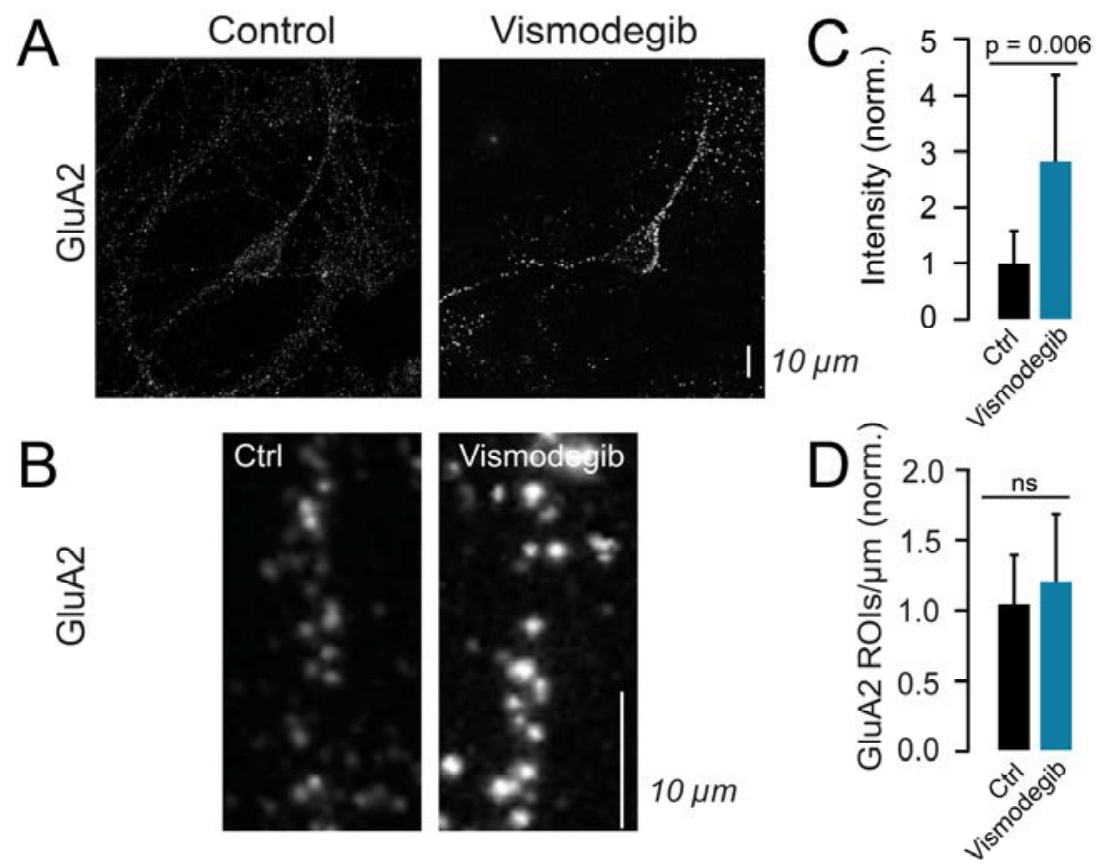

Figure 20 A, Cultured hippocampal neurons stained with antibodies against GluA2; $B$, closeup of dendrite showing GluA2 punctate staining; $C$, quantified fluorescence intensity; D, GluA2 puncta per $\mu \mathrm{m}$ dendrite. 
The effect we see when blocking Smo is similar to what happens when hippocampal cultures are subjected to long-term incubation with the Nav channel blocker tetrodotoxin, TTX. Long-term TTX incubation eventually results in a compensatory increase in synaptic activity seen as increased mEPSC amplitude from up-regulation of AMPARs. This phenomenon is called homeostatic plasticity and could be defined as the initiation of compensatory mechanisms to counteract a perturbation of a neuron (Turrigiano et al. 1998, Turrigiano 2012). Homeostatic plasticity affects all synapses in a network, scaling up or down activity depending in the sign of the perturbation. Analyzing the mEPSC amplitude distribution, Vismodegib incubation generated a general up-scaling of mEPSC amplitudes compared to control, suggesting that $\mathrm{Hh}$ might act as a homeostatic regulator of activity. Homeostatic plasticity is usually a result of abrupt action potential silencing or GABA-ergic receptor block resulting in compensatory mechanisms emerging approximately $24 \mathrm{~h}$ later (Turrigiano et al. 1998). We tested if Vismodegib produced any acute or long-term effects on action potential firing frequency, but we did not see any difference between Vismodegib and control vehicle. Thus, the effect Hh-signaling has on synaptic strength is similar to but does not act through the mechanisms of conventional homeostatic plasticity.

Maturity of hippocampal cultures matter for the effect of canonical and non-canonical Hh-signaling pathways

A general Smo-block does not affect developing cultures; we did not see any effect of Vismodegib in immature (DIV 12-14) neurons (Figure 21), similar results have been seen using the Smo antagonist Cyclopamine 
(Mitchell et al. 2012). Perhaps the non-canonical pathway is not active during this time in hippocampal neuron maturation? We see that blocking Gli binding to DNA using GANT-61 generates an increase in mEPSC frequency in immature cultures as in mature ones (see Figure 18 and Figure 21).

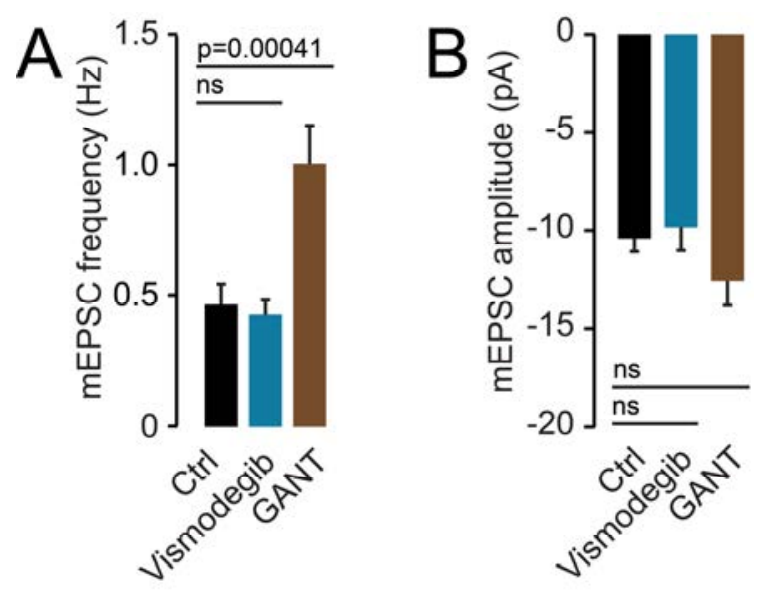

Figure 21 A, mEPSC mean frequency recorded from immature (DIV12-14) hippocampal neurons after exposure to Vismodegib or GANT-61; B, mEPSC peak amplitude under the same conditions as $A$.

Gli goes into a default action whenever $\mathrm{Hh}$ is not present (i.e. no Smo signaling). Without $\mathrm{Hh}, \mathrm{Gli}$ is bound to DNA acting as a repressor of transcription of $\mathrm{Hh}$ controlled genes. With Smo activated by $\mathrm{Hh}$, Gli transforms from a repressor to an activator of transcription. If Gli is unbound to DNA or drugs block its DNA binding, Gli does not produce any effect. If no Hh is released in immature cultures the addition of GANT-61 could still generate an effect, relieving the default repression Gli exerts on 
gene expression. This could explain why we see different effects on immature cultures compared to Petralia et al., 2012.

We do not see any difference in subunit expression levels of GluN1A, GluN2A and GluN2B, otherwise that could explain the differences in NMDA-mEPSC response we observe after Vismodegib incubation. Although, we see a tendency towards an increase in GluN2B containing NMDARs per unit length of dendrite (albeit not significant, $\mathrm{p}=0.1$ ) and a longer time constant of NMDA-mEPSCs suggesting Vismodegib might promote an increase in GluN2B subunits. Probably, Smo regulate NMDARs by another mechanism than changing expression levels of receptor subunits. Phosphorylation of NMDARs by Src family kinases can alter NMDAR current properties (Trepanier et al. 2012) and non-canonical Hhsignaling can activate Src family kinases (Yam et al. 2009). There are tyrosine phosphorylation sites on both GluN2A and GluN2B although GluN2B seems to be the main target for tyrosine phosphorylation by Src family kinases (Sakmann and Neher 1984). The Src family tyrosine kinase Fyn has been shown to phosphorylate GluN2A and GluN2B subunits, but especially GluN2B phosphorylation can result in a stabilization of the receptor in the plasma membrane, preventing endocytosis of the receptor (Trepanier et al. 2012). However, this should mainly affect the amplitude of the NMDAR current, and we do not see that in our recordings after Vismodegib incubation. 
Smo has similarities with G-protein coupled receptors (GPCRs) in that Smo have a 7-transmembrane configuration and can signal via G-proteins (Yao et al. 2016). Smo has been shown to activate $G_{i}$ signaling cascades (Patel et al. 2017). Gi activation results in inhibition of adenylyl cyclase decreasing cyclic adenosine mono phosphate (cAMP) reducing activation of protein kinase A (PKA) (Yao et al. 2016). PKA also has the ability to restrict Smo-signaling tonically and Hh induced activation of Smo can relieve this inhibition (Zhou et al. 2006). PKA is an intracellular effector involved in the induction of LTP (Nayak et al. 1998). PKA indirectly promotes increased activity of $\mathrm{Ca}^{2+}$ - Calmodulin-dependent protein kinase II (CaMKII) an undisputable molecular regulator of LTP (Malenka and Nicoll 1999). Thus, non-canonical Hh-signaling can reduce PKA activation and eventually CaMKII activation restricting or suppressing LTP.

We see a pronounced effect when we add an antagonist of Smo to our hippocampal neurons but how does this translate into a potential effect of the natural ligand $\mathrm{Hh}$ on mature hippocampal neurons? Release of $\mathrm{Hh}$ requires high-frequency stimulation, and that release is dependent on action potential firing, extracellular $\mathrm{Ca}^{2+}$ and SNARE proteins ( $\mathrm{Su}$ et al. 2017) similarly as release of synaptic vesicles containing small molecular neurotransmitters. If harmful high-frequency activity, such as during an epileptic seizure, releases Hh the NMDAR suppressive effects that we have observed from Hh-signaling could be a way to prevent over-excitability. However, contrary to our results is has been suggested that Hh-signaling contributes to the development of epilepsy (Feng et al. 2016). When Hh- 
signaling was inhibited epileptiform activity in cell cultures and hippocampal slices was reduced. The proposed mechanism was that $\mathrm{Hh}$ inhibits glutamate transporters thus increasing glutamate levels in the synaptic cleft.

What would be the role of Hh regulation in the adult hippocampus? Downscaling or depotentiating plasticity is as important as induction of plasticity. Preventing induction of plasticity during uncontrolled excitation such as during an epileptic seizure or after brain trauma is essential for protection of cells and maintenance of normal function of neuronal networks. It has been hypothesized that hyperkinetic disorders can be a consequence of loss of synaptic downscaling (Calabresi et al. 2016). In a recent abstract Malave et al., showed in rats and primates that L-dopa induced dyskinesia was reduced when animals were treated with Smo agonists (SAG or Purmorphamine) (Malave and Kottmann 2017). Perhaps Hh-signaling in the striatum can induce downscaling and/or dampen plasticity to reduce dyskinesia. 


\section{Acknowledgements}

Thank you, Björn! I am impressed that you gave me the freedom early on to work alone with expensive equipment, and relied on me to solve problems myself, it helped me find confidence in the lab. I have greatly appreciated your welcoming and friendly attitude; your door has always been open and you have been willing to discuss matters small as big. You taught me to celebrate whenever positive results appeared, regardless of them at the time feeling small (I especially think about retrobeads positive Ntsr1-Cre negative neurons after CL retrobead injections).

Thank you, Fredrik! You have provided me with support in times of need. Your advice has always been practical and genuine. Your great knowledge in ion channels and your skills as a teacher have given me a good background in parts of neuroscience that have not been my main research focus.

Thank you, Mattias! My un-official co-supervisor! I have really enjoyed working with you in the Hh project. I envy your drive and capacity, and your excellent spamming skills (:) You have given me support and peptalks, and talked about the value of balancing work and family life.

Sarah Lindström, the positive pessimist. You have been the best colleague! You are meticulous in all that you do and have inspired me to strive to be better at noticing the details in research. 
Anna Nilsson and Nina Ottosson, my work support-team! When asked during a PhD course to think about who gave you support at work, you two were the first ones that came to my mind. Thank you for listening and always being on my side!

Gonzalo Sanchez, the constant optimist, thank you for letting me be a part of the Hh-project and for always offering a helping hand.

Johan Brask and Sara Liin, you have offered friendly support and practical problem-solving skills and I have really enjoyed and found great help from our discussions.

A huge thank you to the Elinder, Liin and Fridberger groups, Malin, Jakob, Urban, Andreas, Johan L, Olle, Mark, Anders, Pierre, Batu, Sonal, for making the electro journal club fun and challenging.

My fellow MedBi gang, Susanna, Linnea and Cici, I really value our friendship and look forward to more after-work hang-outs and late tea evenings once this adventure is over.

Thank you, to all wonderful friends. Jonas, Johannes and Anders my beloved dysfunctional family. Jocke, Sandra, Klara and Micke you have made Linköping more fun. 
Marie, Erik och Leonard, tack för er kärlek och stöd! Ser fram emot att träffa er oftare nu!

Mamma, oavsett vad som hänt har du funnits där. Utan barnvaktande och pepp från dig hade denna bok inte blivit klar!

Jonathan, Miranda och Max det är ni som är viktigast, älskar er! ...och Jonathan, all korrekturläsning, tech-support och bildredigering har varit ovärderlig, det blev en bok tillslut kan man tänka sig... 


\section{References}

Ahlsen, G., S. Lindstrom and F. S. Lo (1985). "Interaction between inhibitory pathways to principal cells in the lateral geniculate nucleus of the cat." Exp Brain Res 58(1): 134-143.

Andoniadou, C. L. and J. P. Martinez-Barbera (2013). "Developmental mechanisms directing early anterior forebrain specification in vertebrates." Cell Mol Life Sci 70(20): 3739-3752.

Anthony, T. E., C. Klein, G. Fishell and N. Heintz (2004). "Radial glia serve as neuronal progenitors in all regions of the central nervous system." Neuron 41(6): 881-890.

Atlan, G., A. Terem, N. Peretz-Rivlin, M. Groysman and A. Citri (2017). "Mapping synaptic corticoclaustral connectivity in the mouse." I Comp Neurol 525(6): 1381-1402.

Augustinaite, S., Y. Yanagawa and P. Heggelund (2011). "Cortical feedback regulation of input to visual cortex: role of intrageniculate interneurons." L Physiol 589(Pt 12): 2963-2977.

Baker, R. W. and F. M. Hughson (2016). "Chaperoning SNARE assembly and disassembly." Nat Rev Mol Cell Biol 17(8): 465-479.

Barrett, E. F., J. N. Barrett, D. Botz, D. B. Chang and D. Mahaffey (1978). "Temperature-sensitive aspects of evoked and spontaneous transmitter release at the frog neuromuscular junction." I Physiol 279: 253-273.

Barria, A., D. Muller, V. Derkach, L. C. Griffith and T. R. Soderling (1997). "Regulatory phosphorylation of AMPA-type glutamate receptors by CaM-KII during long-term potentiation." Science 276(5321): 2042-2045.

Bekkers, J. M. (1998). "Neurophysiology: are autapses prodigal synapses?" Curr Biol 8(2): R52-55.

Bernstein, A. and M. Breitman (1989). "Genetic ablation in transgenic mice." Mol Biol Med 6(6): 523-530.

Betz, W. J. (1970). "Depression of transmitter release at the neuromuscular junction of the frog." I Physiol 206(3): 629-644.

Blatow, M., A. Caputi, N. Burnashev, H. Monyer and A. Rozov (2003). "Ca2+ buffer saturation underlies paired pulse facilitation in calbindin-D28k-containing terminals." Neuron 38(1): 79-88.

Bliss, T. V. and G. L. Collingridge (1993). "A synaptic model of memory: long-term potentiation in the hippocampus." Nature 361(6407): 31-39.

Bliss, T. V. and T. Lomo (1973). "Long-lasting potentiation of synaptic transmission in the dentate area of the anaesthetized rabbit following stimulation of the perforant path." I Physiol 232(2): 331356. 
Bloem, B., L. Schoppink, D. C. Rotaru, A. Faiz, P. Hendriks, H. D. Mansvelder, W. D. van de Berg and F. G. Wouterlood (2014). "Topographic mapping between basal forebrain cholinergic neurons and the medial prefrontal cortex in mice." L Neurosci 34(49): 16234-16246.

Bomben, V. C., I. Aiba, J. Qian, M. D. Mark, S. Herlitze and J. L. Noebels (2016). "Isolated P/Q Calcium Channel Deletion in Layer VI Corticothalamic Neurons Generates Absence Epilepsy." L Neurosci 36(2): 405-418.

Bortone, D. S., S. R. Olsen and M. Scanziani (2014). "Translaminar inhibitory cells recruited by layer 6 corticothalamic neurons suppress visual cortex." Neuron 82(2): 474-485.

Briggs, F. and W. M. Usrey (2008). "Emerging views of corticothalamic function." Curr Opin Neurobiol 18(4): 403-407.

Brody, D. L. and D. T. Yue (2000). "Release-independent short-term synaptic depression in cultured hippocampal neurons." \ Neurosci 20(7): 2480-2494.

Brumberg, J. C., F. Hamzei-Sichani and R. Yuste (2003). "Morphological and physiological characterization of layer VI corticofugal neurons of mouse primary visual cortex." I Neurophysiol 89(5): 2854-2867.

Burnashev, N. and A. Rozov (2005). "Presynaptic Ca2+ dynamics, Ca2+ buffers and synaptic efficacy." Cell Calcium 37(5): 489-495.

Bystron, I., C. Blakemore and P. Rakic (2008). "Development of the human cerebral cortex: Boulder Committee revisited." Nat Rev Neurosci 9(2): 110-122.

Bystron, I., P. Rakic, Z. Molnar and C. Blakemore (2006). "The first neurons of the human cerebral cortex." Nat Neurosci 9(7): 880-886.

Calabresi, P., A. Pisani, J. Rothwell, V. Ghiglieri, J. A. Obeso and B. Picconi (2016). "Hyperkinetic disorders and loss of synaptic downscaling." Nat Neurosci 19(7): 868-875.

Camp, J. G., F. Badsha, M. Florio, S. Kanton, T. Gerber, M. Wilsch-Brauninger, E. Lewitus, A. Sykes, W. Hevers, M. Lancaster, J. A. Knoblich, R. Lachmann, S. Paabo, W. B. Huttner and B. Treutlein (2015). "Human cerebral organoids recapitulate gene expression programs of fetal neocortex development." Proc Natl Acad Sci U S A 112(51): 15672-15677.

Case, L., D. J. Lyons and C. Broberger (2017). "Desynchronization of the Rat Cortical Network and Excitation of White Matter Neurons by Neurotensin." Cereb Cortex 27(4): 2671-2685.

Castel, M. N., J. M. Stutzmann, M. Lucas, J. Lafforgue and J. C. Blanchard (1989). "Effects of ICV administration of neurotensin and analogs on EEG in rats." Peptides 10(1): 95-101.

Catterall, W. A., K. Leal and E. Nanou (2013). "Calcium channels and short-term synaptic plasticity." Liol Chem 288(15): 10742-10749.

Catterall, W. A., I. M. Raman, H. P. Robinson, T. J. Sejnowski and O. Paulsen (2012). "The HodgkinHuxley heritage: from channels to circuits." L Neurosci 32(41): 14064-14073. 
Cerpa, W., A. Gambrill, N. C. Inestrosa and A. Barria (2011). "Regulation of NMDA-receptor synaptic transmission by Wnt signaling." L Neurosci 31(26): 9466-9471.

Cerpa, W., E. Latorre-Esteves and A. Barria (2015). "RoR2 functions as a noncanonical Wnt receptor that regulates NMDAR-mediated synaptic transmission." Proc Natl Acad Sci U S A 112(15): 47974802.

Chen, J., C. S. Park and S. J. Tang (2006). "Activity-dependent synaptic Wnt release regulates hippocampal long term potentiation." LBiol Chem 281(17): 11910-11916.

Chinchilla, P., L. Xiao, M. G. Kazanietz and N. A. Riobo (2010). "Hedgehog proteins activate proangiogenic responses in endothelial cells through non-canonical signaling pathways." Cell Cycle 9(3): 570-579.

Choi, S. and D. M. Lovinger (1997). "Decreased frequency but not amplitude of quantal synaptic responses associated with expression of corticostriatal long-term depression." J Neurosci 17(21): 8613-8620.

Clancy, B., B. Kersh, J. Hyde, R. B. Darlington, K. J. Anand and B. L. Finlay (2007). "Web-based method for translating neurodevelopment from laboratory species to humans." Neuroinformatics 5(1): 79-94.

Clancy, B., M. Silva-Filho and M. J. Friedlander (2001). "Structure and projections of white matter neurons in the postnatal rat visual cortex." J Comp Neurol 434(2): 233-252.

Cohen-Tannoudji, M. and C. Babinet (1998). "Beyond 'knock-out' mice: new perspectives for the programmed modification of the mammalian genome." Mol Hum Reprod 4(10): 929-938.

Cohen, M., A. Kicheva, A. Ribeiro, R. Blassberg, K. M. Page, C. P. Barnes and J. Briscoe (2015). "Ptch1 and Gli regulate Shh signalling dynamics via multiple mechanisms." Nat Commun 6: 6709.

Cohen, S. N. (2013). "DNA cloning: a personal view after 40 years." Proc Natl Acad Sci U S A 110(39): 15521-15529.

Connelly, W. M. and G. Lees (2010). "Modulation and function of the autaptic connections of layer V fast spiking interneurons in the rat neocortex." J Physiol 588(Pt 12): 2047-2063.

Cotel, F., L. N. Fletcher, S. Kalita-de Croft, J. Apergis-Schoute and S. R. Williams (2018). "Cell ClassDependent Intracortical Connectivity and Output Dynamics of Layer 6 Projection Neurons of the Rat Primary Visual Cortex." Cereb Cortex 28(7): 2340-2350.

Crandall, S. R., S. J. Cruikshank and B. W. Connors (2015). "A corticothalamic switch: controlling the thalamus with dynamic synapses." Neuron 86(3): 768-782.

Crandall, S. R., S. L. Patrick, S. J. Cruikshank and B. W. Connors (2017). "Infrabarrels Are Layer 6 Circuit Modules in the Barrel Cortex that Link Long-Range Inputs and Outputs." Cell Rep 21(11): 3065-3078. 
Crick, F. (1984). "Function of the thalamic reticular complex: the searchlight hypothesis." Proc Natl Acad Sci U S A 81(14): 4586-4590.

Deisseroth, K. and P. Hegemann (2017). "The form and function of channelrhodopsin." Science 357(6356).

DeSesso, J. M., A. R. Scialli and J. F. Holson (1999). "Apparent lability of neural tube closure in laboratory animals and humans." Am J Med Genet 87(2): 143-162.

Dessaud, E., A. P. McMahon and J. Briscoe (2008). "Pattern formation in the vertebrate neural tube: a sonic hedgehog morphogen-regulated transcriptional network." Development 135(15): 24892503.

Diao, Y., Y. Chen, P. Zhang, L. Cui and J. Zhang (2017). "Molecular guidance cues in the development of visual pathway." Protein Cell.

Dore, K., I. S. Stein, J. A. Brock, P. E. Castillo, K. Zito and P. J. Sjostrom (2017). "Unconventional NMDA Receptor Signaling." Ц Neurosci 37(45): 10800-10807.

Dudek, S. M. and M. F. Bear (1992). "Homosynaptic long-term depression in area CA1 of hippocampus and effects of N-methyl-D-aspartate receptor blockade." Proc Natl Acad Sci U S A 89(10): 4363-4367.

Dutta Roy, R., M. I. Stefan and C. Rosenmund (2014). "Biophysical properties of presynaptic shortterm plasticity in hippocampal neurons: insights from electrophysiology, imaging and mechanistic models." Front Cell Neurosci 8: 141.

Edwards, R. H. (2007). "The neurotransmitter cycle and quantal size." Neuron 55(6): 835-858.

Eriksen, J., R. Chang, M. McGregor, K. Silm, T. Suzuki and R. H. Edwards (2016). "Protons Regulate Vesicular Glutamate Transporters through an Allosteric Mechanism." Neuron 90(4): 768-780.

Feng, S., S. Ma, C. Jia, Y. Su, S. Yang, K. Zhou, Y. Liu, J. Cheng, D. Lu, L. Fan and Y. Wang (2016). "Sonic hedgehog is a regulator of extracellular glutamate levels and epilepsy." EMBO Rep 17(5): 682-694.

Fioravante, D. and W. G. Regehr (2011). "Short-term forms of presynaptic plasticity." Curr Opin Neurobiol 21(2): 269-274.

Galazo, M. J., J. G. Emsley and J. D. Macklis (2016). "Corticothalamic Projection Neuron Development beyond Subtype Specification: Fog2 and Intersectional Controls Regulate Intraclass Neuronal Diversity." Neuron 91(1): 90-106.

Garcia, A. D., R. Petrova, L. Eng and A. L. Joyner (2010). "Sonic hedgehog regulates discrete populations of astrocytes in the adult mouse forebrain." I Neurosci 30(41): 13597-13608.

Ghosh, K. and G. D. Van Duyne (2002). "Cre-loxP biochemistry." Methods 28(3): 374-383. 
Gilbert, C. D. and T. N. Wiesel (1979). "Morphology and intracortical projections of functionally characterised neurones in the cat visual cortex." Nature 280(5718): 120-125.

Goard, M. and Y. Dan (2009). "Basal forebrain activation enhances cortical coding of natural scenes." Nat Neurosci 12(11): 1444-1449.

Gong, S., M. Doughty, C. R. Harbaugh, A. Cummins, M. E. Hatten, N. Heintz and C. R. Gerfen (2007). "Targeting Cre recombinase to specific neuron populations with bacterial artificial chromosome constructs." ¿ Neurosci 27(37): 9817-9823.

Gong, S., C. Zheng, M. L. Doughty, K. Losos, N. Didkovsky, U. B. Schambra, N. J. Nowak, A. Joyner, G. Leblanc, M. E. Hatten and N. Heintz (2003). "A gene expression atlas of the central nervous system based on bacterial artificial chromosomes." Nature 425(6961): 917-925.

Granseth, B. (2004). "Dynamic properties of corticogeniculate excitatory transmission in the rat dorsal lateral geniculate nucleus in vitro." I Physiol 556(Pt 1): 135-146.

Granseth, B., E. Ahlstrand and S. Lindstrom (2002). "Paired pulse facilitation of corticogeniculate EPSCs in the dorsal lateral geniculate nucleus of the rat investigated in vitro." I Physiol 544(Pt 2): 477-486.

Granseth, B. and L. Lagnado (2008). "The role of endocytosis in regulating the strength of hippocampal synapses." L Physiol 586(24): 5969-5982.

Granseth, B. and S. Lindstrom (2003). "Unitary EPSCs of corticogeniculate fibers in the rat dorsal lateral geniculate nucleus in vitro." Ц Neurophysiol 89(6): 2952-2960.

Grant, E., A. Hoerder-Suabedissen and Z. Molnar (2012). "Development of the corticothalamic projections." Front Neurosci 6: 53.

Greig, L. C., M. B. Woodworth, M. J. Galazo, H. Padmanabhan and J. D. Macklis (2013). "Molecular logic of neocortical projection neuron specification, development and diversity." Nat Rev Neurosci 14(11): 755-769.

Gu, H., J. D. Marth, P. C. Orban, H. Mossmann and K. Rajewsky (1994). "Deletion of a DNA polymerase beta gene segment in $\mathrm{T}$ cells using cell type-specific gene targeting." Science 265(5168): 103-106.

Guillem, K., B. Bloem, R. B. Poorthuis, M. Loos, A. B. Smit, U. Maskos, S. Spijker and H. D. Mansvelder (2011). "Nicotinic acetylcholine receptor beta2 subunits in the medial prefrontal cortex control attention." Science 333(6044): 888-891.

Guo, W., A. R. Clause, A. Barth-Maron and D. B. Polley (2017). "A Corticothalamic Circuit for Dynamic Switching between Feature Detection and Discrimination." Neuron 95(1): 180-194 e185.

Hagiwara, S., S. Miyazaki and N. P. Rosenthal (1976). "Potassium current and the effect of cesium on this current during anomalous rectification of the egg cell membrane of a starfish." I Gen Physiol 67(6): 621-638. 
Hall, Z. J., A. R. De Serrano, F. H. Rodd and V. Tropepe (2014). "Casting a wider fish net on animal models in neuropsychiatric research." Prog Neuropsychopharmacol Biol Psychiatry 55: 7-15.

Hamill, O. P., A. Marty, E. Neher, B. Sakmann and F. J. Sigworth (1981). "Improved patch-clamp techniques for high-resolution current recording from cells and cell-free membrane patches." Pflugers Arch 391(2): 85-100.

Han, Y., P. S. Kaeser, T. C. Sudhof and R. Schneggenburger (2011). "RIM determines Ca(2)+ channel density and vesicle docking at the presynaptic active zone." Neuron 69(2): 304-316.

Hay, Y. A., B. Lambolez and L. Tricoire (2016). "Nicotinic Transmission onto Layer 6 Cortical Neurons Relies on Synaptic Activation of Non-alpha7 Receptors." Cereb Cortex 26(6): 2549-2562.

Hedrick, T. and J. Waters (2015). "Acetylcholine excites neocortical pyramidal neurons via nicotinic receptors." \Neurophysiol 113(7): 2195-2209.

Hedström, A. and S. Lindström (1987). Layer 6 cells and focal epileptic seizures in the cat's visual cortex. Advances in Epileptology. P. Wolf, M. Dam, D. Janz and F. E. Dreifuss. New York, Raven Press. 16: $97-100$.

Heffner, C. S., C. Herbert Pratt, R. P. Babiuk, Y. Sharma, S. F. Rockwood, L. R. Donahue, J. T. Eppig and S. A. Murray (2012). "Supporting conditional mouse mutagenesis with a comprehensive cre characterization resource." Nat Commun 3: 1218.

Hevner, R. F., E. Miyashita-Lin and J. L. Rubenstein (2002). "Cortical and thalamic axon pathfinding defects in Tbr1, Gbx2, and Pax6 mutant mice: evidence that cortical and thalamic axons interact and guide each other." J Comp Neurol 447(1): 8-17.

Hevner, R. F., L. Shi, N. Justice, Y. Hsueh, M. Sheng, S. Smiga, A. Bulfone, A. M. Goffinet, A. T. Campagnoni and J. L. Rubenstein (2001). "Tbr1 regulates differentiation of the preplate and layer 6." Neuron 29(2): 353-366.

Hille, B. (1978). "Ionic channels in excitable membranes. Current problems and biophysical approaches." Biophys I 22(2): 283-294.

Hisaoka, T., Y. Nakamura, E. Senba and Y. Morikawa (2010). "The forkhead transcription factors, Foxp1 and Foxp2, identify different subpopulations of projection neurons in the mouse cerebral cortex." Neuroscience 166(2): 551-563.

Hoess, R., K. Abremski and N. Sternberg (1984). "The nature of the interaction of the P1 recombinase Cre with the recombining site loxP." Cold Spring Harb Symp Quant Biol 49: 761-768.

Hua, Y., A. Woehler, M. Kahms, V. Haucke, E. Neher and J. Klingauf (2013). "Blocking endocytosis enhances short-term synaptic depression under conditions of normal availability of vesicles." Neuron 80(2): 343-349.

Hui, C. C. and S. Angers (2011). "Gli proteins in development and disease." Annu Rev Cell Dev Biol 27: 513-537. 
Hynes, M., W. Ye, K. Wang, D. Stone, M. Murone, F. Sauvage and A. Rosenthal (2000). "The seventransmembrane receptor smoothened cell-autonomously induces multiple ventral cell types." Nat Neurosci 3(1): 41-46.

Imig, C., S. W. Min, S. Krinner, M. Arancillo, C. Rosenmund, T. C. Sudhof, J. Rhee, N. Brose and B. H. Cooper (2014). "The morphological and molecular nature of synaptic vesicle priming at presynaptic active zones." Neuron 84(2): 416-431.

Ingham, P. W. and A. P. McMahon (2001). "Hedgehog signaling in animal development: paradigms and principles." Genes Dev 15(23): 3059-3087.

Jackman, S. L., B. M. Beneduce, I. R. Drew and W. G. Regehr (2014). "Achieving high-frequency optical control of synaptic transmission." J Neurosci 34(22): 7704-7714.

Jackman, S. L. and W. G. Regehr (2017). "The Mechanisms and Functions of Synaptic Facilitation." Neuron 94(3): 447-464.

Jackman, S. L., J. Turecek, J. E. Belinsky and W. G. Regehr (2016). "The calcium sensor synaptotagmin 7 is required for synaptic facilitation." Nature 529(7584): 88-91.

Jenkins, D. (2009). "Hedgehog signalling: emerging evidence for non-canonical pathways." Cell Signal 21(7): 1023-1034.

Jones, B. E. (2005). "From waking to sleeping: neuronal and chemical substrates." Trends Pharmacol Sci 26(11): 578-586.

Kaeser, P. S. (2011). "Pushing synaptic vesicles over the RIM." Cell Logist 1(3): 106-110.

Kaeser, P. S. and W. G. Regehr (2017). "The readily releasable pool of synaptic vesicles." Curr Opin Neurobiol 43: 63-70.

Katz, B. and R. Miledi (1968). "The role of calcium in neuromuscular facilitation." L Physiol 195(2): 481-492.

Katz, L. C. (1987). "Local circuitry of identified projection neurons in cat visual cortex brain slices." I Neurosci 7(4): 1223-1249.

Kim, J., C. J. Matney, A. Blankenship, S. Hestrin and S. P. Brown (2014). "Layer 6 corticothalamic neurons activate a cortical output layer, layer 5a." J Neurosci 34(29): 9656-9664.

Klinkenberg, I., A. Sambeth and A. Blokland (2011). "Acetylcholine and attention." Behav Brain Res 221(2): 430-442.

Klyachko, V. A. and C. F. Stevens (2006). "Temperature-dependent shift of balance among the components of short-term plasticity in hippocampal synapses." INeurosci 26(26): 6945-6957. 
Konishi, Y., K. Lindholm, L. B. Yang, R. Li and Y. Shen (2002). "Isolation of living neurons from human elderly brains using the immunomagnetic sorting DNA-linker system." Am J Pathol 161(5): 1567-1576.

Kumar, P. and O. Ohana (2008). "Inter- and intralaminar subcircuits of excitatory and inhibitory neurons in layer 6a of the rat barrel cortex." INeurophysiol 100(4): 1909-1922.

Lai, Y., U. B. Choi, J. Leitz, H. J. Rhee, C. Lee, B. Altas, M. Zhao, R. A. Pfuetzner, A. L. Wang, N. Brose, J. Rhee and A. T. Brunger (2017). "Molecular Mechanisms of Synaptic Vesicle Priming by Munc13 and Munc18." Neuron 95(3): 591-607 e510.

Lee, J. J., D. P. von Kessler, S. Parks and P. A. Beachy (1992). "Secretion and localized transcription suggest a role in positional signaling for products of the segmentation gene hedgehog." Cell 71(1): 33-50.

Liu, H., E. R. Chapman and C. Dean (2013). ""Self" versus "non-self" connectivity dictates properties of synaptic transmission and plasticity." PLoS One 8(4): e62414.

Livingstone, M. S. and D. H. Hubel (1984). "Specificity of intrinsic connections in primate primary visual cortex." \Neurosci 4(11): 2830-2835.

Loscher, W. (2002). "Animal models of epilepsy for the development of antiepileptogenic and disease-modifying drugs. A comparison of the pharmacology of kindling and post-status epilepticus models of temporal lobe epilepsy." Epilepsy Res 50(1-2): 105-123.

Lubke, J., H. Markram, M. Frotscher and B. Sakmann (1996). "Frequency and dendritic distribution of autapses established by layer 5 pyramidal neurons in the developing rat neocortex: comparison with synaptic innervation of adjacent neurons of the same class." L Neurosci 16(10): 3209-3218.

Luscher, C. and R. C. Malenka (2012). "NMDA receptor-dependent long-term potentiation and longterm depression (LTP/LTD)." Cold Spring Harb Perspect Biol 4(6).

Macy, J. and T. L. Horvath (2017). "Comparative Medicine: An Inclusive Crossover Discipline." Yale J Biol Med 90(3): 493-498.

Malave, L. B. and A. H. Kottmann (2017). Stimulation of Sonic Hedgehog (Shh) signaling reduces formation and display of L-Dopa induced dyskinesia (LID) in models of Parkinson's Disease (PD). Society for Neuroscience 2017, Session 455.10, Conference abstract, 2017 Nov 14, Washington DC., USA.

Malenka, R. C. and R. A. Nicoll (1999). "Long-term potentiation--a decade of progress?" Science 285(5435): 1870-1874.

Marigo, V., R. L. Johnson, A. Vortkamp and C. J. Tabin (1996). "Sonic hedgehog differentially regulates expression of GLI and GLI3 during limb development." Dev Biol 180(1): 273-283.

Maurya, D. K., S. Bohm and M. Alenius (2017). "Hedgehog signaling regulates ciliary localization of mouse odorant receptors." Proc Natl Acad Sci U S A 114(44): E9386-E9394. 
McConnell, S. K., A. Ghosh and C. J. Shatz (1989). "Subplate neurons pioneer the first axon pathway from the cerebral cortex." Science 245(4921): 978-982.

McCormick, D. A. and D. Contreras (2001). "On the cellular and network bases of epileptic seizures." Annu Rev Physiol 63: 815-846.

Mennerick, S., J. Que, A. Benz and C. F. Zorumski (1995). "Passive and synaptic properties of hippocampal neurons grown in microcultures and in mass cultures." I Neurophysiol 73(1): 320332.

Mennerick, S. and C. F. Zorumski (1995). "Paired-pulse modulation of fast excitatory synaptic currents in microcultures of rat hippocampal neurons." ¿ Physiol 488 ( Pt 1): 85-101.

Mercer, A., D. C. West, O. T. Morris, S. Kirchhecker, J. E. Kerkhoff and A. M. Thomson (2005). "Excitatory connections made by presynaptic cortico-cortical pyramidal cells in layer 6 of the neocortex." Cereb Cortex 15(10): 1485-1496.

Metherate, R., C. L. Cox and J. H. Ashe (1992). "Cellular bases of neocortical activation: modulation of neural oscillations by the nucleus basalis and endogenous acetylcholine." L Neurosci 12(12): 4701-4711.

Miller, B., L. Chou and B. L. Finlay (1993). "The early development of thalamocortical and corticothalamic projections." L Comp Neurol 335(1): 16-41.

Mitchell, N., R. S. Petralia, D. G. Currier, Y. X. Wang, A. Kim, M. P. Mattson and P. J. Yao (2012). "Sonic hedgehog regulates presynaptic terminal size, ultrastructure and function in hippocampal neurons." I Cell Sci 125(Pt 18): 4207-4213.

Molnar, Z. and C. Blakemore (1995). "How do thalamic axons find their way to the cortex?" Trends Neurosci 18(9): 389-397.

Molnar, Z., S. Garel, G. Lopez-Bendito, P. Maness and D. J. Price (2012). "Mechanisms controlling the guidance of thalamocortical axons through the embryonic forebrain." Eur J Neurosci 35(10): 15731585.

Molyneaux, B. J., P. Arlotta, J. R. Menezes and J. D. Macklis (2007). "Neuronal subtype specification in the cerebral cortex." Nat Rev Neurosci 8(6): 427-437.

Mulkey, R. M. and R. C. Malenka (1992). "Mechanisms underlying induction of homosynaptic longterm depression in area CA1 of the hippocampus." Neuron 9(5): 967-975.

Murone, M., A. Rosenthal and F. J. de Sauvage (1999). "Sonic hedgehog signaling by the patchedsmoothened receptor complex." Curr Biol 9(2): 76-84.

Nabavi, S., H. W. Kessels, S. Alfonso, J. Aow, R. Fox and R. Malinow (2013). "Metabotropic NMDA receptor function is required for NMDA receptor-dependent long-term depression." Proc Natl Acad Sci U S A 110(10): 4027-4032. 
Nagel, G., T. Szellas, W. Huhn, S. Kateriya, N. Adeishvili, P. Berthold, D. Ollig, P. Hegemann and E. Bamberg (2003). "Channelrhodopsin-2, a directly light-gated cation-selective membrane channel." Proc Natl Acad Sci U S A 100(24): 13940-13945.

Nanou, E. and W. A. Catterall (2018). "Calcium Channels, Synaptic Plasticity, and Neuropsychiatric Disease." Neuron 98(3): 466-481.

Nanou, E., J. M. Sullivan, T. Scheuer and W. A. Catterall (2016). "Calcium sensor regulation of the CaV2.1 Ca2+ channel contributes to short-term synaptic plasticity in hippocampal neurons." Proc Natl Acad Sci U S A 113(4): 1062-1067.

Nayak, A., D. J. Zastrow, R. Lickteig, N. R. Zahniser and M. D. Browning (1998). "Maintenance of latephase LTP is accompanied by PKA-dependent increase in AMPA receptor synthesis." Nature 394(6694): 680-683.

Neher, E. and T. Sakaba (2008). "Multiple roles of calcium ions in the regulation of neurotransmitter release." Neuron 59(6): 861-872.

Niciu, M. J., B. Kelmendi and G. Sanacora (2012). "Overview of glutamatergic neurotransmission in the nervous system." Pharmacol Biochem Behav 100(4): 656-664.

Nowak, L. G., R. Azouz, M. V. Sanchez-Vives, C. M. Gray and D. A. McCormick (2003). "Electrophysiological classes of cat primary visual cortical neurons in vivo as revealed by quantitative analyses." J Neurophysiol 89(3): 1541-1566.

Nusslein-Volhard, C. and E. Wieschaus (1980). "Mutations affecting segment number and polarity in Drosophila." Nature 287(5785): 795-801.

Olsen, S. R., D. S. Bortone, H. Adesnik and M. Scanziani (2012). "Gain control by layer six in cortical circuits of vision." Nature 483(7387): 47-52.

Parekh, R. and G. A. Ascoli (2015). "Quantitative investigations of axonal and dendritic arbors: development, structure, function, and pathology." Neuroscientist 21(3): 241-254.

Paridaen, J. T. and W. B. Huttner (2014). "Neurogenesis during development of the vertebrate central nervous system." EMBO Rep 15(4): 351-364.

Patel, S. S., S. Tomar, D. Sharma, N. Mahindroo and M. Udayabanu (2017). "Targeting sonic hedgehog signaling in neurological disorders." Neurosci Biobehav Rev 74(Pt A): 76-97.

Petralia, R. S., C. M. Schwartz, Y. X. Wang, M. P. Mattson and P. J. Yao (2011a). "Subcellular localization of Patched and Smoothened, the receptors for Sonic hedgehog signaling, in the hippocampal neuron." L Comp Neurol 519(18): 3684-3699.

Petralia, R. S., Y. X. Wang, M. P. Mattson and P. J. Yao (2011b). "Sonic hedgehog distribution within mature hippocampal neurons." Commun Integr Biol 4(6): 775-777. 
Petrof, I., A. N. Viaene and S. M. Sherman (2012). "Two populations of corticothalamic and interareal corticocortical cells in the subgranular layers of the mouse primary sensory cortices." I Comp Neurol 520(8): 1678-1686.

Petrova, R. and A. L. Joyner (2014). "Roles for Hedgehog signaling in adult organ homeostasis and repair." Development 141(18): 3445-3457.

Poorthuis, R. B., B. Bloem, B. Schak, J. Wester, C. P. de Kock and H. D. Mansvelder (2013). "Layerspecific modulation of the prefrontal cortex by nicotinic acetylcholine receptors." Cereb Cortex 23(1): 148-161.

Rabadan-Diehl, C. and P. Nathanielsz (2013). "From Mice to Men: research models of developmental programming." J Dev Orig Health Dis 4(1): 3-9.

Regehr, W. G. (2012). "Short-term presynaptic plasticity." Cold Spring Harb Perspect Biol 4(7): a005702.

Rizo, J. (2018). "Mechanism of neurotransmitter release coming into focus." Protein Sci 27(8): 1364-1391.

Rizo, J. and C. Rosenmund (2008). "Synaptic vesicle fusion." Nat Struct Mol Biol 15(7): 665-674.

Rosenmund, C. and C. F. Stevens (1996). "Definition of the readily releasable pool of vesicles at hippocampal synapses." Neuron 16(6): 1197-1207.

Rowitch, D. H. and A. R. Kriegstein (2010). "Developmental genetics of vertebrate glial-cell specification." Nature 468(7321): 214-222.

Rozov, A., N. Burnashev, B. Sakmann and E. Neher (2001). "Transmitter release modulation by intracellular $\mathrm{Ca} 2+$ buffers in facilitating and depressing nerve terminals of pyramidal cells in layer $2 / 3$ of the rat neocortex indicates a target cell-specific difference in presynaptic calcium dynamics." LPhysiol 531(Pt 3): 807-826.

Sakmann, B. and E. Neher (1984). "Patch clamp techniques for studying ionic channels in excitable membranes." Annu Rev Physiol 46: 455-472.

Sanchez, G. M., L. Alkhori, E. Hatano, S. W. Schultz, A. Kuzhandaivel, S. Jafari, B. Granseth and M. Alenius (2016). "Hedgehog Signaling Regulates the Ciliary Transport of Odorant Receptors in Drosophila." Cell Rep 14(3): 464-470.

Sauer, B. (1987). "Functional expression of the cre-lox site-specific recombination system in the yeast Saccharomyces cerevisiae." Mol Cell Biol 7(6): 2087-2096.

Sauer, B. and N. Henderson (1988). "Site-specific DNA recombination in mammalian cells by the Cre recombinase of bacteriophage P1." Proc Natl Acad Sci U S A 85(14): 5166-5170.

Segraves, M. A. and G. M. Innocenti (1985). "Comparison of the distributions of ipsilaterally and contralaterally projecting corticocortical neurons in cat visual cortex using two fluorescent tracers." \Neurosci 5(8): 2107-2118. 
Semple, B. D., K. Blomgren, K. Gimlin, D. M. Ferriero and L. J. Noble-Haeusslein (2013). "Brain development in rodents and humans: Identifying benchmarks of maturation and vulnerability to injury across species." Prog Neurobiol 106-107: 1-16.

Sirko, S., G. Behrendt, P. A. Johansson, P. Tripathi, M. Costa, S. Bek, C. Heinrich, S. Tiedt, D. Colak, M. Dichgans, I. R. Fischer, N. Plesnila, M. Staufenbiel, C. Haass, M. Snapyan, A. Saghatelyan, L. H. Tsai, A. Fischer, K. Grobe, L. Dimou and M. Gotz (2013). "Reactive glia in the injured brain acquire stem cell properties in response to sonic hedgehog. [corrected]." Cell Stem Cell 12(4): 426-439.

Steriade, M. (2004). "Acetylcholine systems and rhythmic activities during the waking--sleep cycle." Prog Brain Res 145: 179-196.

Stone, D. M., M. Hynes, M. Armanini, T. A. Swanson, Q. Gu, R. L. Johnson, M. P. Scott, D. Pennica, A. Goddard, H. Phillips, M. Noll, J. E. Hooper, F. de Sauvage and A. Rosenthal (1996). "The tumoursuppressor gene patched encodes a candidate receptor for Sonic hedgehog." Nature 384(6605): 129-134.

Su, Y., Y. Yuan, S. Feng, S. Ma and Y. Wang (2017). "High frequency stimulation induces sonic hedgehog release from hippocampal neurons." Sci Rep 7: 43865.

Suarez-Sola, M. L., F. J. Gonzalez-Delgado, M. Pueyo-Morlans, O. C. Medina-Bolivar, N. C. HernandezAcosta, M. Gonzalez-Gomez and G. Meyer (2009). "Neurons in the white matter of the adult human neocortex." Front Neuroanat 3: 7.

Sudhof, T. C. (2012). "The presynaptic active zone." Neuron 75(1): 11-25.

Sudhof, T. C. (2013). "Neurotransmitter release: the last millisecond in the life of a synaptic vesicle." Neuron 80(3): 675-690.

Sudhof, T. C. and J. E. Rothman (2009). "Membrane fusion: grappling with SNARE and SM proteins." Science 323(5913): 474-477.

Sundberg, S. C. and B. Granseth (2018). "Cre-expressing neurons in the cortical white matter of Ntsr1-Cre GN220 mice." Neurosci Lett 675: 36-40.

Swanson, L. W., G. Grant, T. Hokfelt, E. G. Jones and J. H. Morrison (2007). "A century of neuroscience discovery: reflecting on the Nobel Prize awarded to Golgi and Cajal in 1906." Brain Res Rev 55(2): 191-192.

Tamas, G., E. H. Buhl and P. Somogyi (1997). "Massive autaptic self-innervation of GABAergic neurons in cat visual cortex." J Neurosci 17(16): 6352-6364.

Tarczy-Hornoch, K., K. A. Martin, K. J. Stratford and J. J. Jack (1999). "Intracortical excitation of spiny neurons in layer 4 of cat striate cortex in vitro." Cereb Cortex 9(8): 833-843.

Tasic, B., V. Menon, T. N. Nguyen, T. K. Kim, T. Jarsky, Z. Yao, B. Levi, L. T. Gray, S. A. Sorensen, T. Dolbeare, D. Bertagnolli, J. Goldy, N. Shapovalova, S. Parry, C. Lee, K. Smith, A. Bernard, L. Madisen, S. M. Sunkin, M. Hawrylycz, C. Koch and H. Zeng (2016). "Adult mouse cortical cell taxonomy revealed by single cell transcriptomics." Nat Neurosci 19(2): 335-346. 
Thanawala, M. S. and W. G. Regehr (2013). "Presynaptic calcium influx controls neurotransmitter release in part by regulating the effective size of the readily releasable pool." I Neurosci 33(11): 4625-4633.

Thiele, A. (2013). "Muscarinic signaling in the brain." Annu Rev Neurosci 36: 271-294.

Thomas, K. R. and M. R. Capecchi (1987). "Site-directed mutagenesis by gene targeting in mouse embryo-derived stem cells." Cell 51(3): 503-512.

Thomson, A. M. (2010). "Neocortical layer 6, a review." Front Neuroanat 4: 13.

Torii, M. and P. Levitt (2005). "Dissociation of corticothalamic and thalamocortical axon targeting by an EphA7-mediated mechanism." Neuron 48(4): 563-575.

Traiffort, E., D. Charytoniuk, L. Watroba, H. Faure, N. Sales and M. Ruat (1999). "Discrete localizations of hedgehog signalling components in the developing and adult rat nervous system." Eur I Neurosci 11(9): 3199-3214.

Trepanier, C. H., M. F. Jackson and J. F. MacDonald (2012). "Regulation of NMDA receptors by the tyrosine kinase Fyn." FEBS I 279(1): 12-19.

Turner, J. P. and T. E. Salt (1998). "Characterization of sensory and corticothalamic excitatory inputs to rat thalamocortical neurones in vitro." L Physiol 510 ( Pt 3): 829-843.

Turrigiano, G. (2012). "Homeostatic synaptic plasticity: local and global mechanisms for stabilizing neuronal function." Cold Spring Harb Perspect Biol 4(1): a005736.

Turrigiano, G. G., K. R. Leslie, N. S. Desai, L. C. Rutherford and S. B. Nelson (1998). "Activitydependent scaling of quantal amplitude in neocortical neurons." Nature 391(6670): 892-896.

Uchida, N., Y. Honjo, K. R. Johnson, M. J. Wheelock and M. Takeichi (1996). "The catenin/cadherin adhesion system is localized in synaptic junctions bordering transmitter release zones." Ц Cell Biol 135(3): 767-779.

Wang, H. S., Z. Pan, W. Shi, B. S. Brown, R. S. Wymore, I. S. Cohen, J. E. Dixon and D. McKinnon (1998). "KCNQ2 and KCNQ3 potassium channel subunits: molecular correlates of the M-channel." Science 282(5395): 1890-1893.

Wang, Q., L. Ng, J. A. Harris, D. Feng, Y. Li, J. J. Royall, S. W. Oh, A. Bernard, S. M. Sunkin, C. Koch and H. Zeng (2017). "Organization of the connections between claustrum and cortex in the mouse." I Comp Neurol 525(6): 1317-1346.

Warren, R. A. and E. G. Jones (1997). "Maturation of neuronal form and function in a mouse thalamo-cortical circuit." J Neurosci 17(1): 277-295.

Velez-Fort, M., C. V. Rousseau, C. J. Niedworok, I. R. Wickersham, E. A. Rancz, A. P. Brown, M. Strom and T. W. Margrie (2014). "The stimulus selectivity and connectivity of layer six principal cells reveals cortical microcircuits underlying visual processing." Neuron 83(6): 1431-1443. 
Wen, Z., H. N. Nguyen, Z. Guo, M. A. Lalli, X. Wang, Y. Su, N. S. Kim, K. J. Yoon, J. Shin, C. Zhang, G. Makri, D. Nauen, H. Yu, E. Guzman, C. H. Chiang, N. Yoritomo, K. Kaibuchi, J. Zou, K. M. Christian, L. Cheng, C. A. Ross, R. L. Margolis, G. Chen, K. S. Kosik, H. Song and G. L. Ming (2014). "Synaptic dysregulation in a human iPS cell model of mental disorders." Nature 515(7527): 414-418.

Verhoog, M. B., J. Obermayer, C. A. Kortleven, R. Wilbers, J. Wester, J. C. Baayen, C. P. De Kock, R. M. Meredith and H. D. Mansvelder (2016). "Layer-specific cholinergic control of human and mouse cortical synaptic plasticity." Nat Commun 7: 12826.

West, D. C., A. Mercer, S. Kirchhecker, O. T. Morris and A. M. Thomson (2006). "Layer 6 corticothalamic pyramidal cells preferentially innervate interneurons and generate facilitating EPSPs." Cereb Cortex 16(2): 200-211.

Wierenga, C. J., K. Ibata and G. G. Turrigiano (2005). "Postsynaptic expression of homeostatic plasticity at neocortical synapses." Ц Neurosci 25(11): 2895-2905.

Villano, I., A. Messina, A. Valenzano, F. Moscatelli, T. Esposito, V. Monda, M. Esposito, F. Precenzano, M. Carotenuto, A. Viggiano, S. Chieffi, G. Cibelli, M. Monda and G. Messina (2017). "Basal Forebrain Cholinergic System and Orexin Neurons: Effects on Attention." Front Behav Neurosci 11: 10.

Vinson, P. N. and J. B. Justice, Jr. (1997). "Effect of neostigmine on concentration and extraction fraction of acetylcholine using quantitative microdialysis." ЦNeurosci Methods 73(1): 61-67.

Yam, P. T., S. D. Langlois, S. Morin and F. Charron (2009). "Sonic hedgehog guides axons through a noncanonical, Src-family-kinase-dependent signaling pathway." Neuron 62(3): 349-362.

Yao, P. J., R. S. Petralia and M. P. Mattson (2016). "Sonic Hedgehog Signaling and Hippocampal Neuroplasticity." Trends Neurosci 39(12): 840-850.

Zardoya, R., E. Abouheif and A. Meyer (1996). "Evolution and orthology of hedgehog genes." Trends Genet 12(12): 496-497.

Zeng, H. and J. R. Sanes (2017). "Neuronal cell-type classification: challenges, opportunities and the path forward." Nat Rev Neurosci 18(9): 530-546.

Zhang, Y. P. and T. G. Oertner (2007). "Optical induction of synaptic plasticity using a light-sensitive channel." Nat Methods 4(2): 139-141.

Zhang, Z. W. and M. Deschenes (1997). "Intracortical axonal projections of lamina VI cells of the primary somatosensory cortex in the rat: a single-cell labeling study." L Neurosci 17(16): 63656379.

Zhou, Q., S. Apionishev and D. Kalderon (2006). "The contributions of protein kinase A and smoothened phosphorylation to hedgehog signal transduction in Drosophila melanogaster." Genetics 173(4): 2049-2062.

Zucker, R. S. (2001). "Increased Ca2+ buffering enhances Ca2+-dependent process." J Physiol 531(Pt 3): 583. 
Zucker, R. S. and W. G. Regehr (2002). "Short-term synaptic plasticity." Annu Rev Physiol 64: 355405. 



\section{Papers}

The papers associated with this thesis have been removed for copyright reasons. For more details about these see:

http://urn.kb.se/resolve?urn=urn:nbn:se:liu:diva-151986 